Supporting Information

for

Structural elucidation and ultrasensitive analyses of volatile organic compounds by paper-based nano optoelectronic noses

Mohammad Mahdi Bordbar, Javad Tashkhourian,* Bahram Hemmateenejad*

Chemistry Department, Shiraz University, Shiraz, Iran 


\section{Preparation of nanoparticles solution}

AuNPs and AgNPs were synthesized according to published procedures which were described briefly in the following.

Bare AgNPs, $100.0 \mathrm{~mL}$ of aqueous solution of $\mathrm{AgNO}_{3}$ was reduced by $0.01 \mathrm{~g}$ of $\mathrm{NaBH}_{4}$ causing the color of solution was changed from colorless to yellow. The solution was stirrer for 5 min at room temperature ${ }^{1}$.

Bare AuNPs. $0.01 \mathrm{~g}$ of $\mathrm{NaBH}_{4}$ was added to $100.0 \mathrm{~mL}$ of aqueous solution of $\mathrm{HAuCl}_{4}$ under boiling condition. Changing in the color of solution into ruby-red color confirmed the formation of AuNPs ${ }^{2}$.

Chitosan capped AgNPs. $0.2 \%$ chitosan solution was mixed with $\mathrm{AgNO}_{3}$ aqueous solution $\left(1.00 \times 10^{-3} \mathrm{M}\right)$ at room temperature under vigorous stirring for $30 \mathrm{~min}$. Adding drop by drop of the freshly prepared $\mathrm{NaBH}_{4}$ solution to prepared mixture turned the color of solution to bright yellow. Then, the mixture was stirrer again for $1 \mathrm{~h}^{3}$.

Chitosan capped AuNPs. An aqueous solution of $\mathrm{HAuCl}_{4}\left(1.00 \times 10^{-1} \mathrm{M}\right)$ was reduced by $0.05 \%$ chitosan solution. The mixture was heated to $70^{\circ} \mathrm{C}$ under magnetic stirring and these conditions were kept until the color of solution changed to red ${ }^{4}$.

CTAB capped AgNPs. An aqueous solution of CTAB with the concentration of $1.0 \times 10^{-3} \mathrm{M}$ was added to $5.0 \times 10^{-3} \mathrm{M}$ of $\mathrm{AgNO}_{3}$ water solution. The mixture was stirrer for $10 \mathrm{~min}$ at room temperature. The color of the mixture was gradually changed to yellow by adding the freshly prepared $\mathrm{NaBH}_{4}$ solution drop by drop. This work was continued until the color of solution did not change ${ }^{5}$.

CTAB capped AuNPs. The freshly prepared $\mathrm{NaBH}_{4}$ solution $\left(3.0 \times 10^{-3} \mathrm{M}\right)$ and an aqueous solution of CTAB $\left(7.5 \times 10^{-2} \mathrm{M}\right)$ were added simultaneously to an aqueous solution of $\mathrm{HAuCl}_{4}$ leading to change the color of mixture into light-brown color after $30 \mathrm{~min}$. Then, the mixture was stirrer for about $2 \mathrm{~h}$ until the red color solution was obtained ${ }^{6}$.

BSA modified AgNPs. $50.0 \mathrm{mg}$ of BSA protein was dissolved in $40.0 \mathrm{~mL}$ of deionized water. This solution was mixed by $1.0 \mathrm{~mL}$ of $6.8 \times 10^{-2} \mathrm{M} \mathrm{AgNO}_{3}$ under vigorous stirring. The freshly prepared $\mathrm{NaBH}_{4}$ solution $\left(6.0 \times 10^{-1} \mathrm{M}\right)$ was added to mixture and the color of solution became a deep brown color which indicate that AgNPs was synthesized. To remove the excess protein from the solution, the prepared mixture was centrifuged and the solid was re-dispersed in water ${ }^{7}$. 
BSA functionalized AuNPs. This NPs was prepared by heating an aqueous solution of $\mathrm{HAuCl}_{4}$ to boil under stirring condition. Then, the freshly prepared tri sodium citrate solution (1\%) was added to boiled solution resulting in observation of ruby red color which is confirmed that AuNPs was synthesized. This mixture was stirrer under boiling condition for $15 \mathrm{~min}$ and then cooled to room temperature. In the next step, $3.0 \mathrm{ml}$ of BSA solution $(20 \mathrm{mg} / \mathrm{mL})$ was added to AuNPs solution. This mixture was kept in the stirring condition for $20 \mathrm{~h}$. To separate modified AuNPs, the prepared mixture was centrifuged at $10000 \mathrm{rpm}$ for $10 \mathrm{~min}$ and the solid was re-dispersed in water ${ }^{8}$.

D-Glucose capped AgNPs. An aqueous solution of $\mathrm{AgNO}_{3}\left(1.0 \times 10^{-2} \mathrm{M}\right)$ was reduced by using D-glucose with the concentration of $3.0 \times 10^{-1} \mathrm{M}$ as reducing agent. The mixture should be heated to boil under stirring condition. After $30 \mathrm{~min}$, the color of solution was changed from colorless to yellow which is confirmed the formation of AgNPs ${ }^{9}$.

D-glucose capped AuNPs. An aqueous solution of $\mathrm{HAuCl}_{4}\left(5.0 \times 10^{-2} \mathrm{M}\right)$ was added to D-glucose water solution with the concentration of $3.0 \times 10^{-2} \mathrm{M}$. A NaOH water solution $\left(5.0 \times 10^{-2} \mathrm{M}\right)$ was added dropwise to this mixture until the color of the solution changed to wine red color ${ }^{10}$.

PVP modied AgNPs. $20.0 \mathrm{~mL}$ Ethylene glycol (EG) was heated in the oil bath at $150^{\circ} \mathrm{C}$ and was stirrer for $30 \mathrm{~min}$. Then, $0.2 \mathrm{~g} \mathrm{AgNO}_{3}$ and $0.12 \mathrm{~g}$ PVP (with $\mathrm{MW}=10000$ ) which are mixed together in $10.0 \mathrm{~mL}$ EG, were added to the hot previous solution. This mixture was kept in the stirring condition for $15 \mathrm{~min}$. changing in the color of solution from colorless to yellow shows that AgNPs were synthesized ${ }^{11}$.

PVP modified AuNPs. Under reflux and stirring condition, a $\mathrm{HAuCl}_{4}$ aqueous solution $\left(1.0 \times 10^{-3}\right.$ M) was heated to boil for $30 \mathrm{~min}$. Then, $1.0 \mathrm{ml}$ of an aqueous solution of tri sodium citrate (1\%) was added to boiling solution leading to turn the color of solution into ruby red which is a reason for formation of AuNPs. After that, a solution provided by dissolving $15.0 \mathrm{mg}$ of PVP in the 15.0 $\mathrm{mL}$ deionized water, was added to AuNPs solution that is synthesized previously. This mixture was kept in the room temperature under stirring condition for $20 \min ^{12}$.

Cysteine capped AgNPs. $0.01 \mathrm{~g}$ of $\mathrm{NaBH}_{4}$ as reducing agent was added to $\mathrm{AgNO}_{3}$ water solution causing the color of solution became yellow. Then, the prepared AgNPs was functionalized by an aqueous solution of cysteine $\left(1.0 \times 10^{-3} \mathrm{M}\right)$ and the mixture was stirrer for $1 \mathrm{~h}^{13}$.

Cysteine functionalized AuNPs. A $\mathrm{HAuCl}_{4}$ water solution $\left(1.0 \times 10^{-3} \mathrm{M}\right)$ was reduced by a chemical wet method using tri sodium citrate $(38.8 \mathrm{mM})$ as reducing agent. The solution was kept 
in under boiling, stirring and reflux condition until its color changed from pale yellow to wine red. After the mixture was cooled to room temperature, $100.0 \mu \mathrm{L}$ of L-cysteine solution $\left(2.0 \times 10^{-4} \mathrm{M}\right)$ was added to $5.0 \mathrm{ml}$ of AuNPs. Then, the mixture was stirrer for $2 \mathrm{~h}$ causing the cysteine-AuNPs were prepared ${ }^{14}$.

GSH modified AgNPs. This NPs were synthesized by reducing a concentrated aqueous solution of $\mathrm{AgNO}_{3}$ by $\mathrm{NaBH}_{4}(0.01 \mathrm{~g})$ at room temperature and the mixture was stirrer for $5 \mathrm{~min}$. After that, the AgNPs was stabilized by an aqueous solution of GSH $\left(1.0 \times 10^{-3} \mathrm{M}\right){ }^{1}$.

GSH capped AuNPs. An aqueous solution of $\mathrm{HAuCl}_{4}\left(2.50 \times 10^{-2} \mathrm{M}\right)$ was mixed with GSH water solution $\left(1.9 \times 10^{-2} \mathrm{M}\right)$. The $\mathrm{pH}$ of solution was adjusted at 8.0 by addition of $\mathrm{NaOH}(1 \mathrm{M})$. Finally, GSH-AuNPs was synthesized by adding the freshly prepared $\mathrm{NaBH}_{4}$ solution drop by drop to previous mixture and the color of solution was changed to wine red ${ }^{15}$.

\section{Characterization of the synthesized NPs}

The plasmon resonance peaks of synthesized NPs were recorded by a UV/Vis spectrophotometer. Figure S1 shows the SPR bands in the range of 500 to $550 \mathrm{~nm}$ for AuNPs and the resonance peaks between 400 to $450 \mathrm{~nm}$ for prepared AgNPs. For clarity, the maximum peaks of synthesized NPs appeared in following wavelengths: bare AuNPs at $510 \mathrm{~nm}$, bare AgNPs at $405 \mathrm{~nm}$, chitosan capped AuNPs at $540 \mathrm{~nm}$, chitosan capped AgNPs at $443 \mathrm{~nm}$, CTAB capped AuNPs at $535 \mathrm{~nm}$, CTAB capped AgNPs at $410 \mathrm{~nm}$, BSA capped AuNPs at $525 \mathrm{~nm}$, BSA capped AgNPs at $420 \mathrm{~nm}$, glucose capped AuNPs at $550 \mathrm{~nm}$, glucose capped AgNPs at $390 \mathrm{~nm}$, PVP capped AuNPs at 530 nm, PVP capped AgNPs at 435 nm, Cys capped AuNPs at 550 nm, Cys capped AgNPs at 460 nm, GSH capped AuNPs at $455 \mathrm{~nm}$ and GSH capped AgNPs at $535 \mathrm{~nm}$. The additional evidence to prove the synthesis of NPs was obtained by FT-IR spectroscopy which indicated the changing in the structure of reducing agents before and after using to functionalize nanoparticles. The modification surface of NPs leads to decrease the intensity or displacement of the particular band. Figure S2 shows the FT-IR spectra of soluble chitosan, CTAB, BSA, glucose, PVP, cysteine, glutathione and synthesized silver and gold nanoparticles using these reducing and stabilizing agents.

Figure S3 indicated the hydrodynamic size distribution of synthesized NPs obtained by dynamic light scattering (DLS). As can be seen, the hydrodynamic sizes of NPs were estimated in the range of $28 \mathrm{~nm}$ to $35 \mathrm{~nm}$. The Zeta potential measurements which are shown in Figure $\mathrm{S} 4$ revealed that 
chitosan and CTAB present a positive surface charge while the other NPs exhibit a clear negative surface charge. As can be seen, The zeta potential values were about $-8,-4,+29,+21,+47,+37,-$ $10,-13,-22,-29,-23,-19,-11,-17,-30$ and -26 for bare AgNPs, bare AuNP, chitosan- AgNPs, chitosan - AuNPs, CTAB -AgNPs, CTAB-AuNPs, BSA-AgNPs, BSA-AuNPs, glucose-AgNPs, glucose-AuNPs, PVP-AgNPs, PVP-AuNPs, Cys-AgNPs, Cys-AuNPs, GSH-AgNPs and GSHAuNPs, respectively.

The morphological study of coating the paper with NPs was investigated by SEM. The image obtained from the bare paper represents only the interwoven polymeric fibers made of paper (Figure S5a). By spotting the NPs on the paper, a layer of NPs solution was coated on the paper surface (Figure S5b) and NPs are distributed irregularly in the $0.5 \times 0.5$ space (Figure S5c-s). The evidence for aggregation of NPs after interaction with the studied VOCs were represented in Figure S6.

The EDS spectra of chitosan capped both Au and Ag NPs indicate the intense signal at $3 \mathrm{keV}$ for $\mathrm{Ag}$ (Figure S7a) and at $2.3 \mathrm{keV}$ for $\mathrm{Au}$ (Figure 7b) and element that could be the good reason for reduction of silver and gold ions to elemental of gold and silver, respectively. Also, the EDS mapping images (Figure S7c-d) describe that silver and gold elements are distributed homogeneously in the PVDF paper surface. The density of NPs on the surface of paper can be evaluated by amounts of silver and gold which are calculated by EDS, quantitatively. These values that collected in Table S2 indicate that the paper was covered by enough amounts of NPs.

\section{Characterization of fabricated NOEN}

The two prominent features of the sensors which affect their performance, are their stability in terms of air humidity and durability. To assess the humidity resistance, the developed NOEN was exposed to a media with relative humidity in the range of 0 to $100 \%$. Then, the color changes of NPs used in NOEN was investigated. As shown in Figure S9a, the developed NOEN can tolerate the relative humidity up to $70 \%$ and after that, changing in the color of NPs or leaching was occurred. For evaluation of durability, changes in the color of NOEN were studied for a time interval of 5 months. Figure S9b shows that the NOEN was stable over a period of 75 days when was not in use and the color values of the sensing elements did not change.

Also, to evaluate the repeatability of fabrication process, the RGB values of sensing elements using in the five fabricated sensors were determined and were compared together. The results 
represented in Table S3, indicate very low RSD values for each sensing element which are confirmed a repeatable process for fabricating NOEN.

\section{Reproducibility of the NOEN}

To evaluate the reproducibility of the developed NOEN, the response of sensor to all studied VOCs were determined for 5 times and the coefficient of variations of the responses were calculated for each analyte. The results for propanol, acetaldehyde, acetic acid, ethyl acetate were shown in Figure S10 and those for the other VOCs were collected in Table S4. The reproducibility of the developed NOEN was satisfactory because the relative standard deviations for all studied samples are lower than $7 \%$. In the other experiment, the developed sensor was exposed to different concentrations of acetic acid for 5 times and the responses of sensor for each concentration were calculated and the relative standard deviations of the responses were determined which are shown

in Table S5. As can be seen, the results show that the NOEN is a reproducible device for quantitative analysis of different VOCs.

\section{References}

(1) Li, H.; Cui, Z.; Han, C. Glutathione-Stabilized Silver Nanoparticles as Colorimetric Sensor for Ni2+ Ion. Sensors Actuators, B Chem. 2009, 143 (1), 87-92.

(2) Aryal, S.; Remant, B. K. C.; Dharmaraj, N.; Bhattarai, N.; Kim, C. H.; Kim, H. Y. Spectroscopic Identification of SAu Interaction in Cysteine Capped Gold Nanoparticles. Spectrochim. Acta - Part A Mol. Biomol. Spectrosc. 2006, 63 (1), 160-163.

(3) Chen, Z.; Zhang, X.; Cao, H.; Huang, Y. Chitosan-Capped Silver Nanoparticles as a Highly Selective Colorimetric Probe for Visual Detection of Aromatic Ortho-Trihydroxy Phenols. Analyst 2013, 138 (8), 2343-2349.

(4) Bhumkar, D. R.; Joshi, H. M.; Sastry, M.; Pokharkar, V. B. Chitosan Reduced Gold Nanoparticles as Novel Carriers for Transmucosal Delivery of Insulin. Pharm. Res. 2007, 24 (8), 1415-1426.

(5) Wei, G.; Wang, L.; Zhou, H.; Liu, Z.; Song, Y.; Li, Z. Electrostatic Assembly of CTABCapped Silver Nanoparticles along Predefined $\lambda$-DNA Template. Appl. Surf. Sci. 2005, 252 (5), 1189-1196.

(6) Wang, J.; Li, Y. F.; Huang, C. Z.; Wu, T. Rapid and Selective Detection of Cysteine 
Based on Its Induced Aggregates of Cetyltrimethylammonium Bromide Capped Gold Nanoparticles. Anal. Chim. Acta 2008, 626 (1), 37-43.

(7) Garza-Ocañas, L.; Ferrer, D. A.; Burt, J.; Diaz-Torres, L. A.; Ramírez Cabrera, M.; Rodríguez, V. T.; Luján Rangel, R.; Romanovicz, D.; Jose-Yacaman, M. Biodistribution and Long-Term Fate of Silver Nanoparticles Functionalized with Bovine Serum Albumin in Rats. Metallomics 2010, 2 (3), 204-210.

(8) Fu, R.; Wang, C.; Zhuang, J.; Yang, W. Adsorption and Desorption of DNA on Bovine Serum Albumin Modified Gold Nanoparticles. Colloids Surfaces A Physicochem. Eng. Asp. 2014, 444, 326-329.

(9) Panzarini, E.; Mariano, S.; Vergallo, C.; Carata, E.; Fimia, G. M.; Mura, F.; Rossi, M.; Vergaro, V.; Ciccarella, G.; Corazzari, M.; et al. Glucose Capped Silver Nanoparticles Induce Cell Cycle Arrest in HeLa Cells. Toxicol. Vitr. 2017, 41, 64-74.

(10) Liu, J.; Qin, G.; Raveendran, P.; Ikushima, Y.; Ikushima, Y. Facile “Green” Synthesis, Characterization, and Catalytic Function of Beta-D-Glucose-Stabilized Au Nanocrystals. Chemistry 2006, 12 (8), 2131-2138.

(11) Wei, Q.; Li, B.; Li, C.; Wang, J.; Wang, W.; Yang, X. PVP-Capped Silver Nanoparticles as Catalysts for Polymerization of Alkylsilanes to Siloxane Composite Microspheres. $J$. Mater. Chem. 2006, 16 (36), 3606-3608.

(12) Dhumale, V. A.; Gangwar, R. K.; Datar, S. S.; Sharma, R. B. Reversible Aggregation Control of Polyvinylpyrrolidone Capped Gold Nanoparticles as a Function of PH. Mater. Express 2012, 2 (4), 311-318.

(13) Mandal, S.; Gole, A.; Lala, N.; Gonnade, R.; Ganvir, V.; Sastry, M. Studies on the Reversible Aggregation of Cysteine-Capped Colloidal Silver Particles Interconnected via Hydrogen Bonds. Langmuir 2001, 17 (20), 6262-6268.

(14) Chai, F. and C. W. and T. W. and Z. M. and Z. S. L-Cysteine Functionalized Gold Nanoparticles for the Colorimetric Detection of $\mathrm{Hg} 2+$ Induced by Ultraviolet Light. Nanotechnology 2010, 21 (2), 25501-25507.

(15) Chai, F.; Wang, C.; Wang, T.; Li, L.; Su, Z. Colorimetric Detection of Pb 2+ Using Glutathione Functionalized Gold Nanoparticles. ACS Appl. Mater. Interfaces 2010, 2 (5), 1466-1470. 
Figure S1
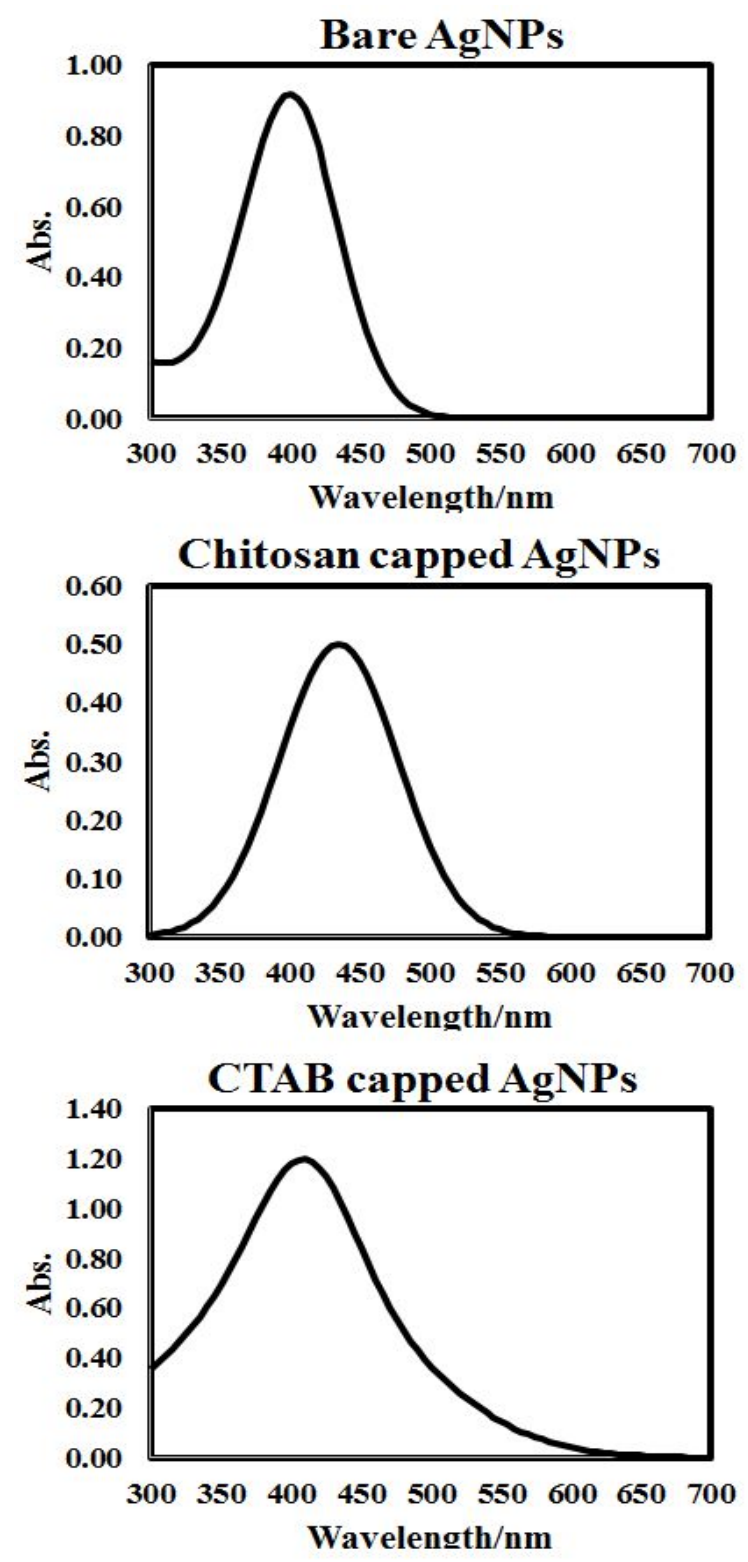
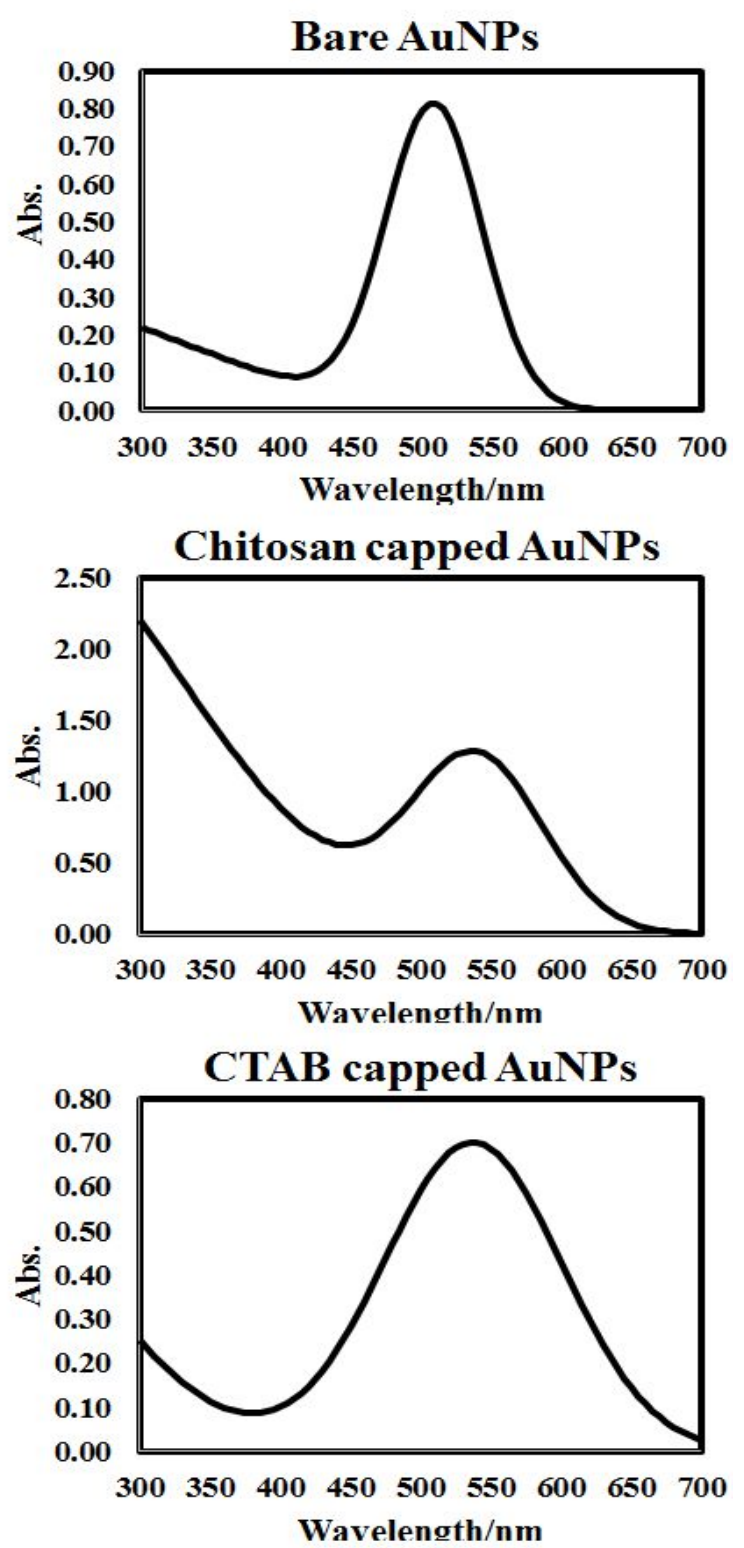

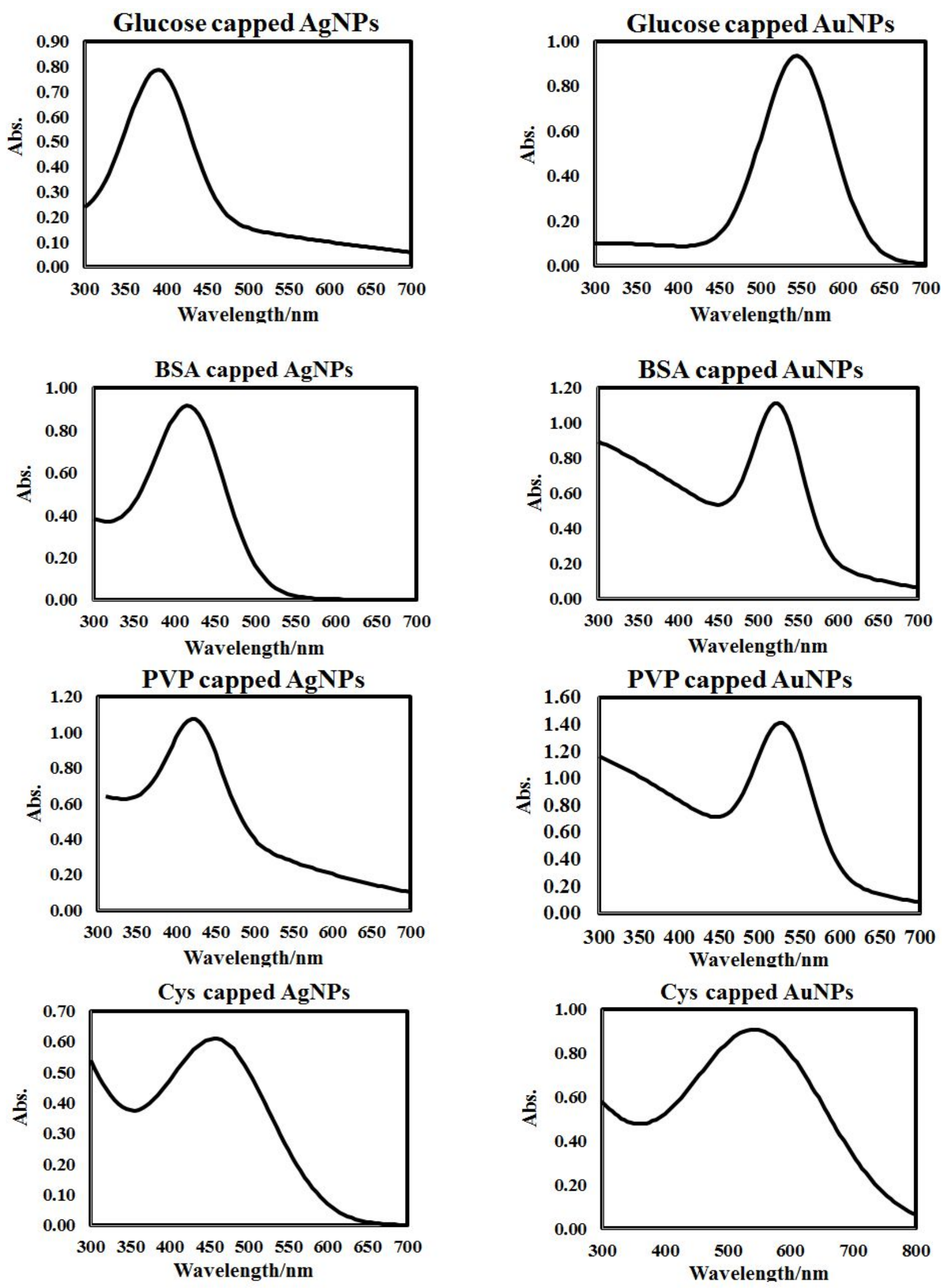

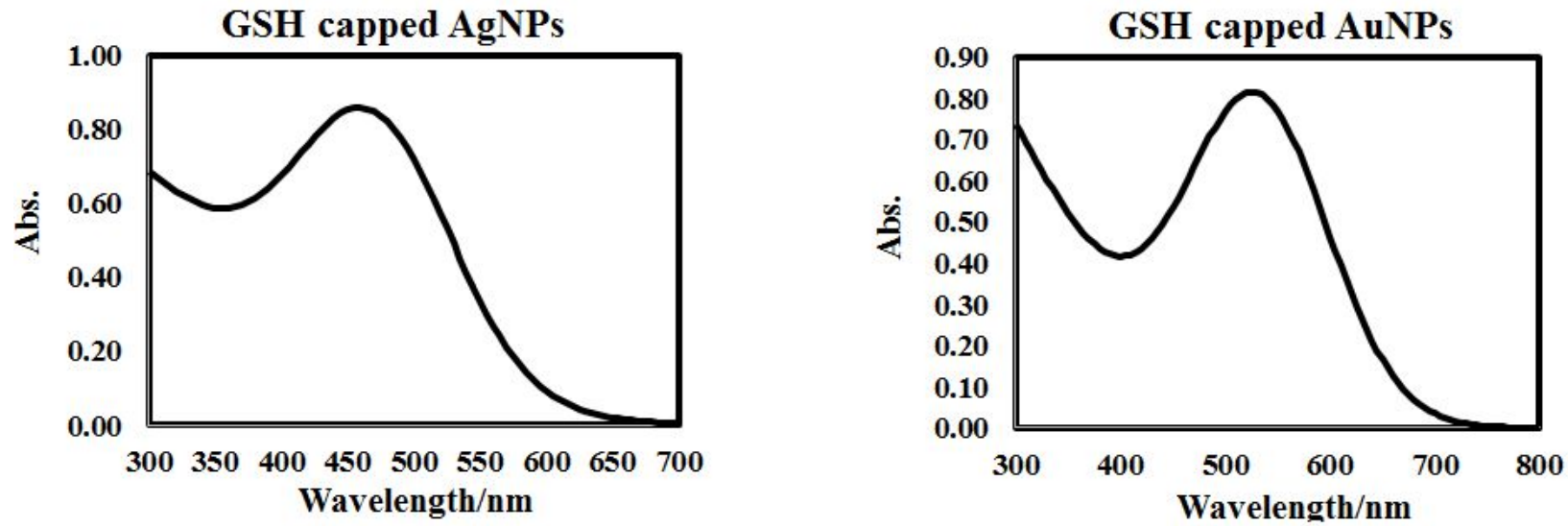

Figure S1. Absorption spectra of synthesized nanoparticles. 


\section{Figure S2}

(a)

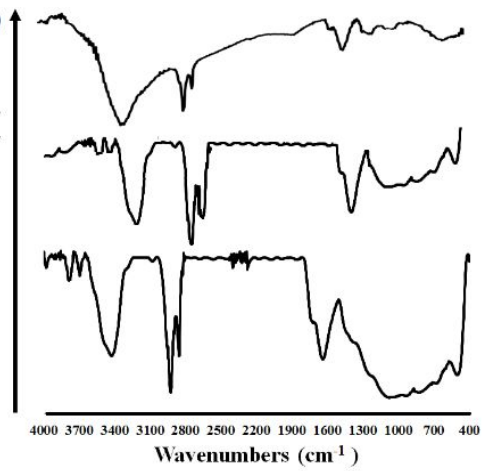

Chitosan capped AgNPs

Chitosan capped AuNPs

Chitosan Wavenumbers $\left(\mathrm{cm}^{1}\right)$
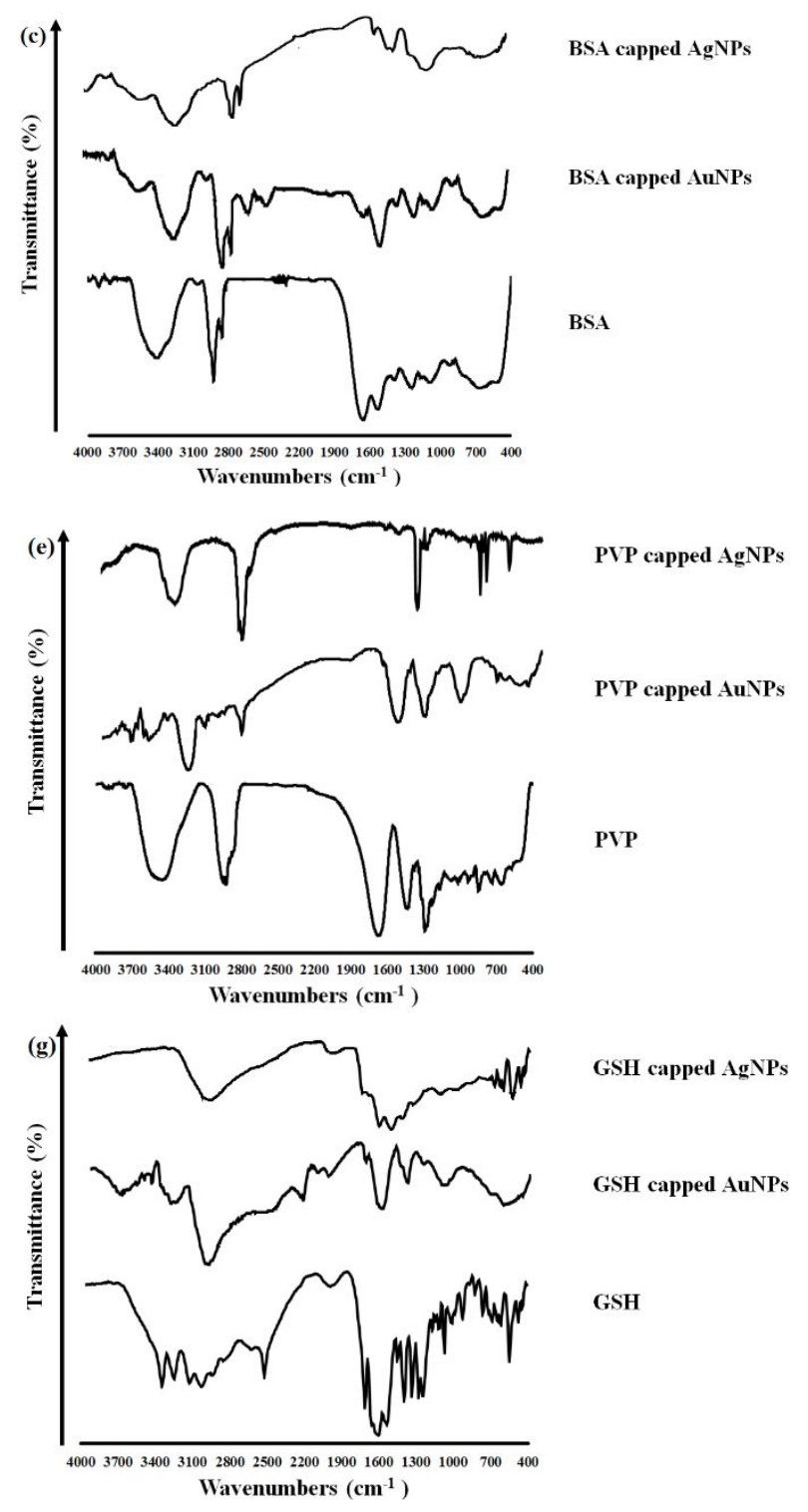
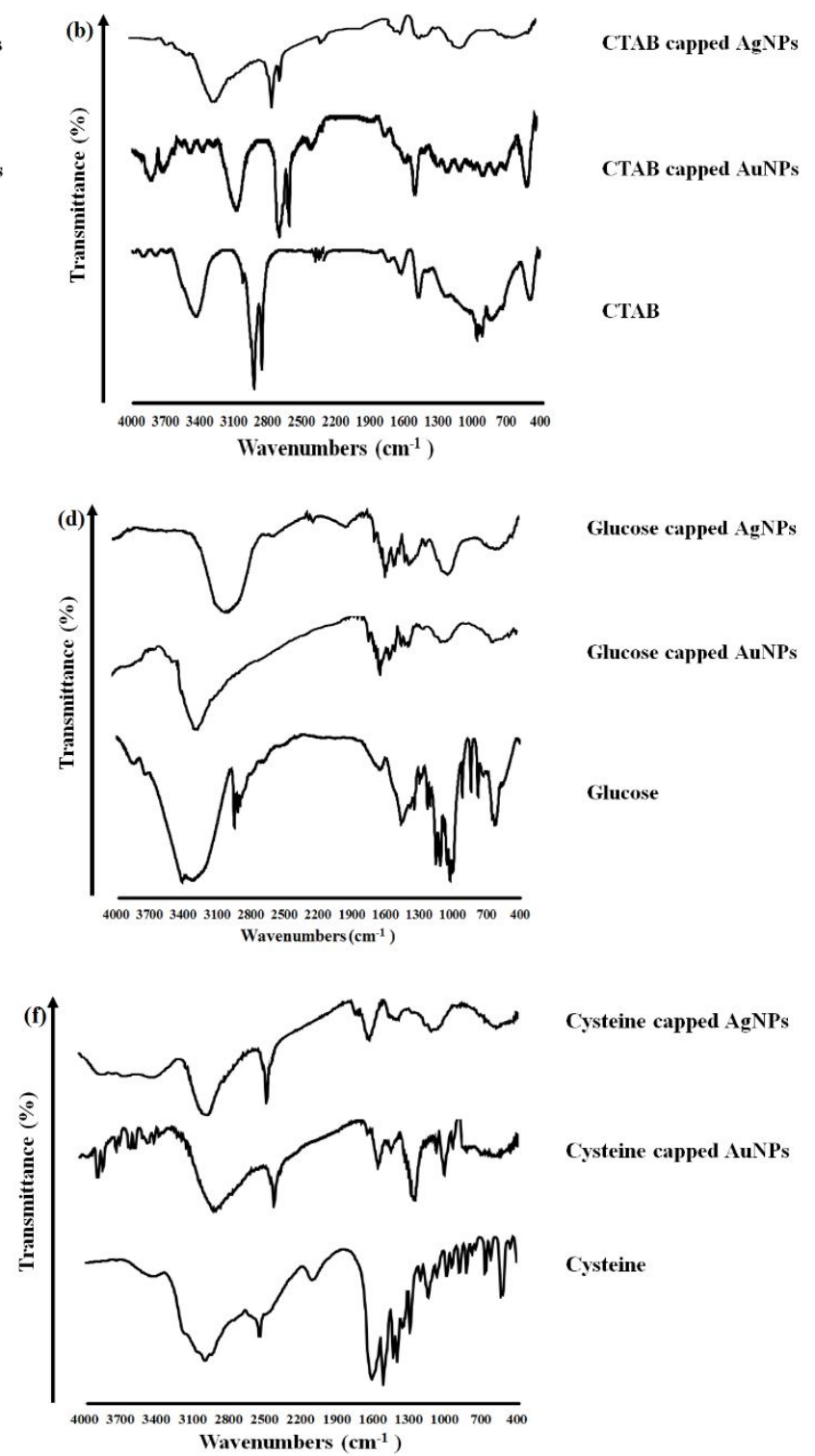
Figure S2. FTIR spectra for (a) chitosan, (b) CTAB, (c) BSA, (d) glucose, (e) PVP, (f) Cysteine, (g) GSH and their functionalized gold and silver nanoparticles. As can be seen, the certain absorption bands in chitosan spectrum (a) are $3400 \mathrm{~cm}^{-1}$ for the symmetric stretching vibration of $\mathrm{OH}$ and amine, $2900 \mathrm{~cm}^{-1}$ for $\mathrm{C}-\mathrm{H}$ stretch, $1650 \mathrm{~cm}^{-1}$ for $\mathrm{C}=\mathrm{O}$ stretching (amide I), $1095 \mathrm{~cm}^{-1}$ and $1033 \mathrm{~cm}^{-1}$ for C-O stretching and $894 \mathrm{~cm}^{-1}$ for $\beta-1-4$ glycosidic linkage. The certain absorption bands in CTAB spectrum (b) are $1395 \mathrm{~cm}^{-1}$ for alkyl chains of CTAB, $3300 \mathrm{~cm}^{-1}, 1465 \mathrm{~cm}^{-1}$ and $960 \mathrm{~cm}^{-1}$ for asymmetric vibration of $\mathrm{N}$ $\left(\mathrm{CH}_{3}\right)^{+}, \mathrm{C}-\mathrm{N}$ and $\mathrm{C}-\mathrm{H}$ stretching, respectively, $2845 \mathrm{~cm}^{-1}$ and $2922 \mathrm{~cm}^{-1}$ for the asymmetric and symmetric bands related to $\mathrm{CH}_{2}$. The main bands in BSA spectrum (c) are located in the range of $3000 \mathrm{~cm}^{-1}$ to $3400 \mathrm{~cm}^{-1}$ for the $\mathrm{O}-\mathrm{H}$ and N-H stretching vibrations and $1600 \mathrm{~cm}^{-1}$ to $1229 \mathrm{~cm}^{-1}$ related to $\mathrm{C}=\mathrm{O}$ stretching, $\mathrm{N}-\mathrm{H}$ bending, $\mathrm{C}-\mathrm{N}$ stretching, $\mathrm{C}=\mathrm{O}$ bending, and $\mathrm{C}-\mathrm{C}$ stretching. The specific bands in glucose spectrum (d) are $3400 \mathrm{~cm}^{-1}, 2900 \mathrm{~cm}^{-1}$ and $1650 \mathrm{~cm}^{-1}$ related to $\mathrm{O}-\mathrm{H}, \mathrm{C}-\mathrm{H}$ and $\mathrm{C}=\mathrm{O}$ stretching vibration, respectively. Two main absorption peaks in PVP spectrum are $1660 \mathrm{~cm}^{-1}$ for $\mathrm{C}=\mathrm{O}$ stretching vibration and $1290 \mathrm{~cm}^{-1}$ which is due to and $\mathrm{C}-\mathrm{N}$ stretching vibration. In cysteine spectrum (f), the peaks at $1600 \mathrm{~cm}^{-1}$ and $1390 \mathrm{~cm}^{-1}$ are indicated the asymmetric and symmetric stretching vibrations of carboxylate, $1532 \mathrm{~cm}^{-1}$ for N-H bending vibration. The broad band located in the range of 3000 to $3500 \mathrm{~cm}^{-1}$ shows the $\mathrm{NH}_{3}{ }^{+}$stretching vibration and a weak band near $2550 \mathrm{~cm}^{-1}$ corresponds to $\mathrm{S}-\mathrm{H}$ vibrational band. Finally, two main peaks observed in the GSH spectrum are a strong band at $2550 \mathrm{~cm}^{-1}$ for S-H stretching vibrations and a band at $1709 \mathrm{~cm}^{-1}$ corresponding to carboxylate groups. 
Figure S3
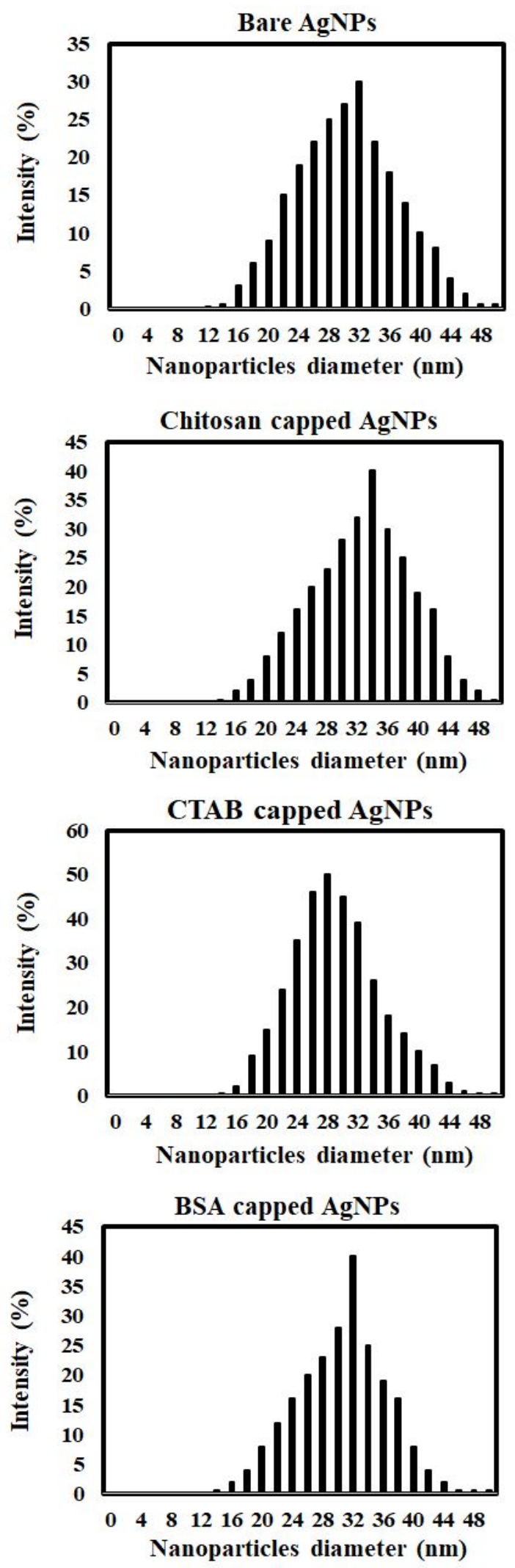
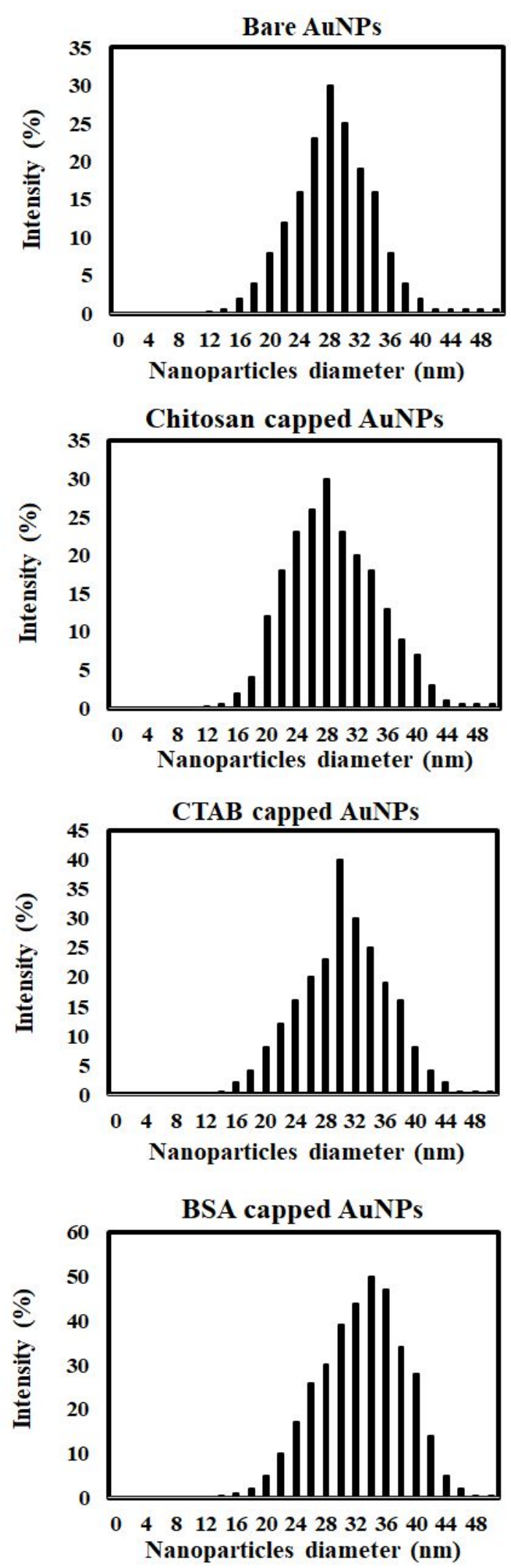

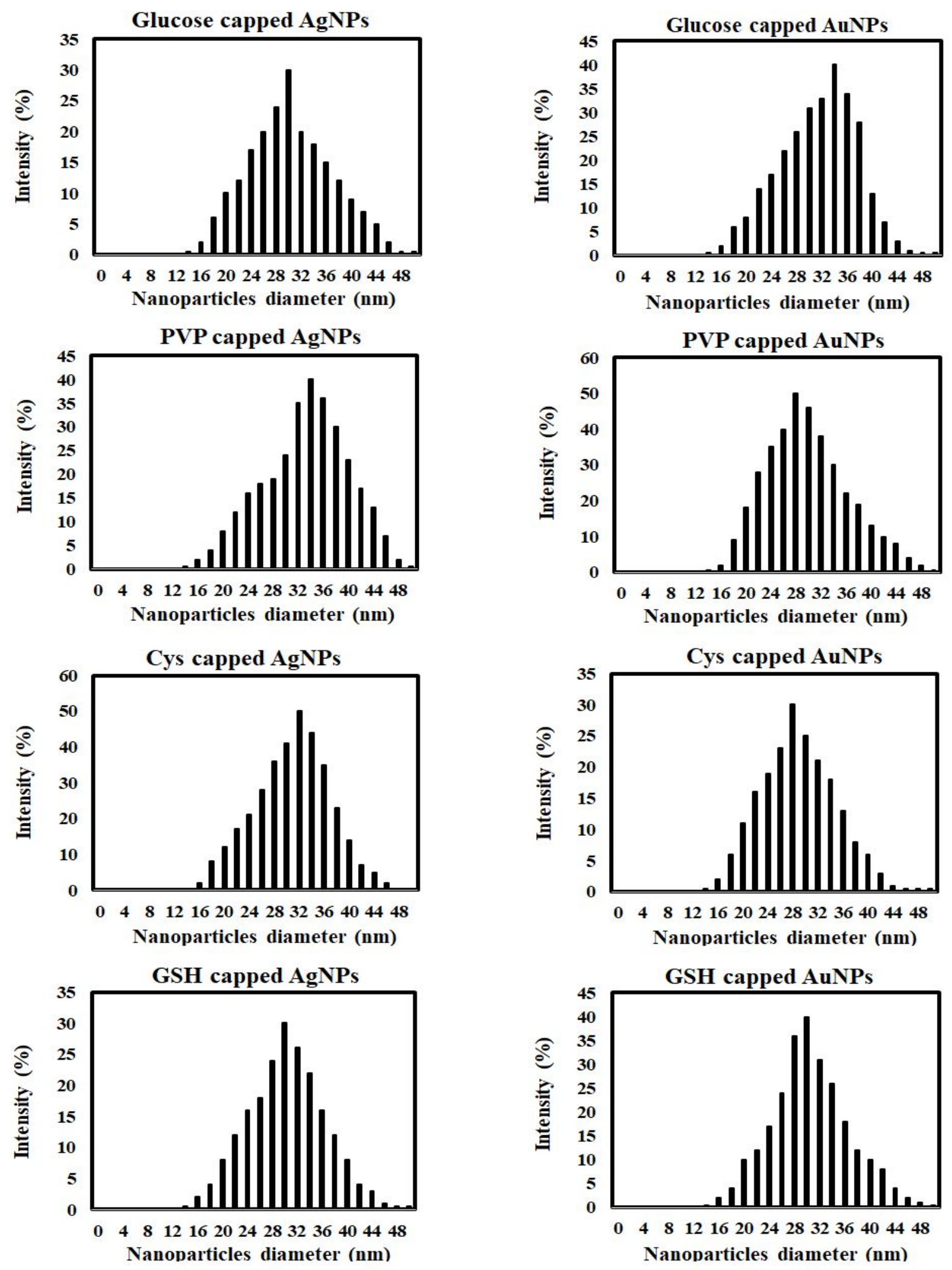

Figure S3. Size distribution by intensity obtained using dynamic light scattering. 
Figure S4
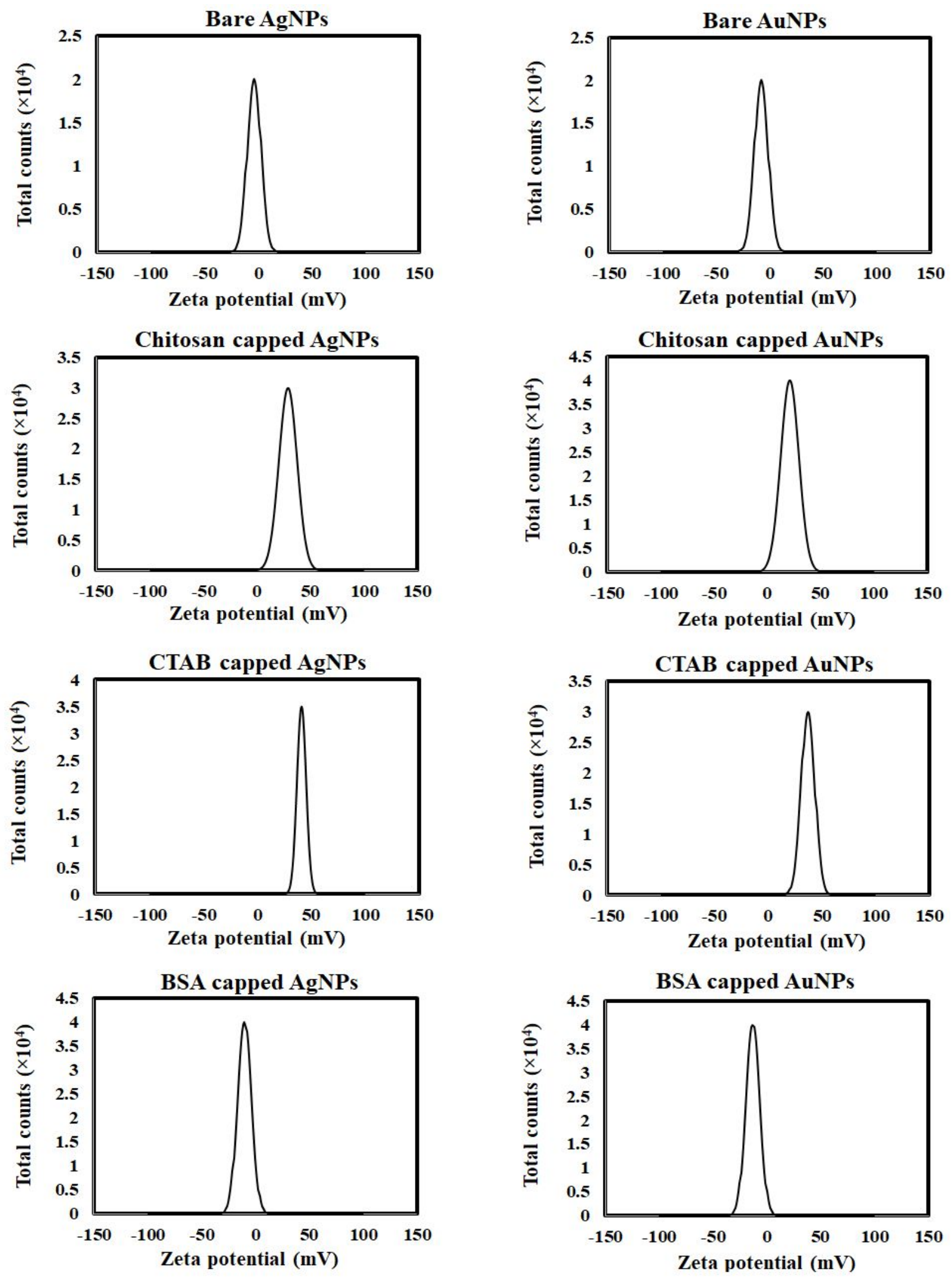

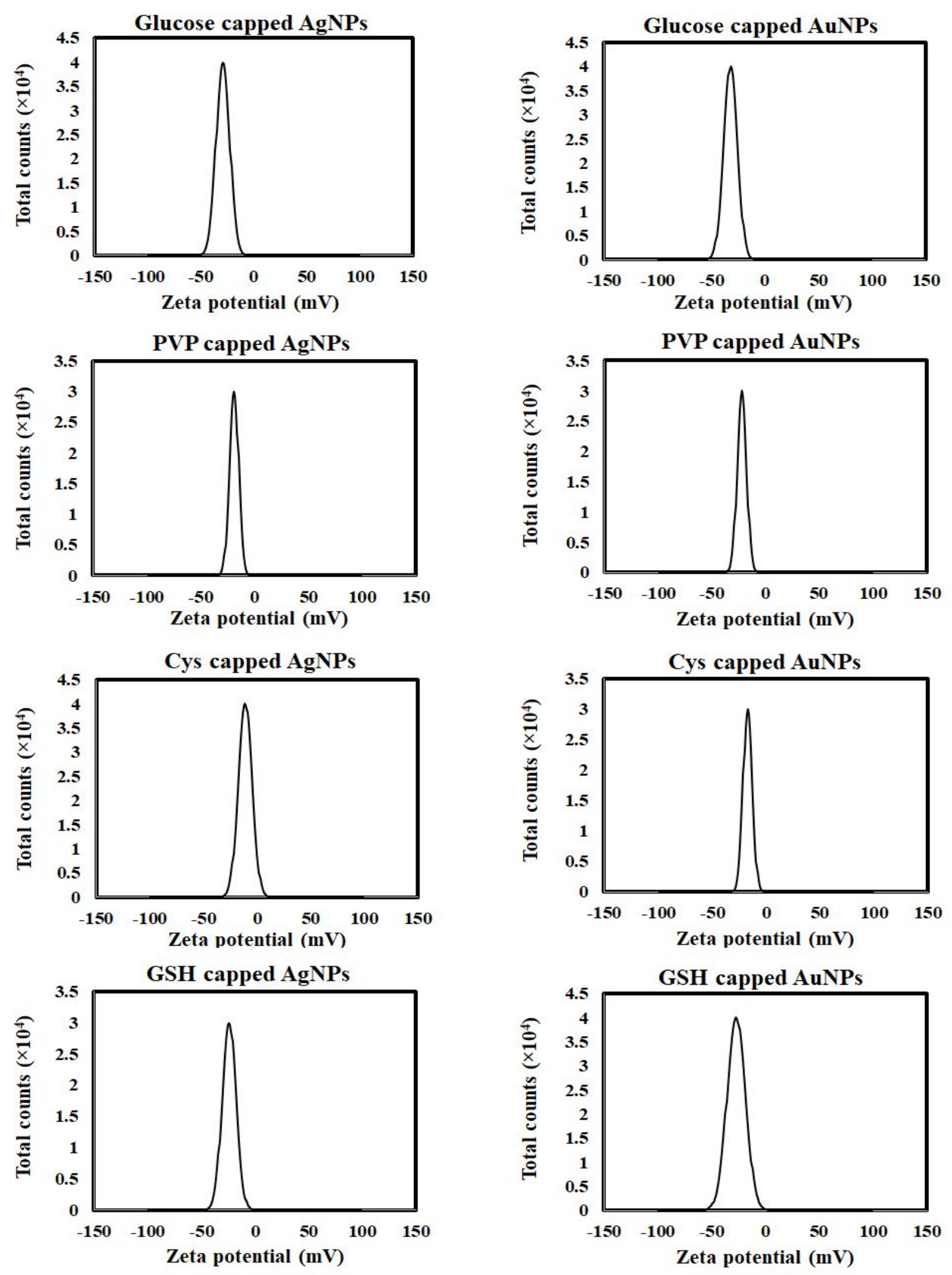

Figure S4. Zeta potential intensity distributions for 16 synthesized NPs. 
(a)

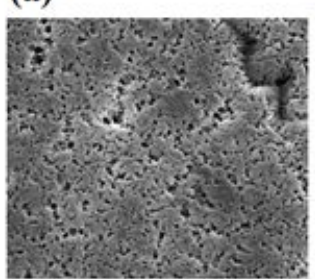

(e)

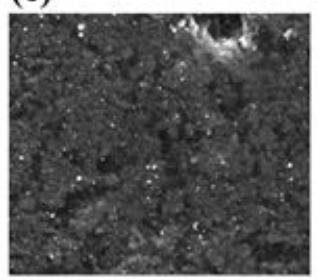

(i)

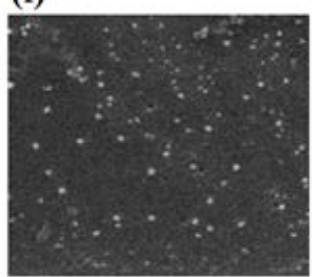

(m)

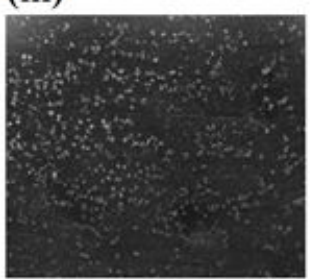

(q)

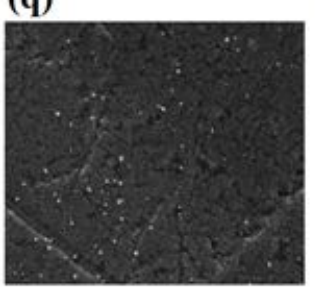

(b)

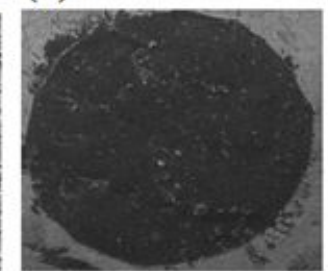

(f)

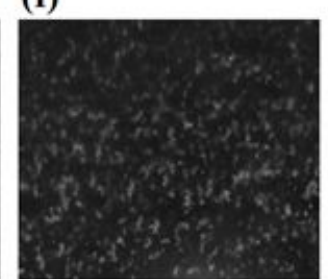

(j)

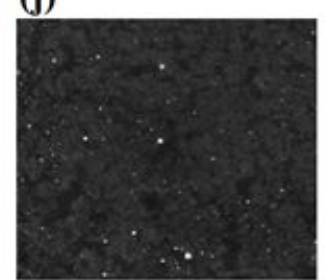

(n)

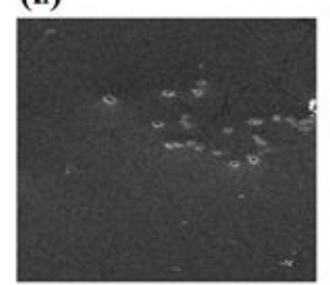

(r)

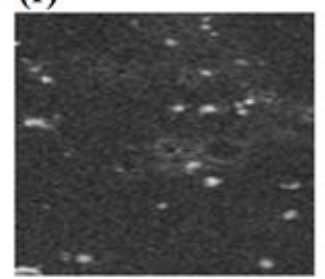

(c)

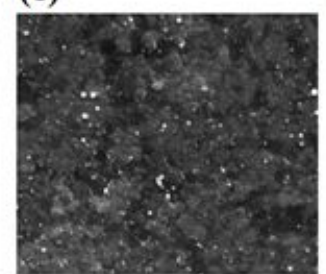

(g)

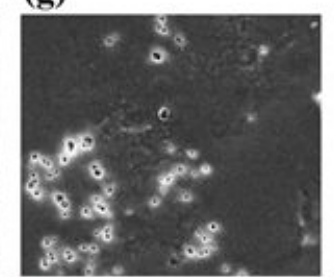

(k)

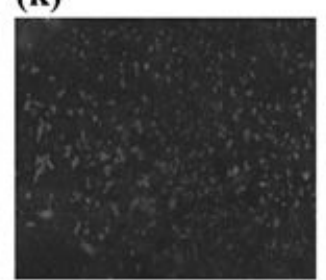

(o)

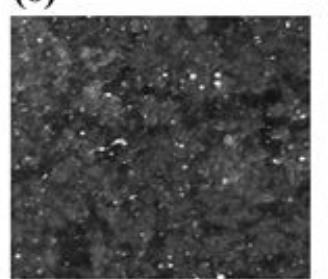

(s) (d)

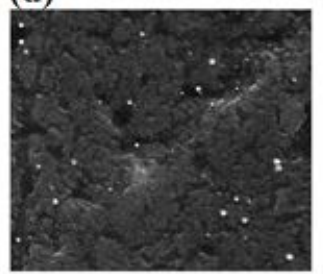

(h)

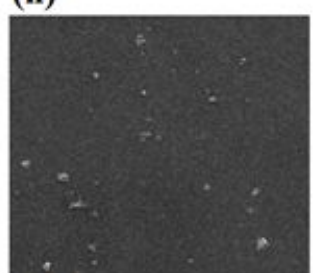

(I)

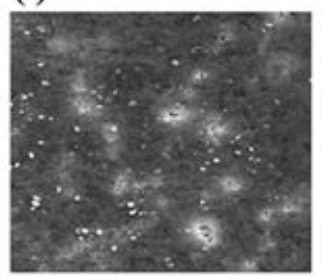

(p)
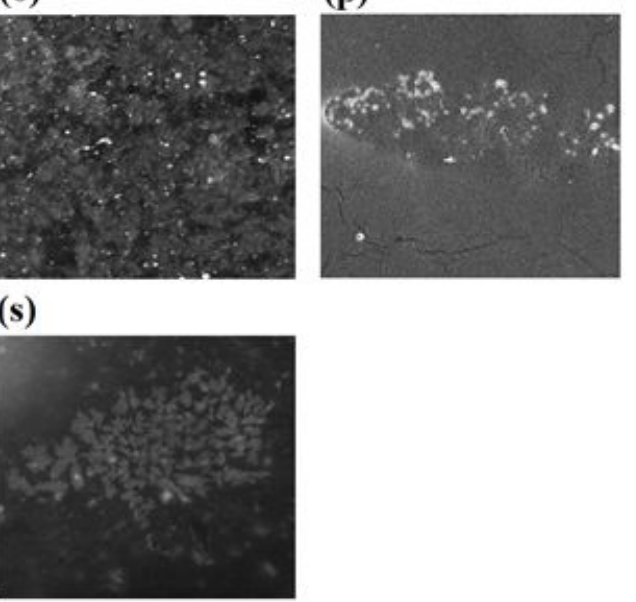

\begin{tabular}{|c|c|c|c|}
\hline SEM HV: $15.0 \mathrm{kV}$ & WD: $8.73 \mathrm{~mm}$ & MIRA3 TESCAN \\
\hline SEM MAG: $75.0 \mathrm{kx}$ & Det: SE & $500 \mathrm{~nm}$ & \\
\hline View field: $2.77 \mu \mathrm{m}$ & Date(m/d/y): 04/21/18 & RMRC
\end{tabular}

Figure S5. The SEM image of (a) PVDF paper, (b) One of the spotted nanoparticles used in the sensor, (c) Bare AgNPs, (d) Bare AuNPs, (e) Chitosan capped AgNPs, (f) Chitosan capped AuNPs, (g) CTAB capped AgNPs, (h) CTAB capped AuNPs, (i) BSA capped AgNPs, (j) BSA capped AuNPs, (k) Glucose capped AgNPs, (l) Glucose capped AuNPs, 
(m) PVP capped AgNPs, (n) PVP capped AuNPs, (o) Cysteine capped AgNPs, (p) Cysteine capped AuNPs, (q) GSH capped AgNPs, (r) GSH capped AuNPs and (s) the aggregated Glucose capped AgNPs. 
(a)

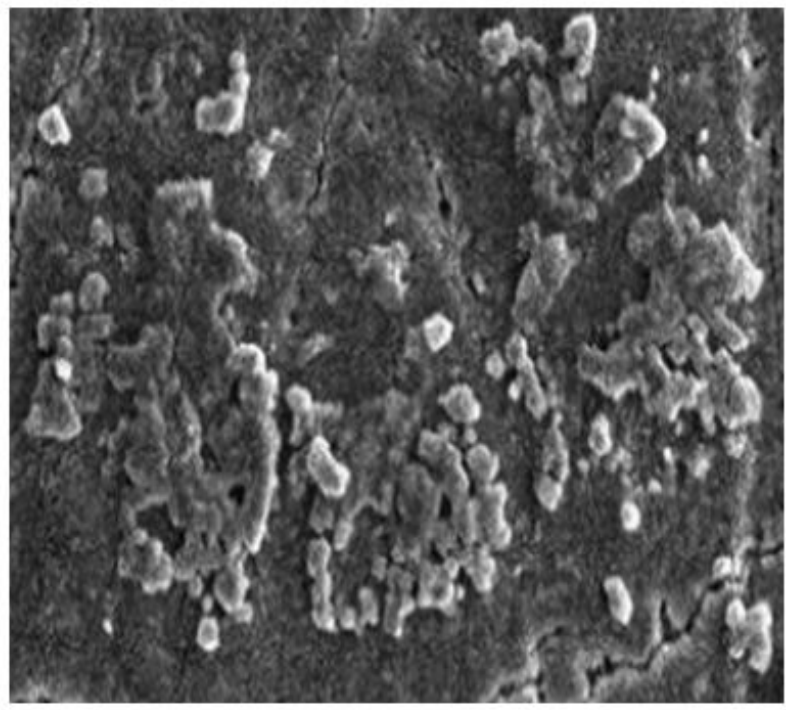

(c)

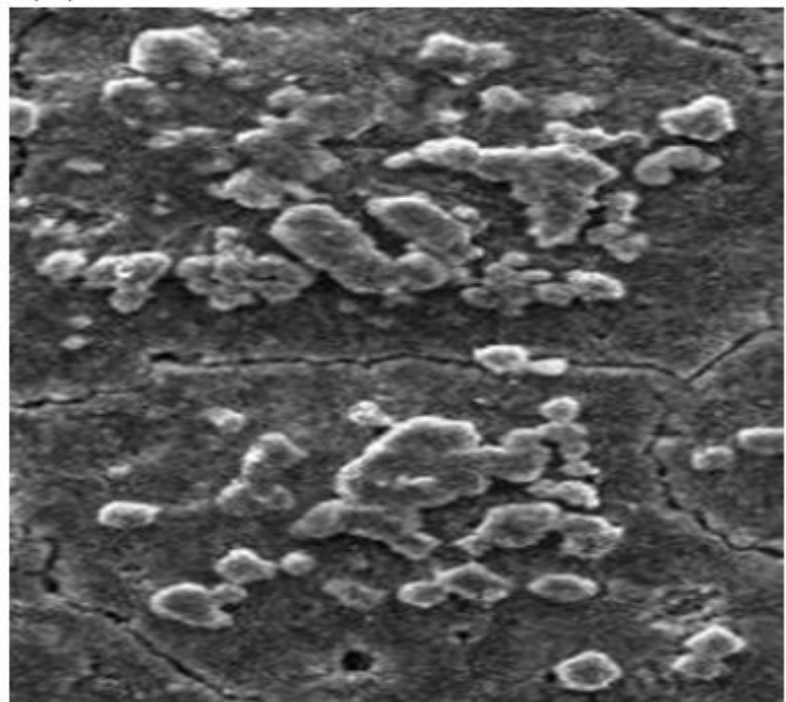

\begin{tabular}{|c|c|}
\hline SEM HV: $15.0 \mathrm{kV}$ & WD: $8.51 \mathrm{~mm}$ \\
\hline SEM MAG: $75.0 \mathrm{kx}$ & Det: SE \\
\hline View field: $2.77 \mu \mathrm{m}$ & Date(m/d/y): 04/21/18 \\
\hline
\end{tabular}

(b)

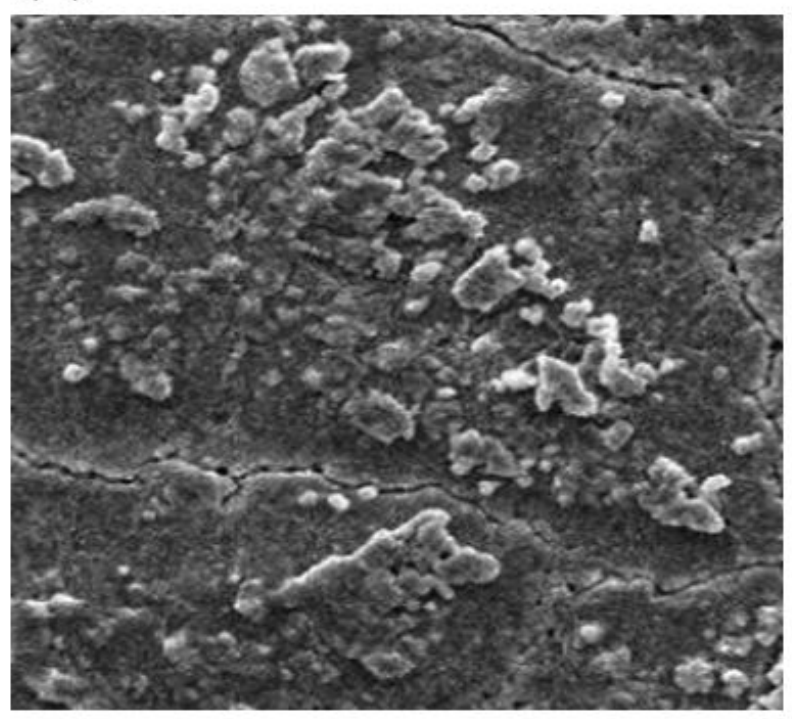

(d)

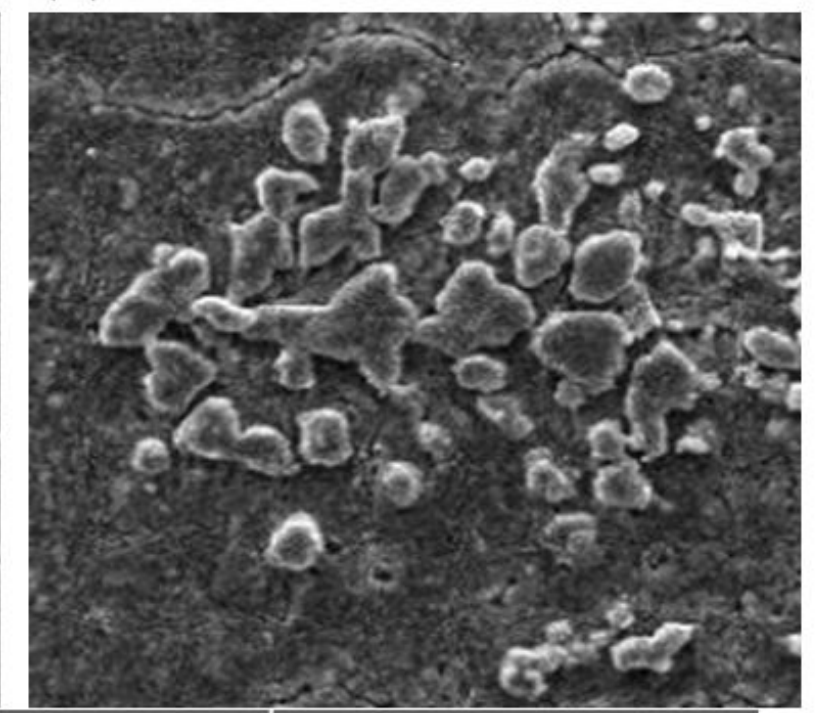

MIRA3 TESCAN

$500 \mathrm{~nm}$

RMRC

Figure S6. The SEM images of (a) CTAB capped AgNPs, (b) CTAB capped AuNPs, (c) PVP capped AgNPs, (d) PVP capped AuNPs after interaction with VOCs, showing aggregation of NPs. 
(a)

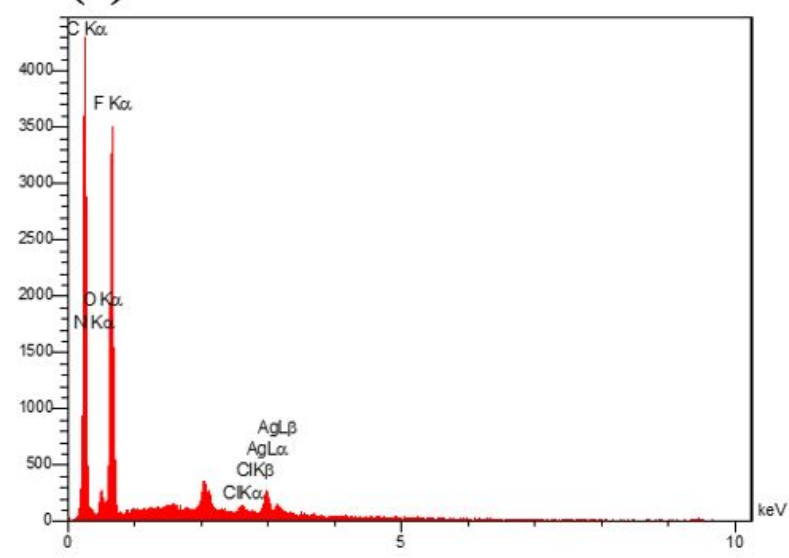

(c)

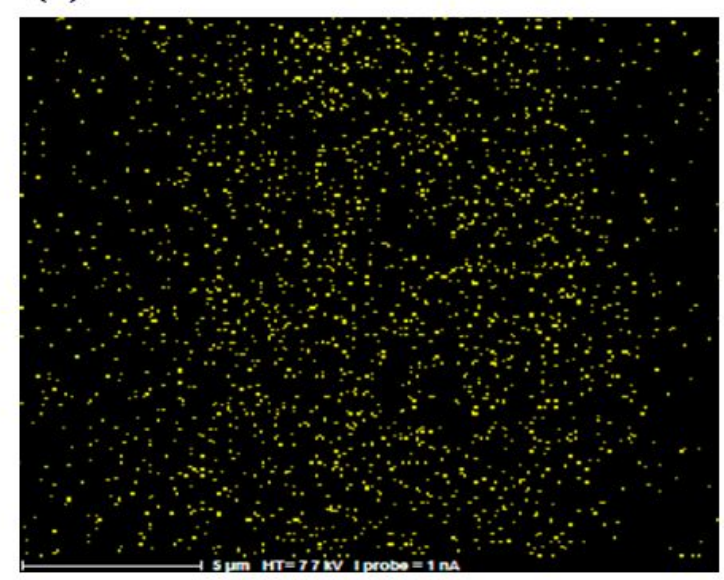

(b)

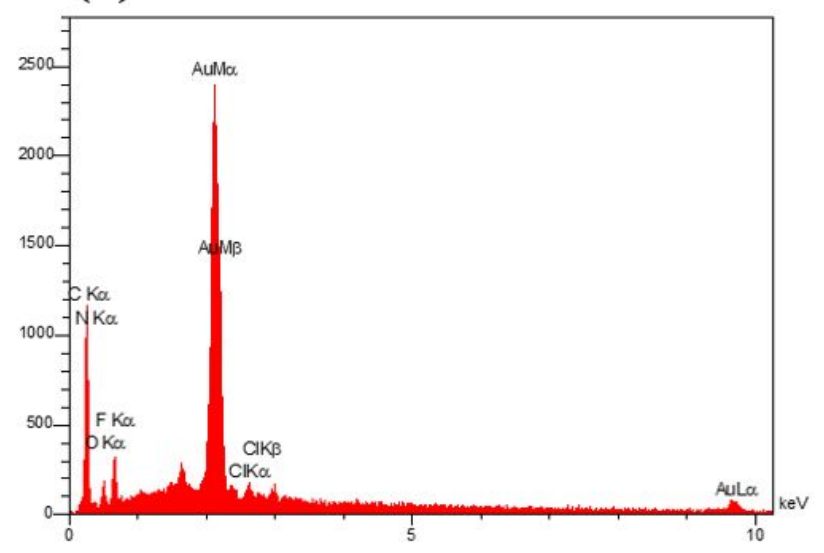

(d)

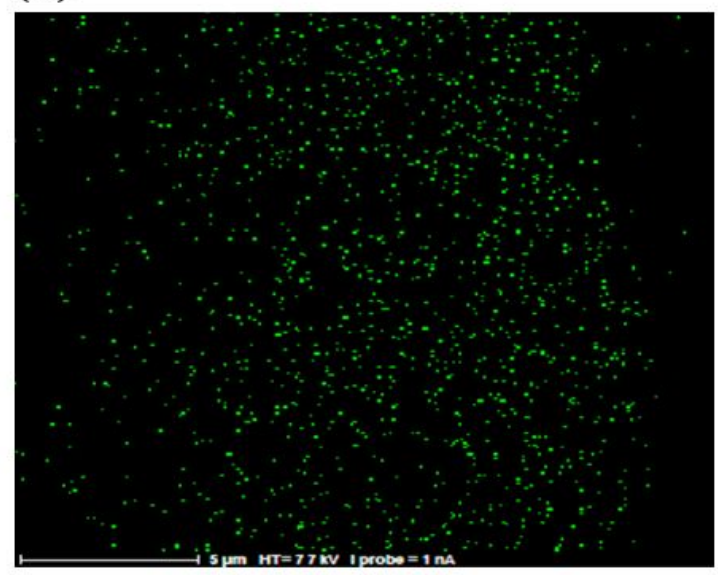

Figure S7. EDS spectrum of (a) AgNPs and (b) AuNPs. Elements mapping images of (c) Ag and (d) Au. 


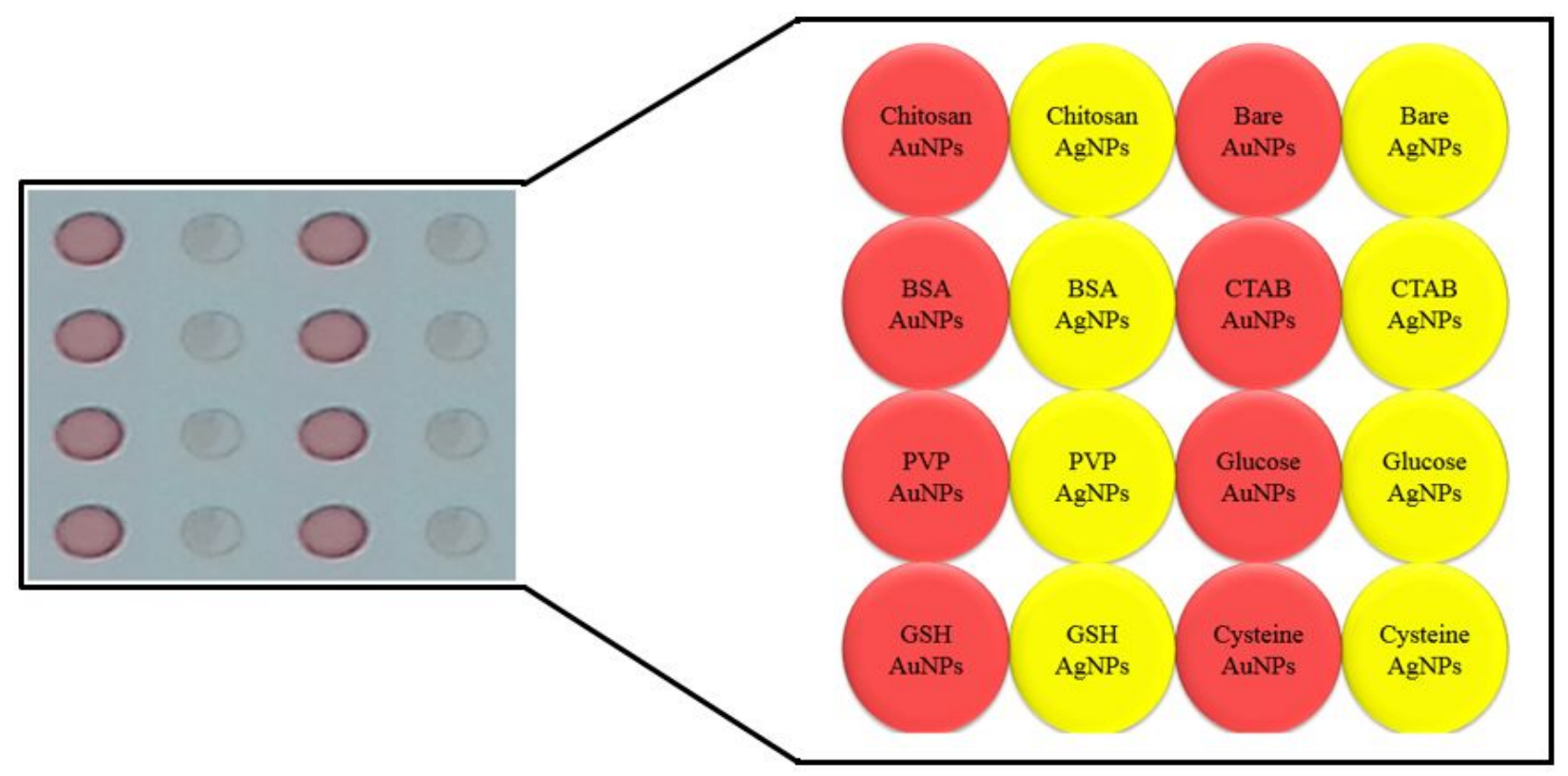

Figure S8. The fabricated nano optoelectronic nose. The nanoparticles used in the array are listed. 


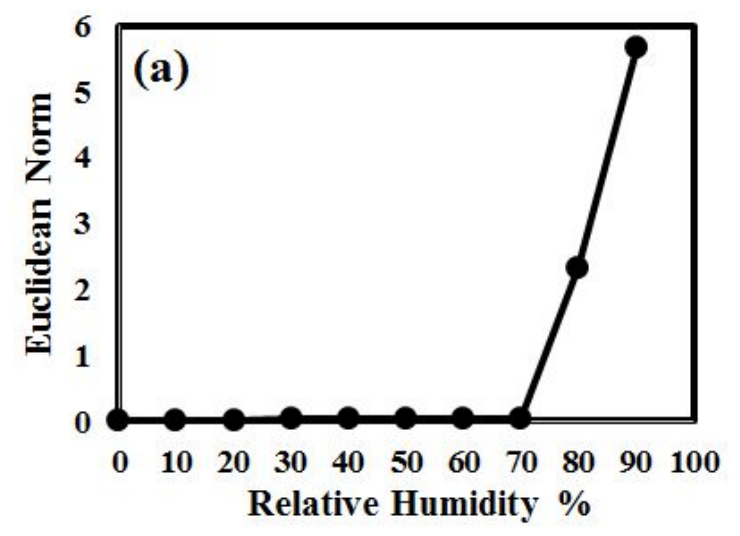

(c)

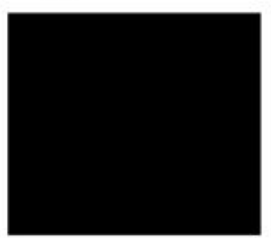

Control

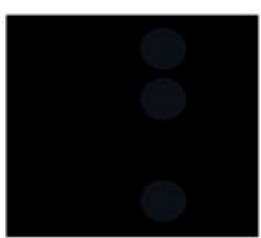

90 day

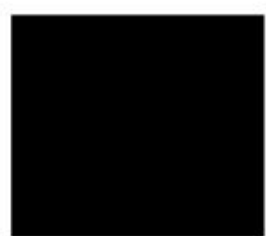

15 day

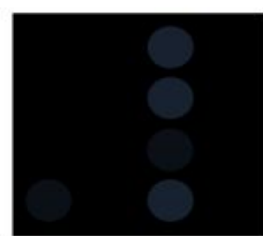

105 day

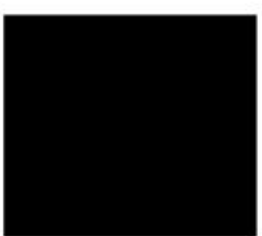

30 day

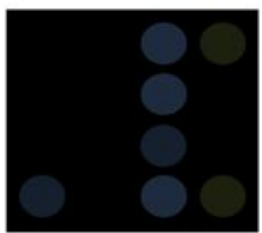

120 day
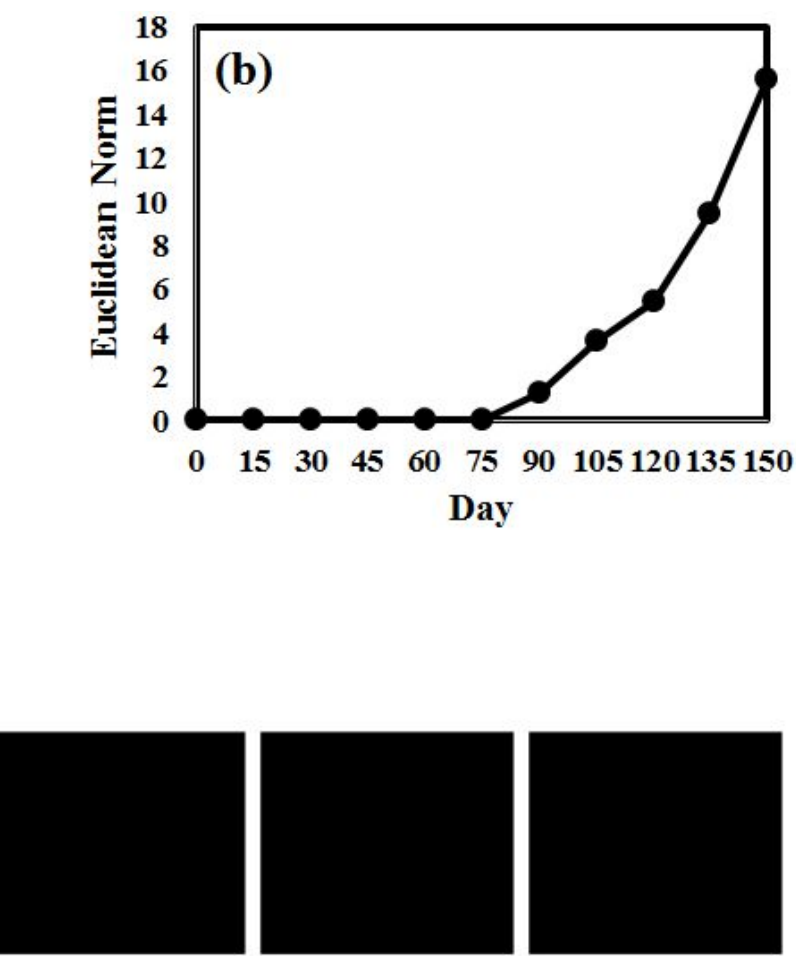

45 day

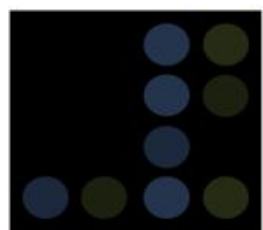

135 day

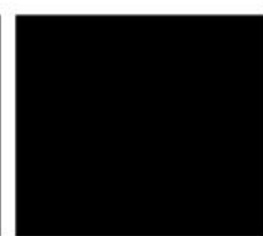

60 day

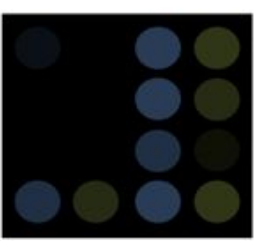

150 day

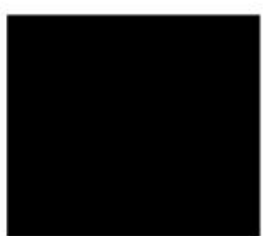

75 day

Figure S9. (a) The humidity, (b) durability of fabricated NOEN and (c) the RGB-based responses of fabricated sensor during the time when was not in use. 
(a)

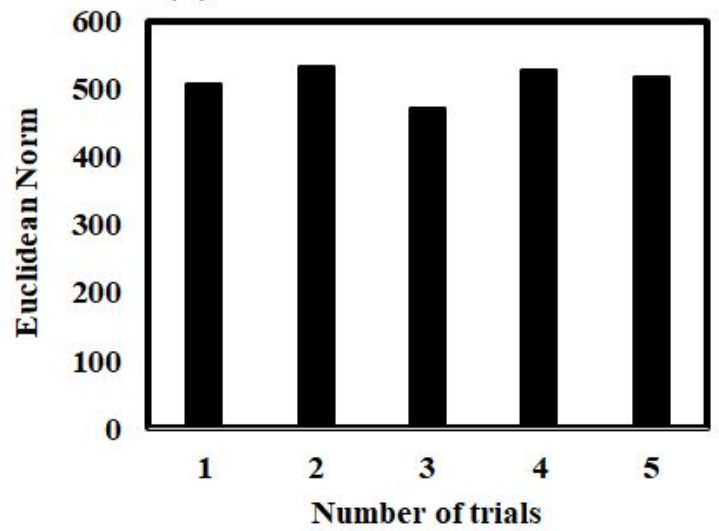

(c)

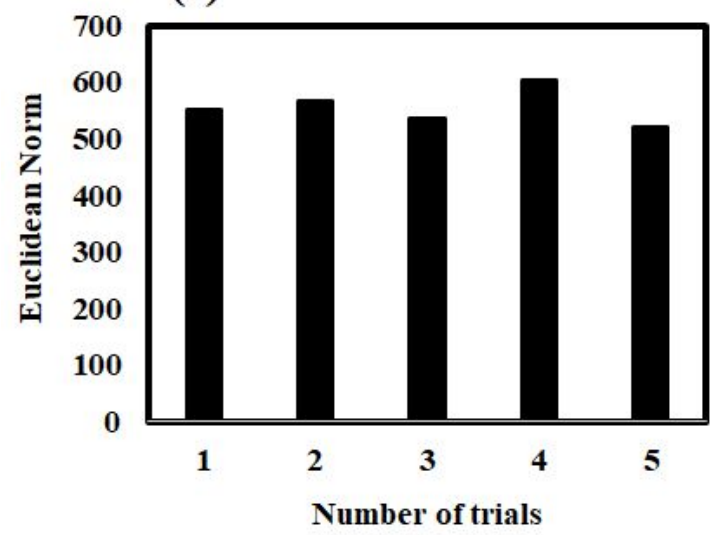

(b)

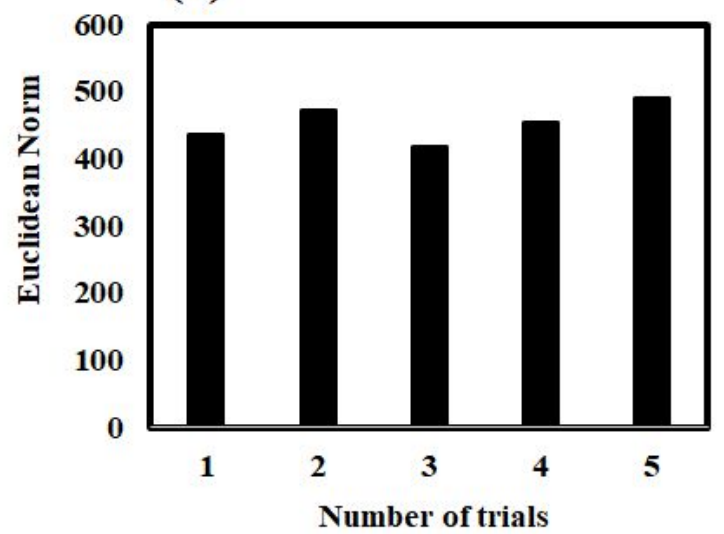

(d)

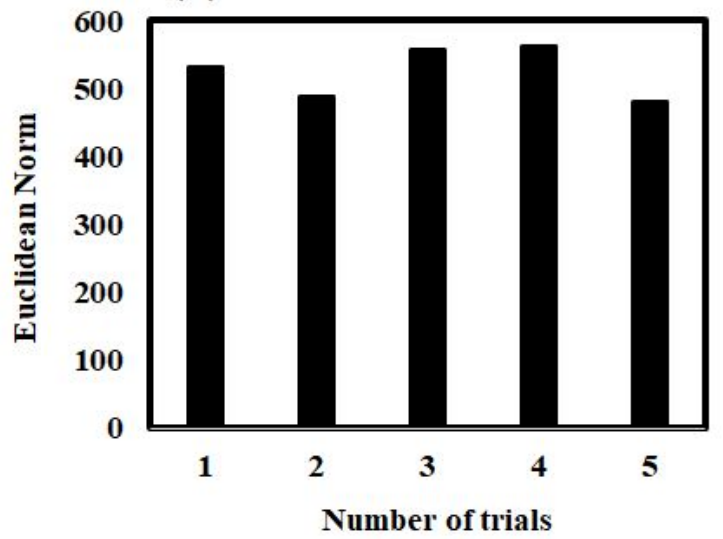

Figure S10. The reproducibility of the response of developed NOEN for detection of (a) propanol, (b) acetaldehyde, (c) acetic acid, (d) ethyl acetate with the coefficient of variation of the array response was about $4.75 \%, 6.20 \%, 5.67 \%, 7.17 \%$ respectively. The Euclidean norm is the total length of the full dimensional color-difference vector, that is, the total array response. 

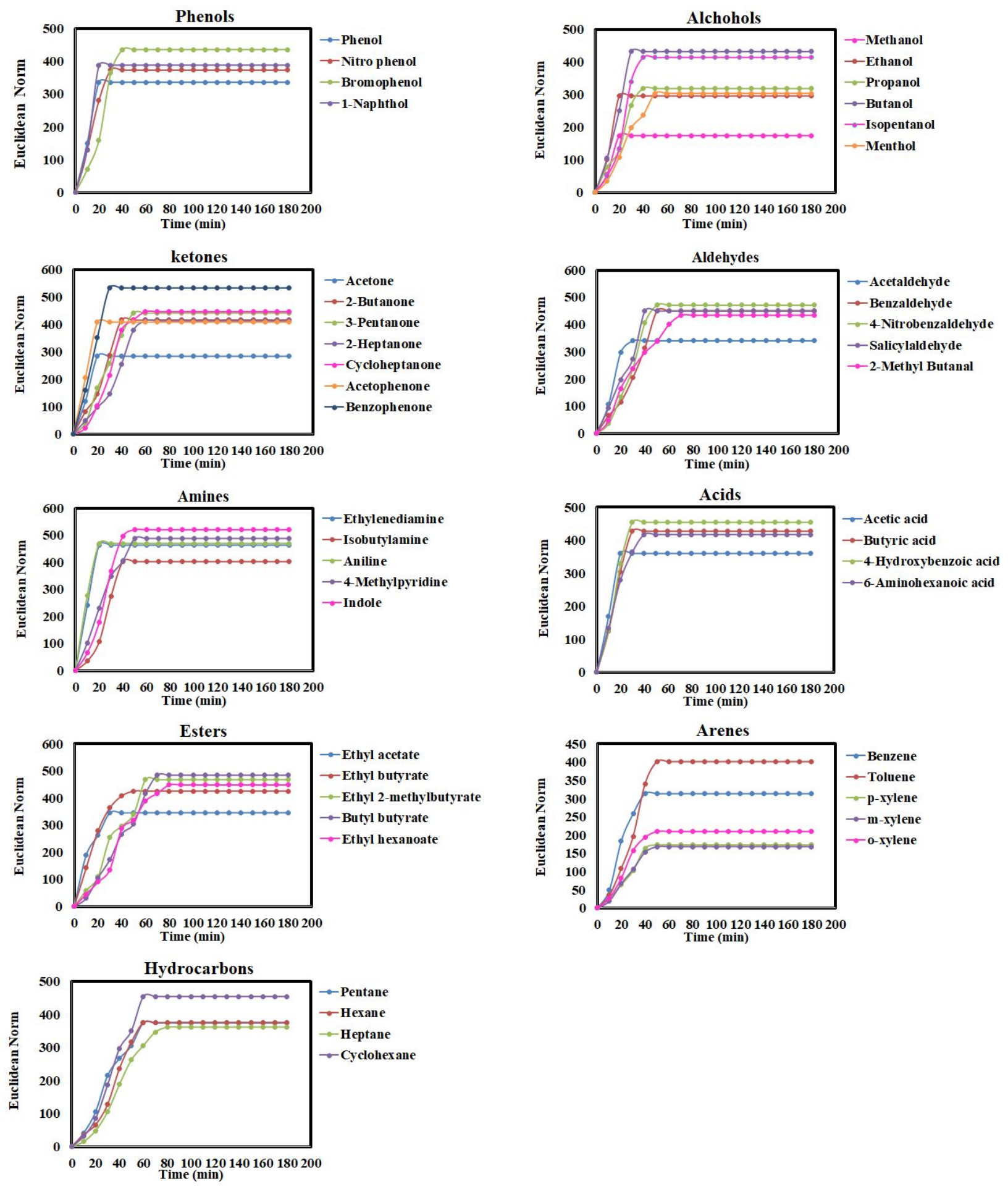

Figure S11. Response time of the NOEN for 45 VOCs. 
Figure S12
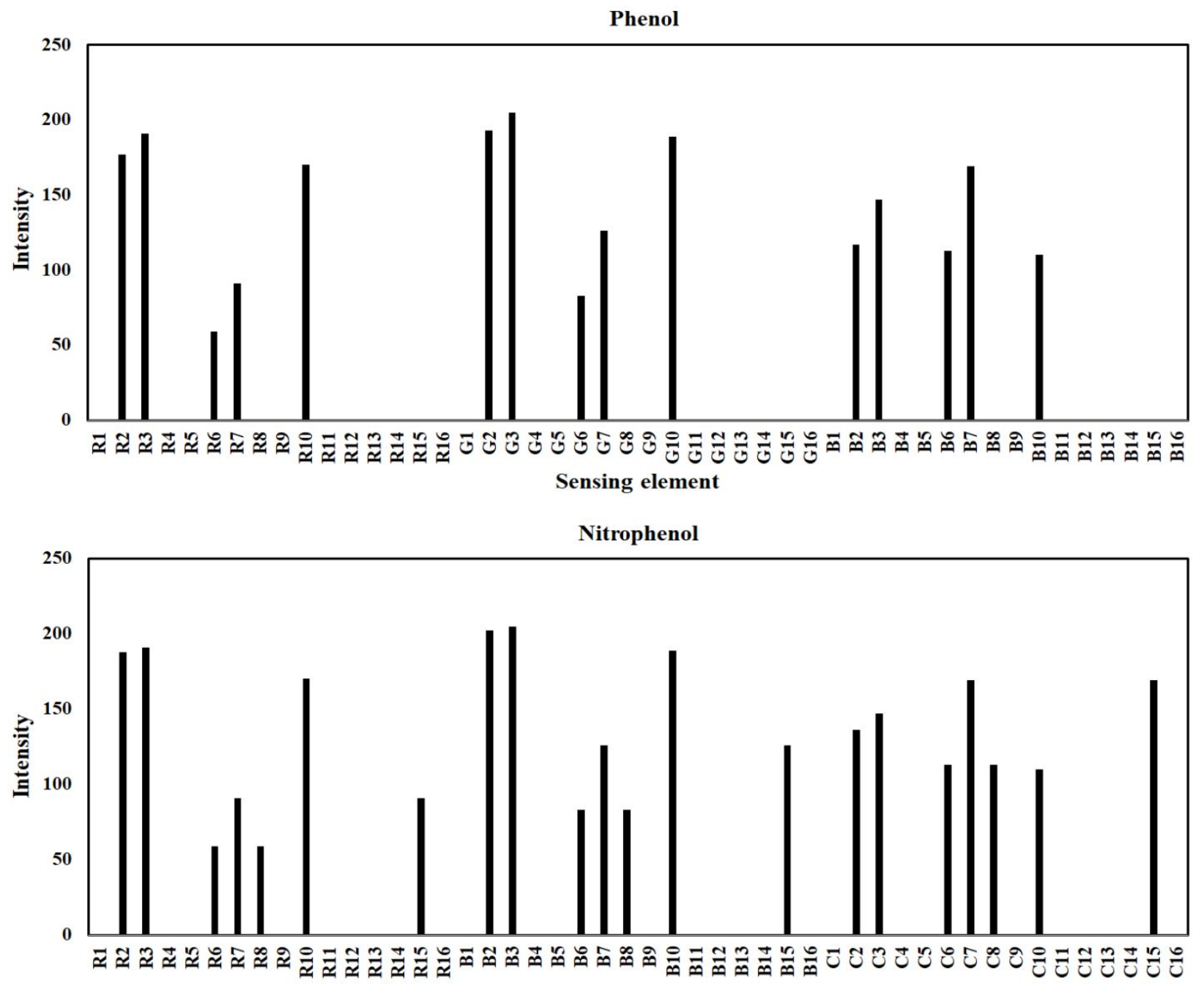

Sening element

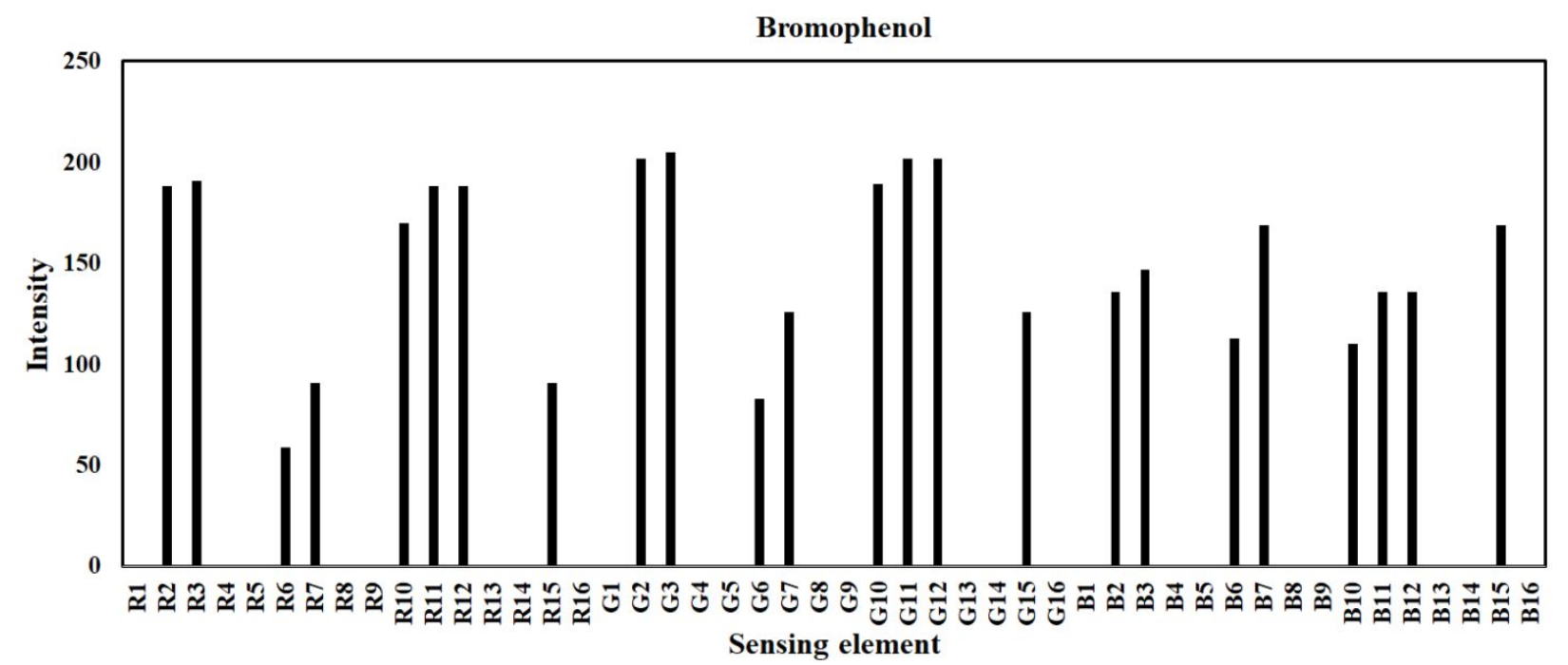




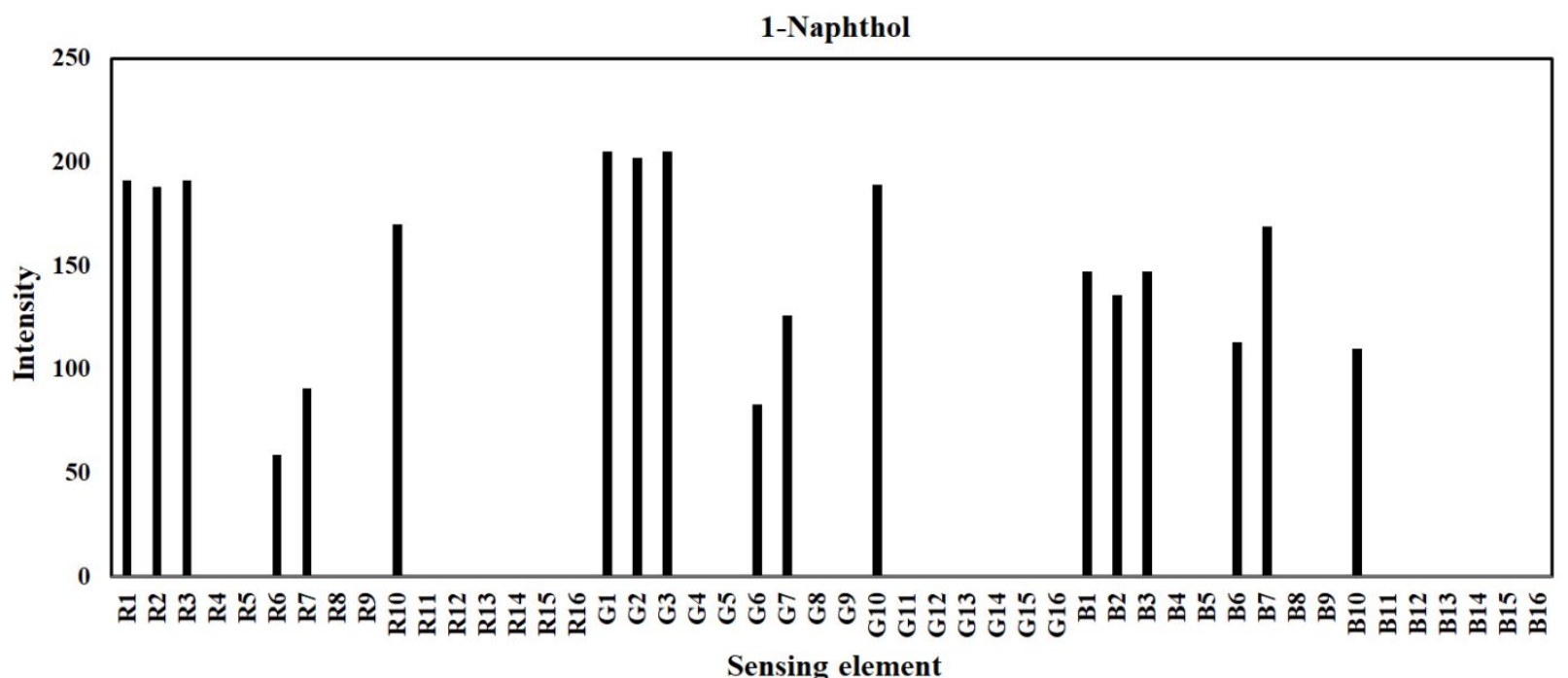

Methanol
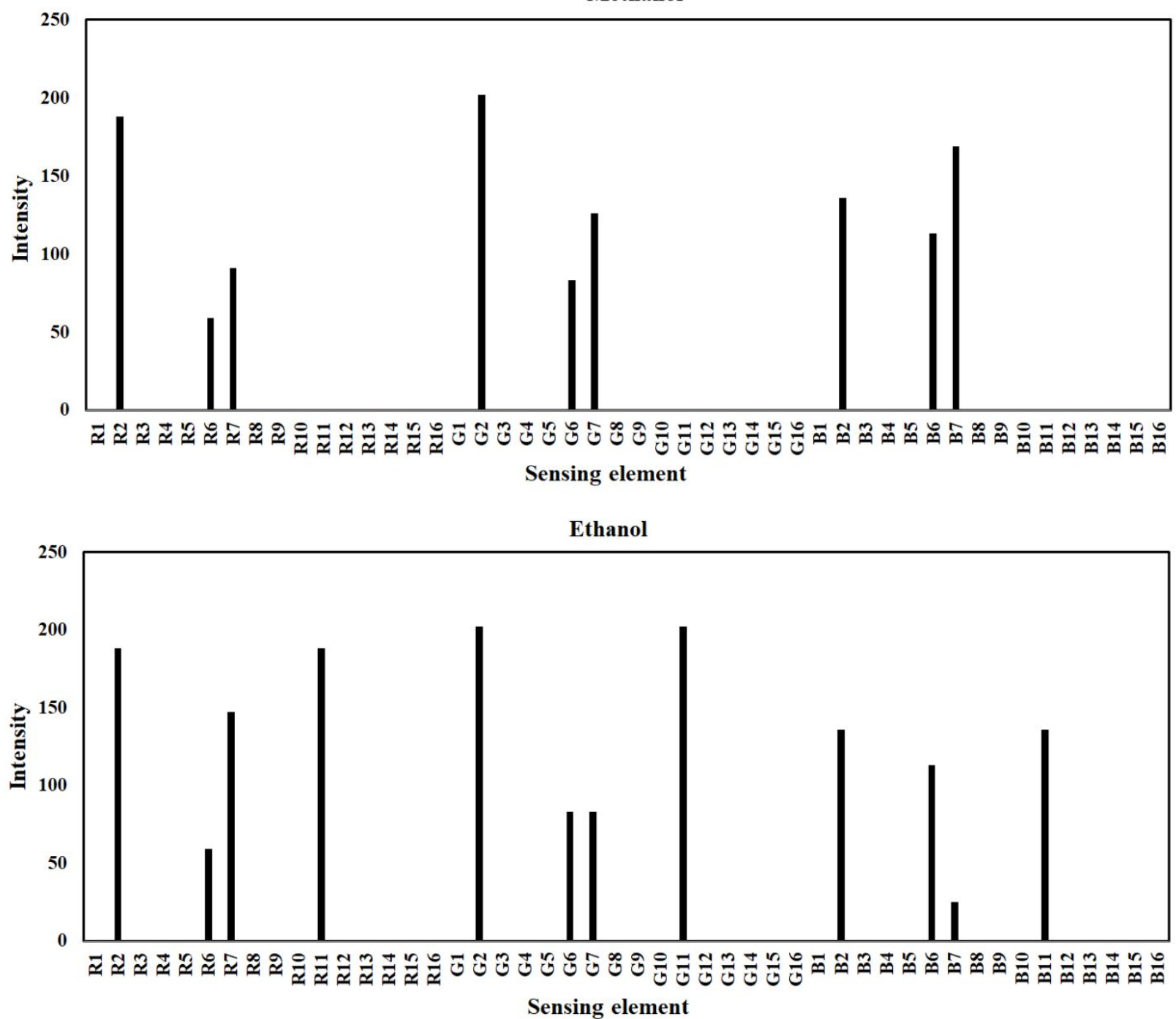


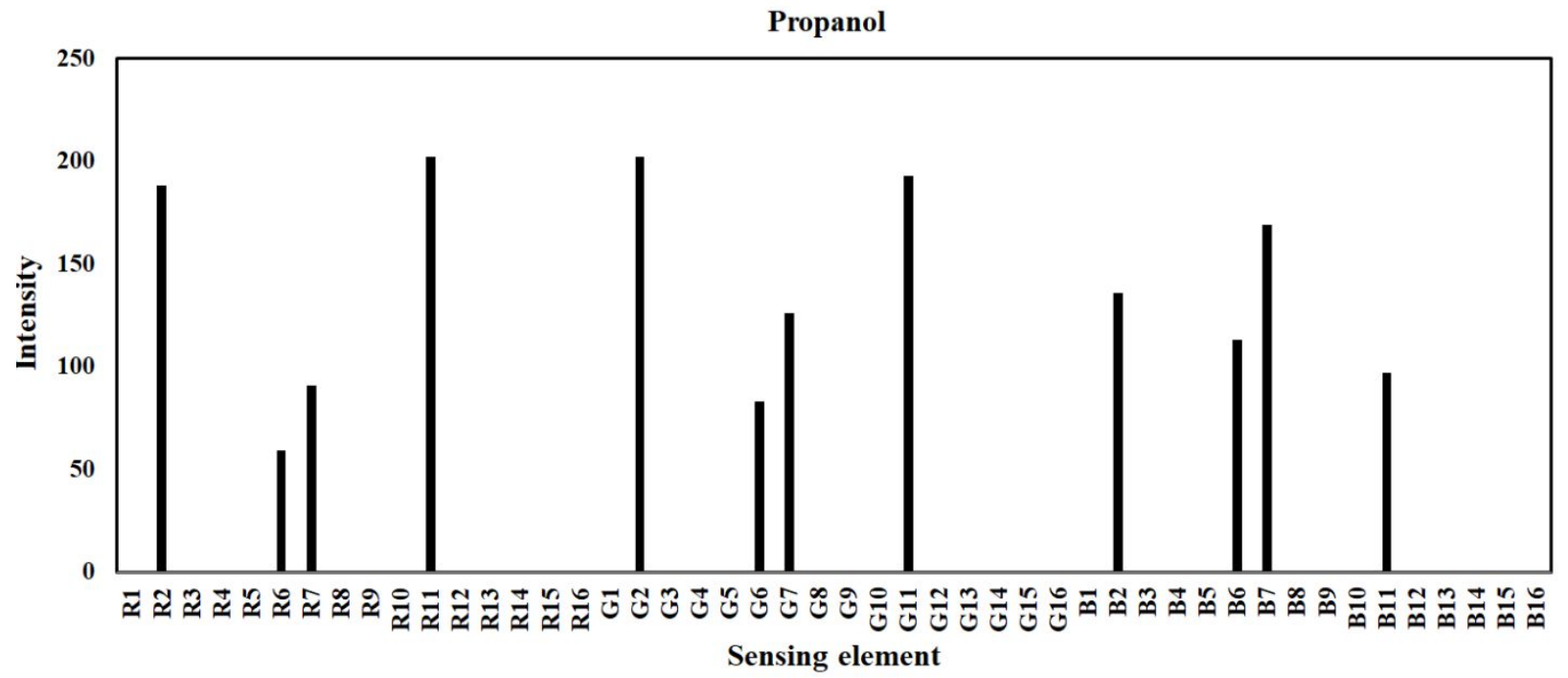

Butanol
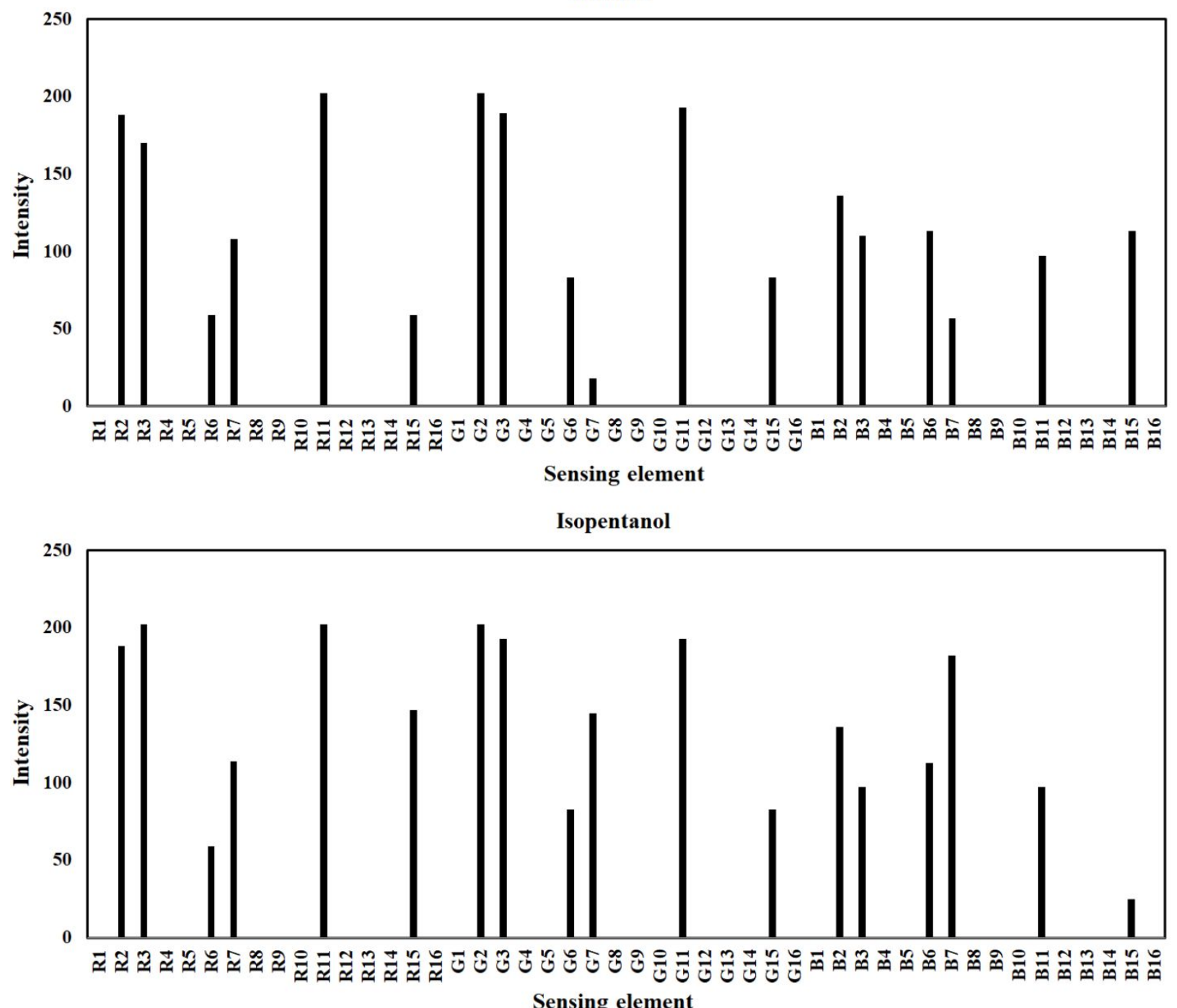

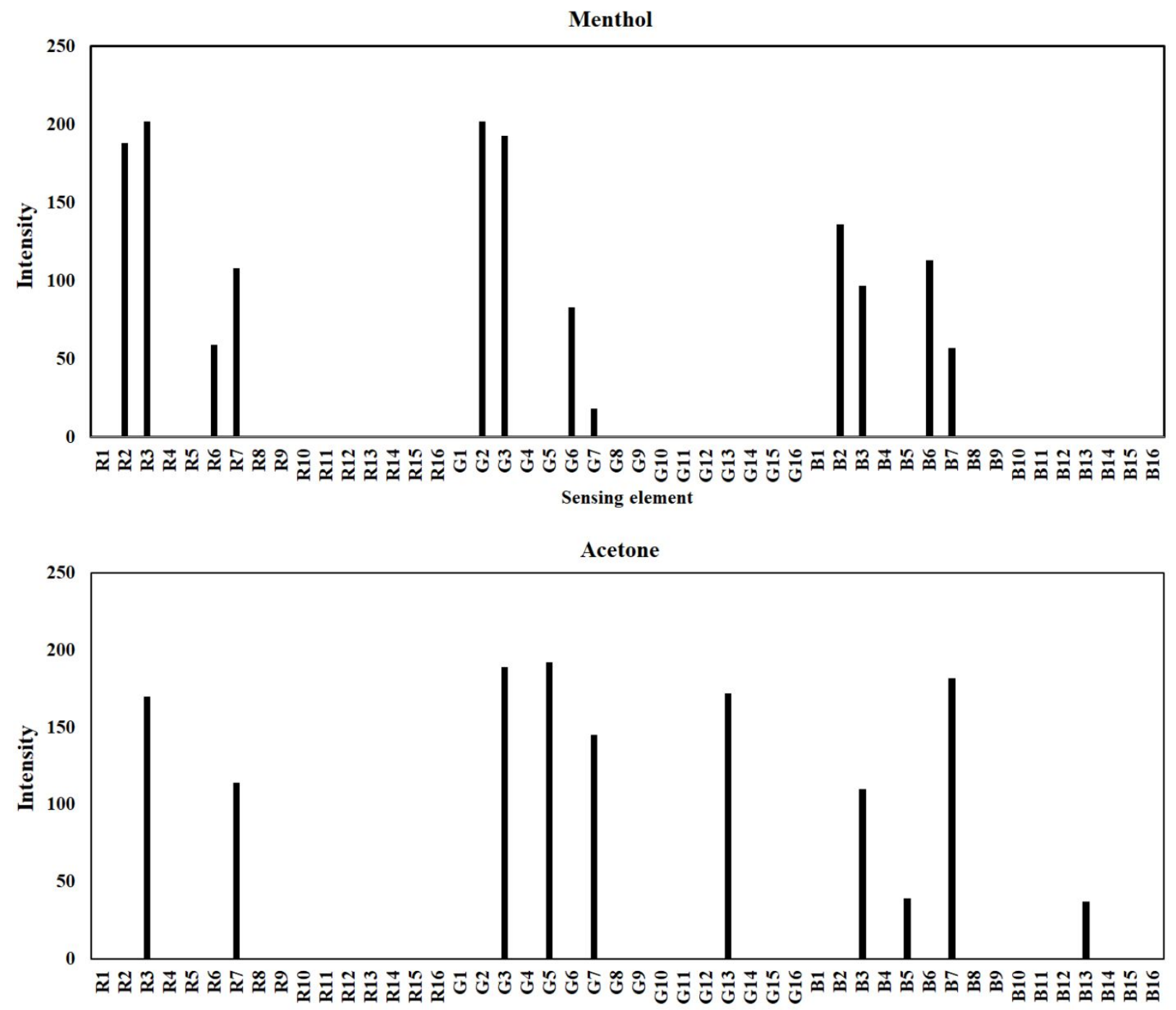

Sensing element

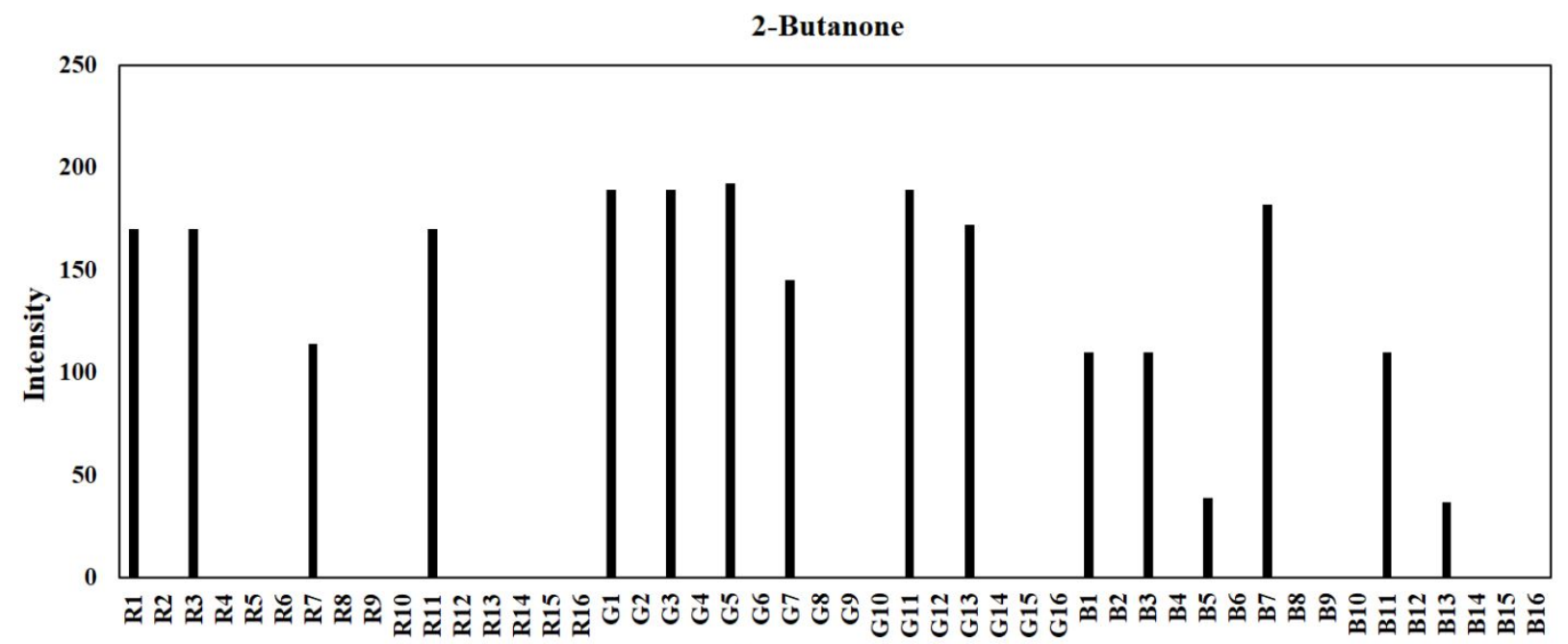

Sensing element 


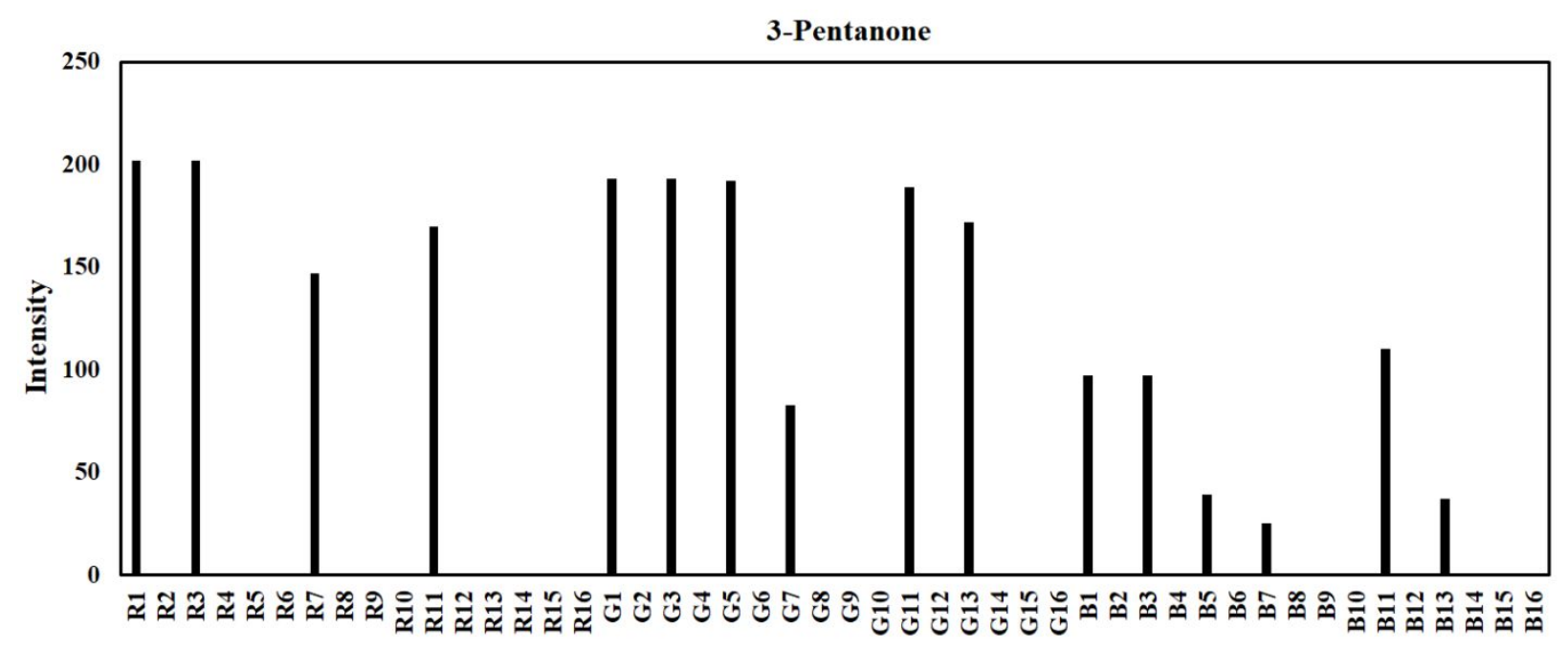

Sensing element
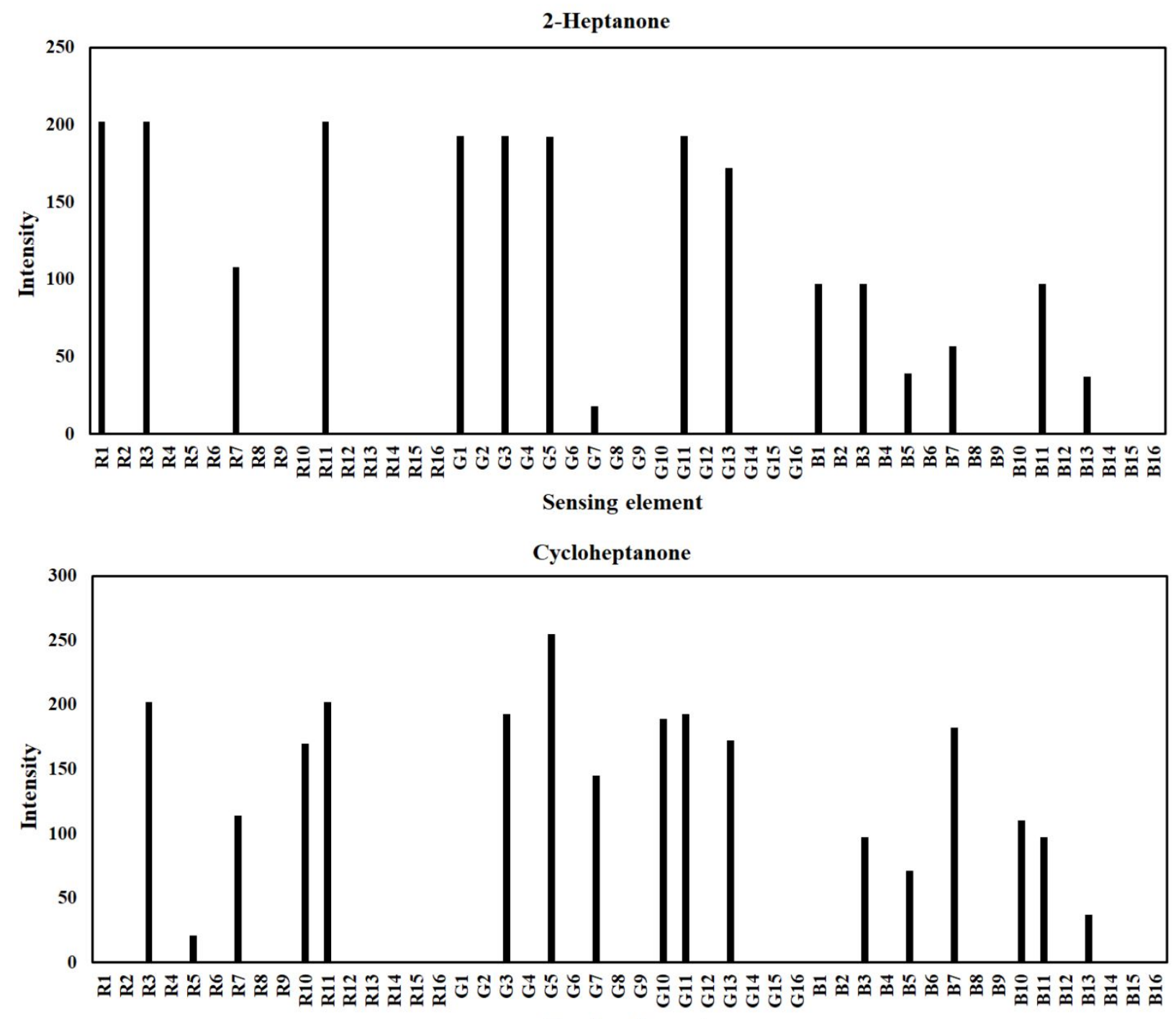

Sensing element 

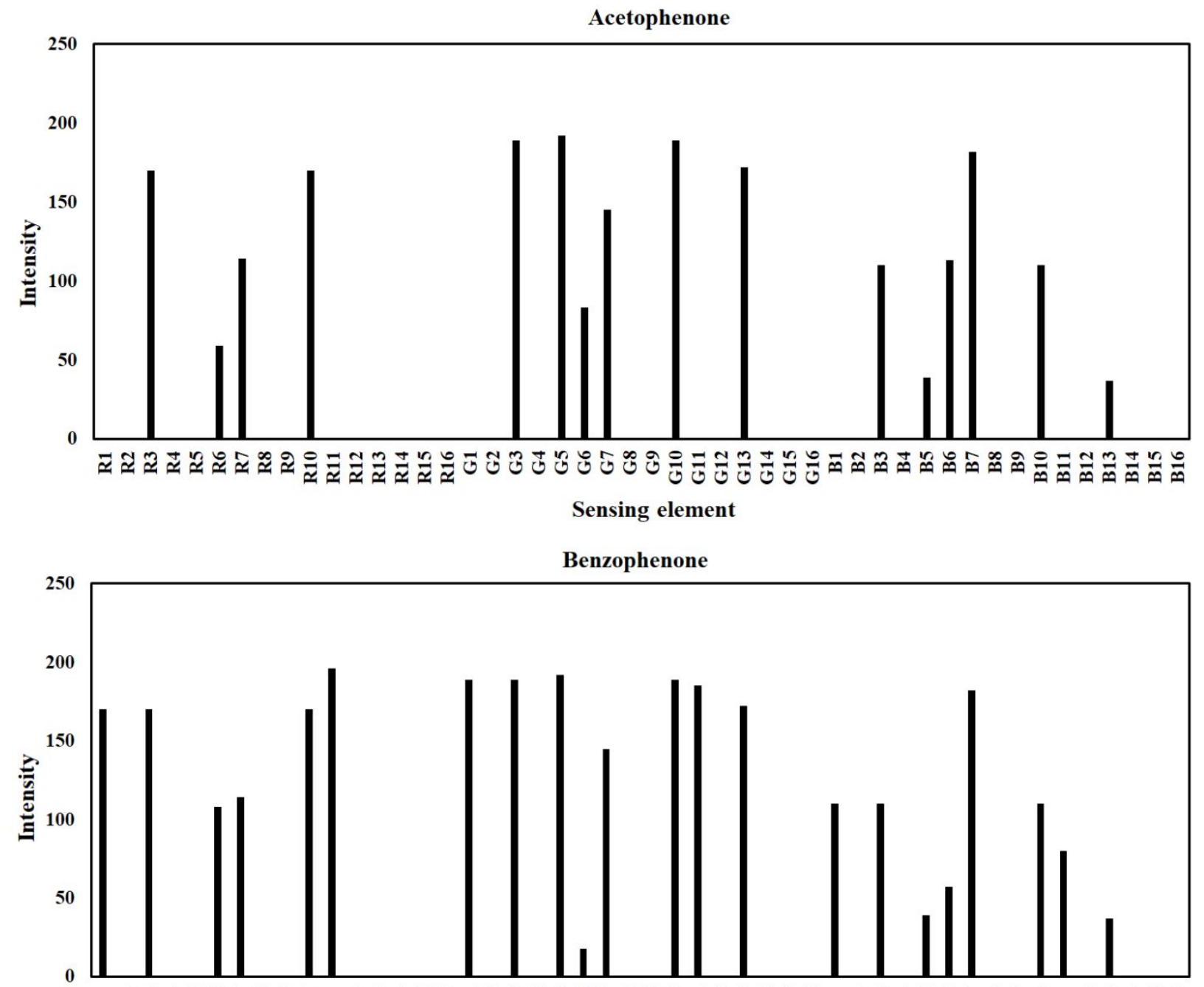

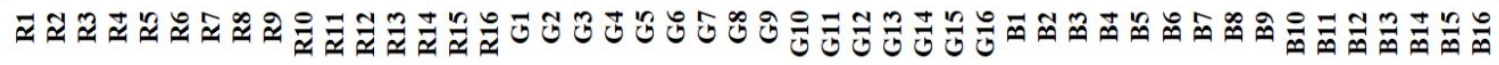
Sensing element

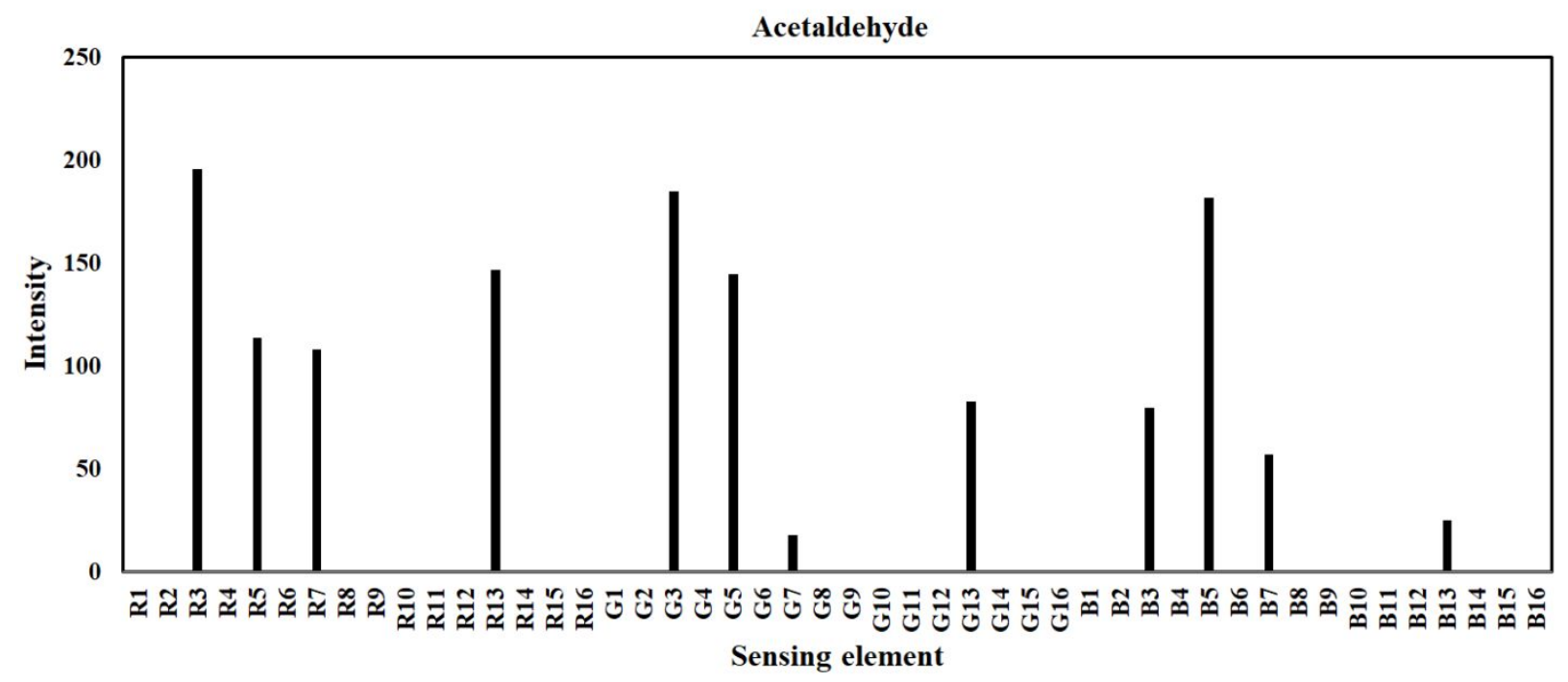



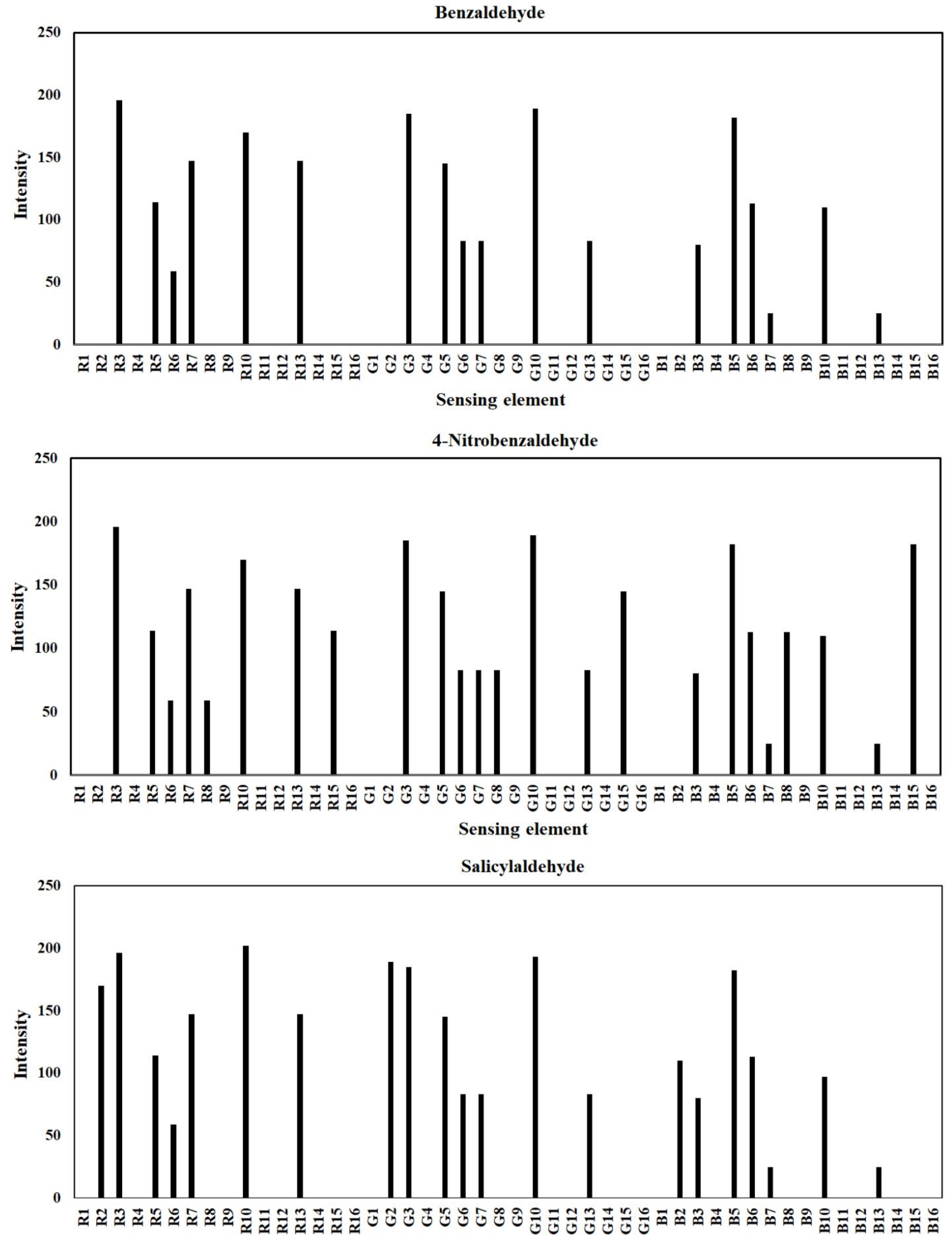

Sensing element 

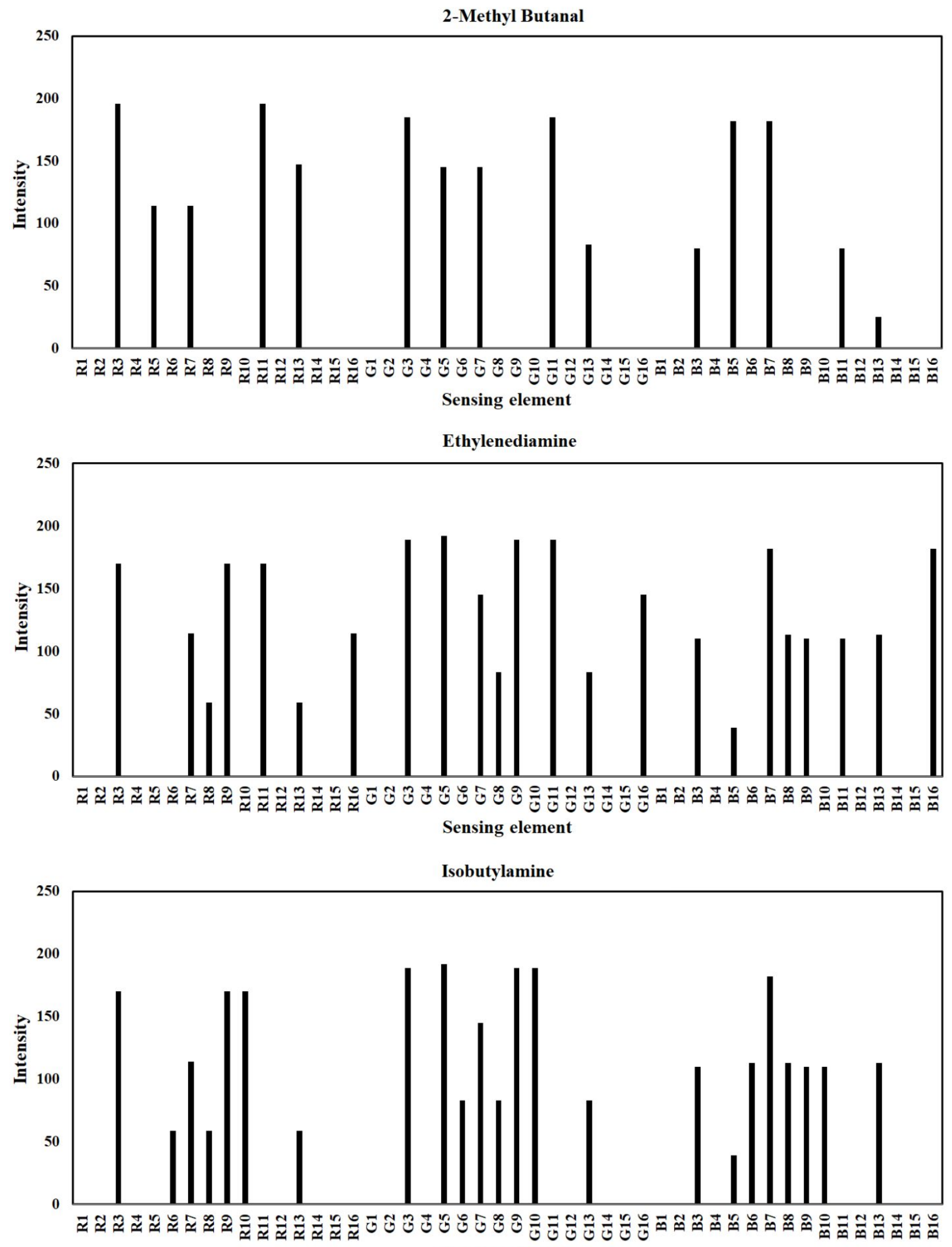

Sensing element 


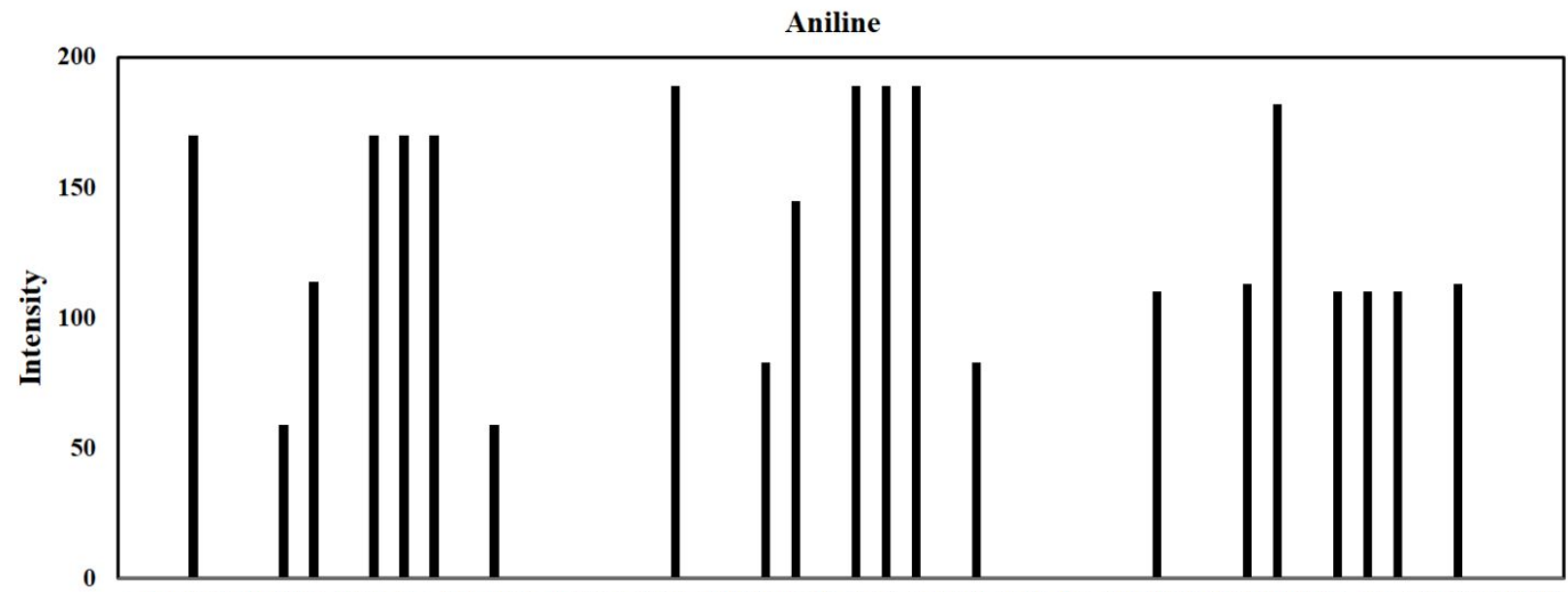

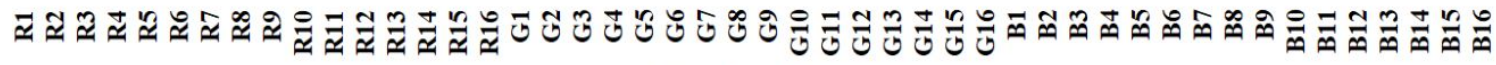
Sensing element
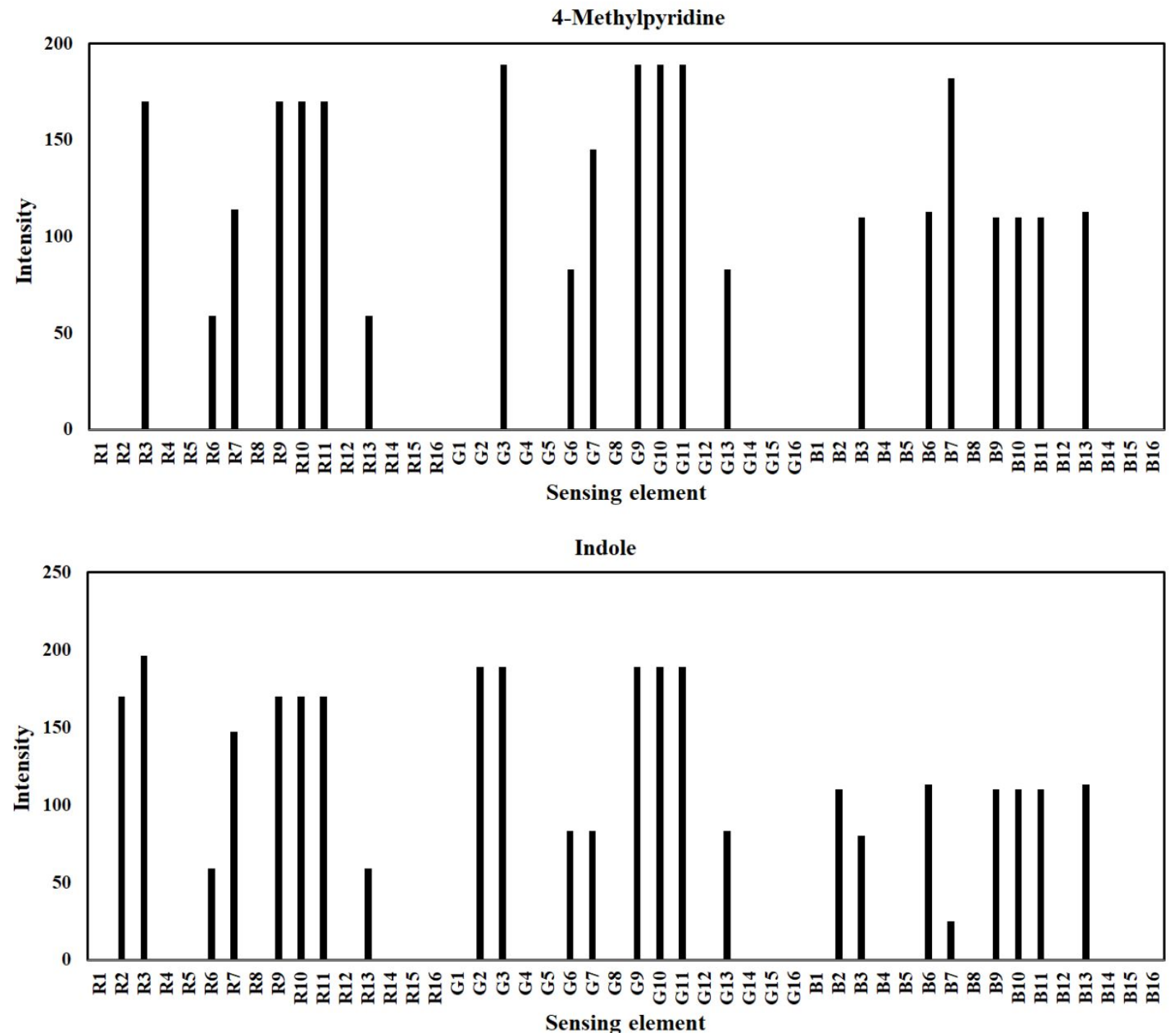


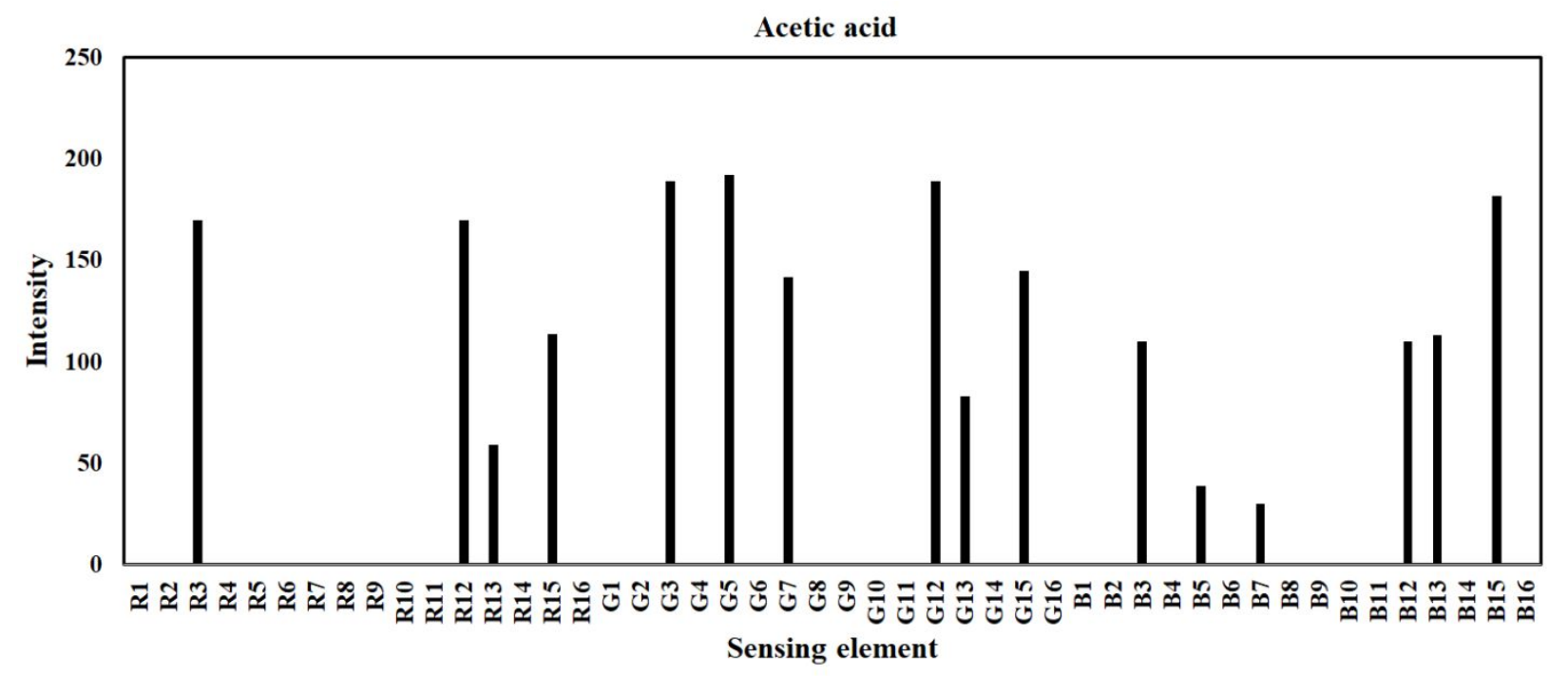

Butyric acid
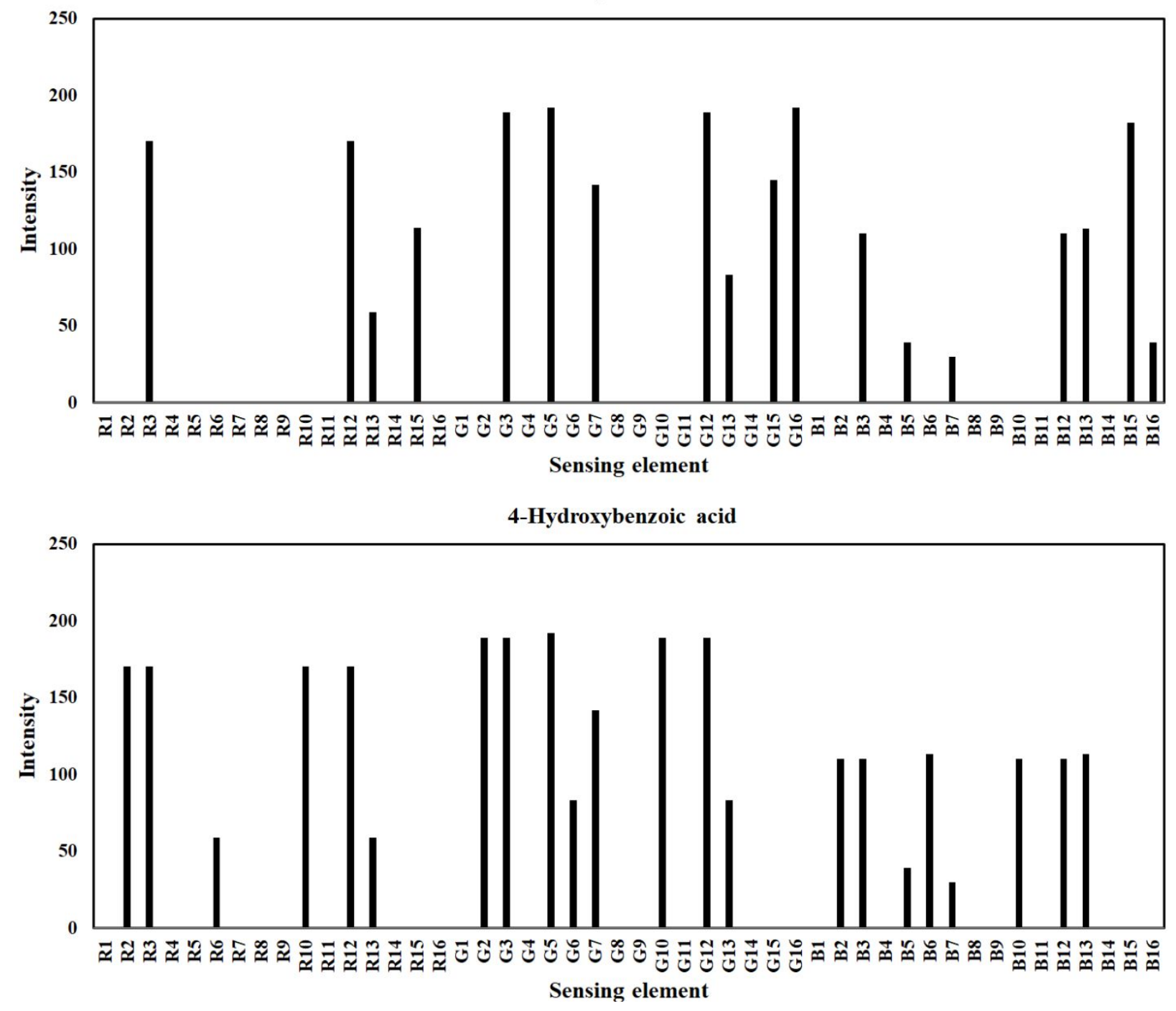
6-Aminohexanoic acid

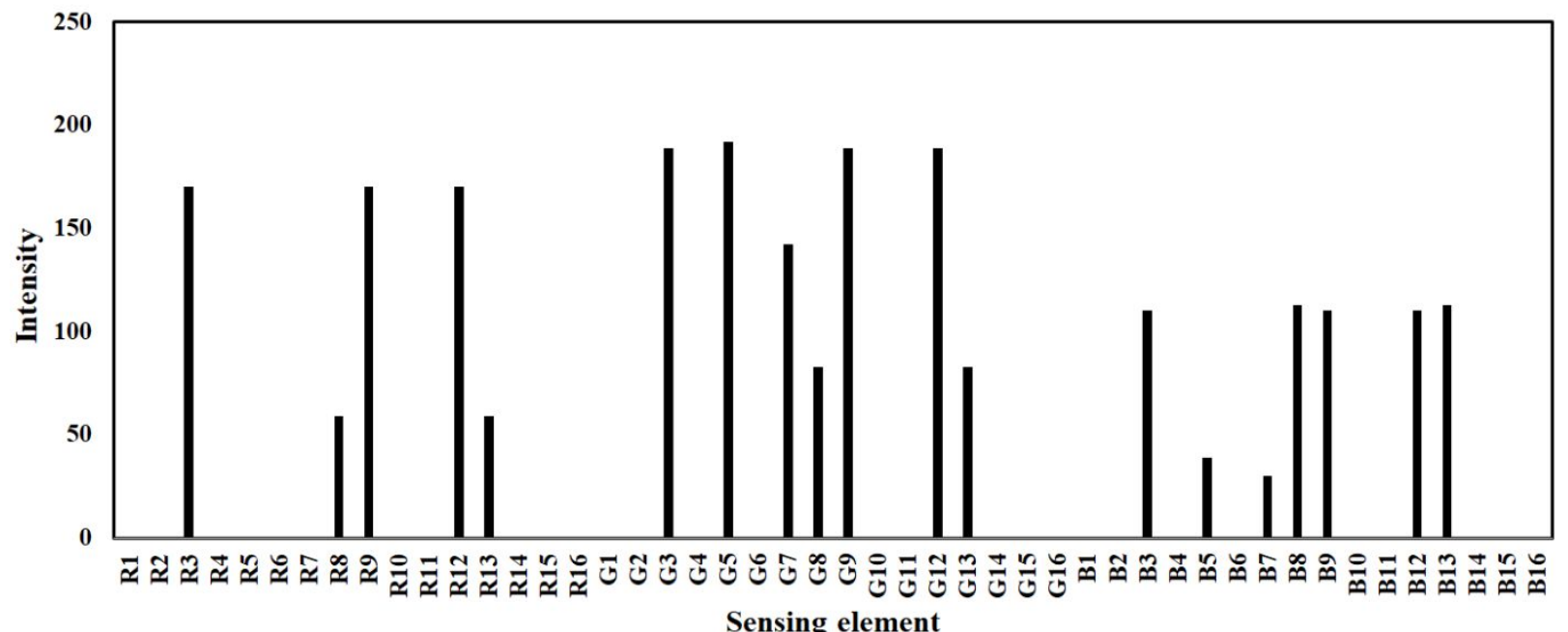

Ethyl acetate

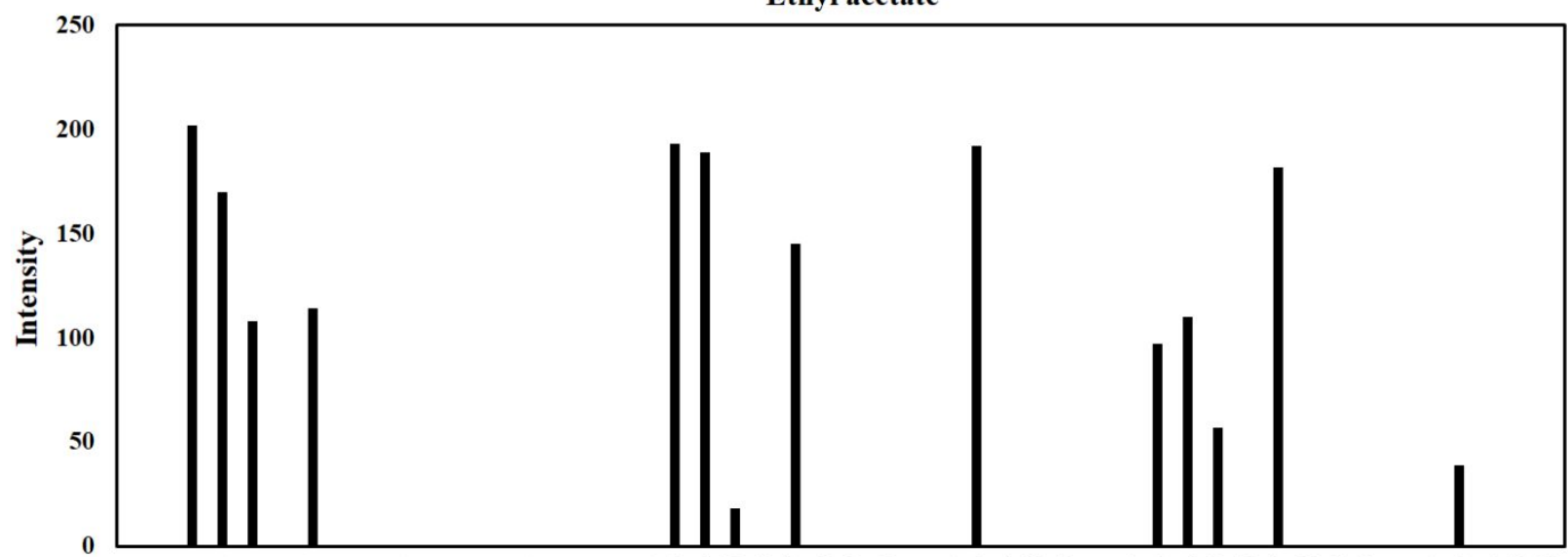

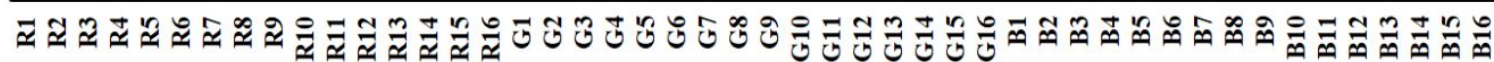

Sensing element

Ethyl butyrate

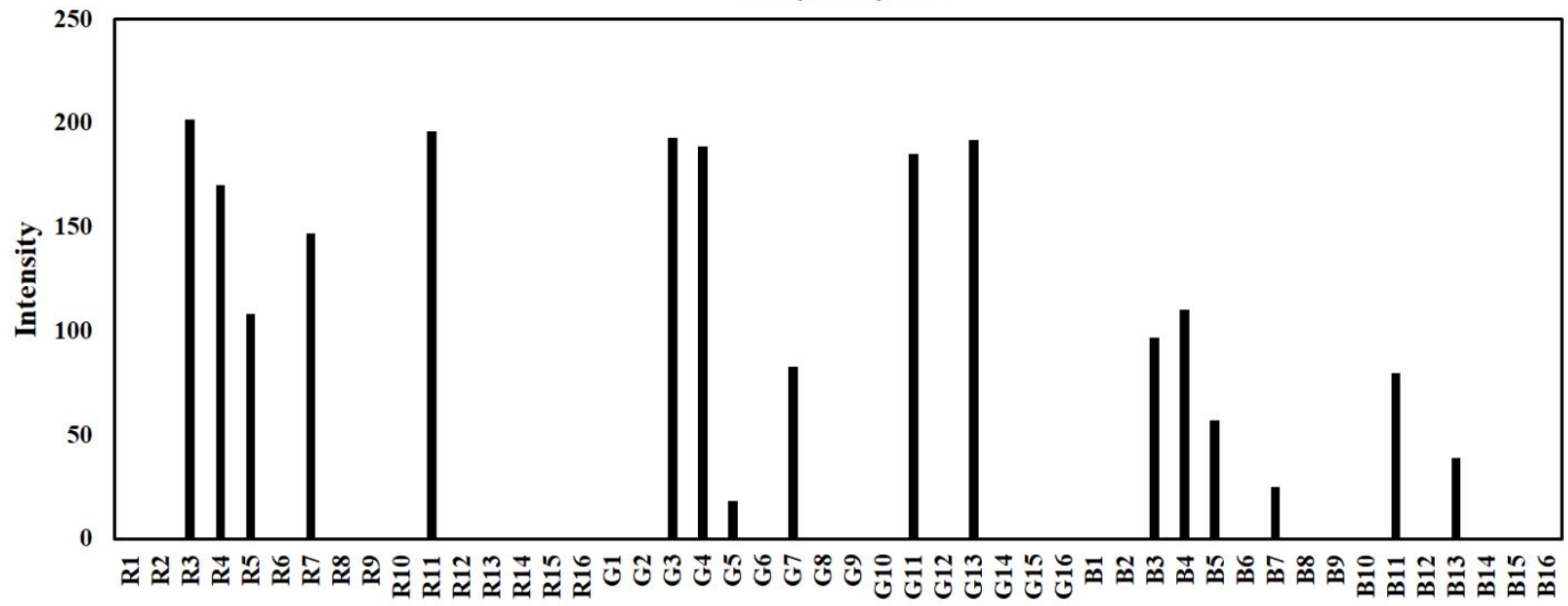

Sensing element 


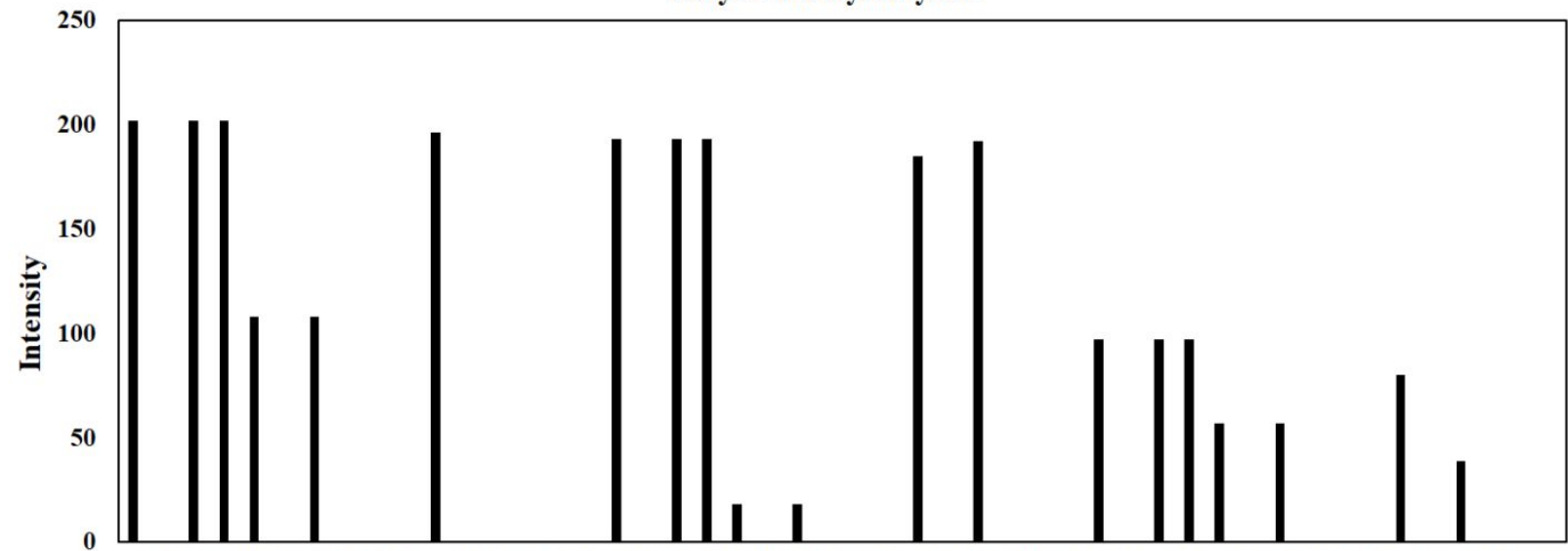

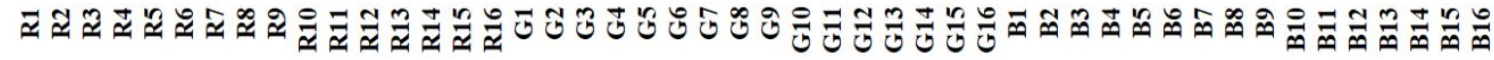
Sensing element
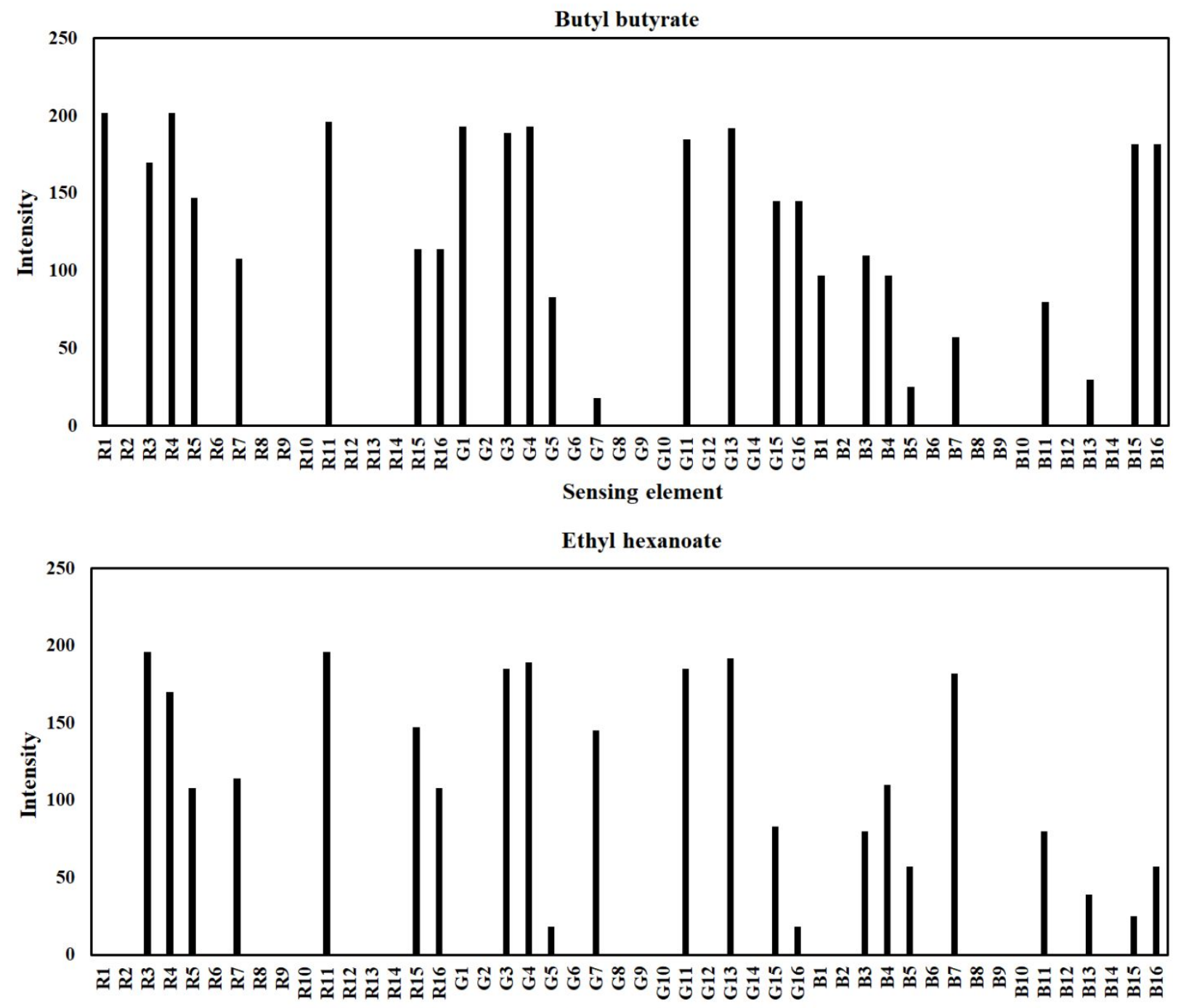


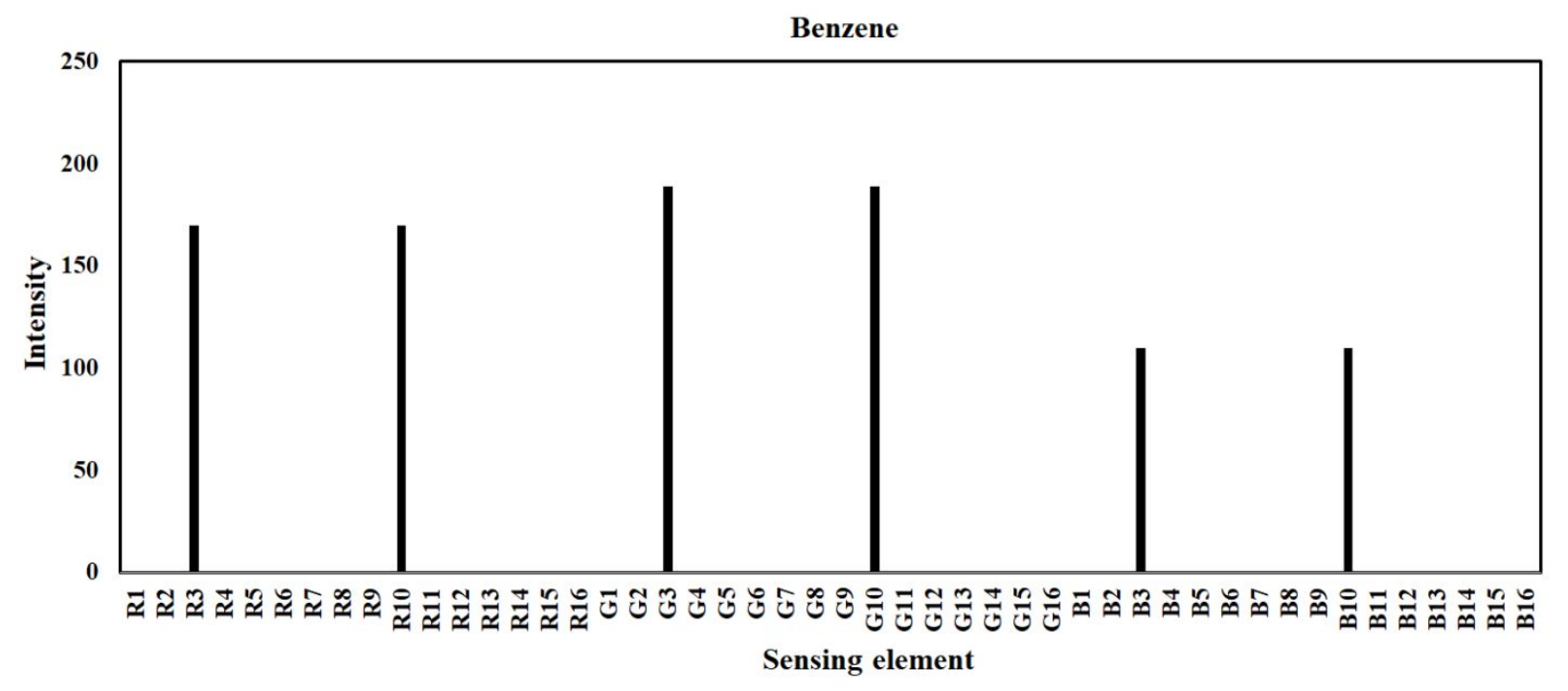

Toluene

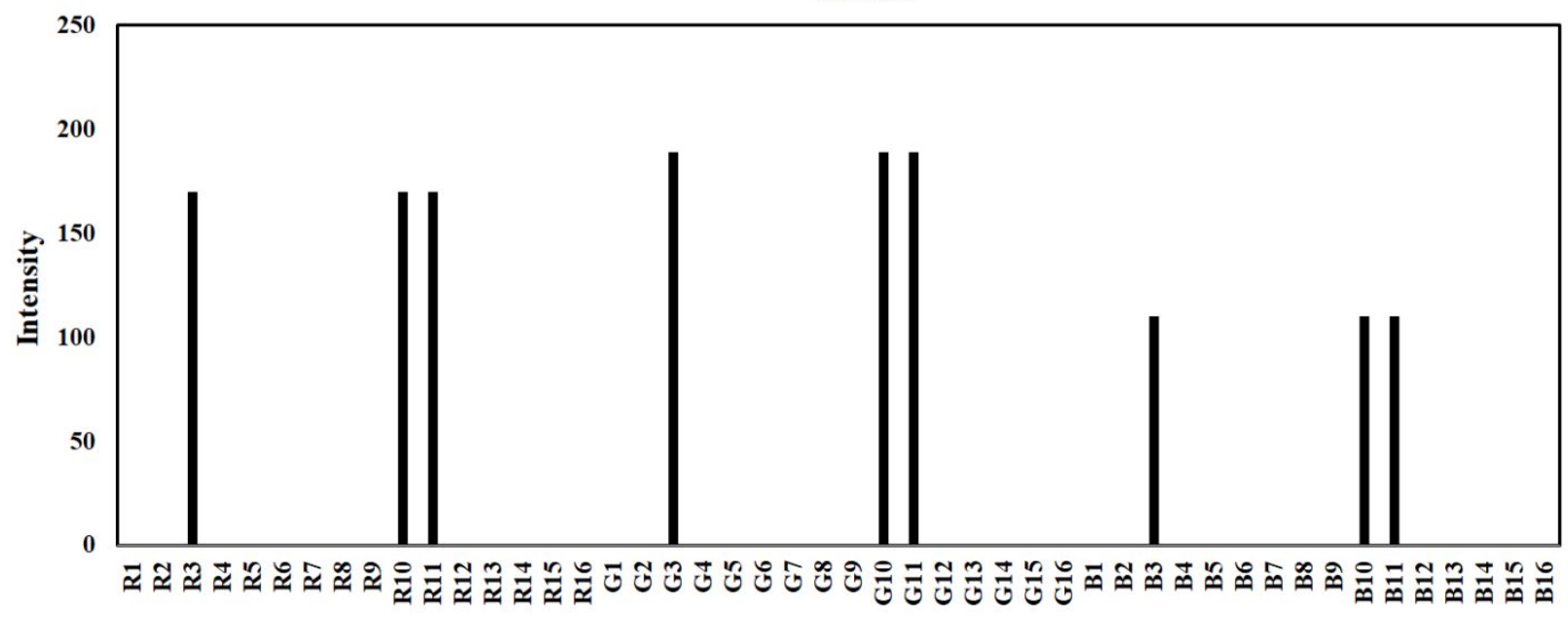
Sensing element

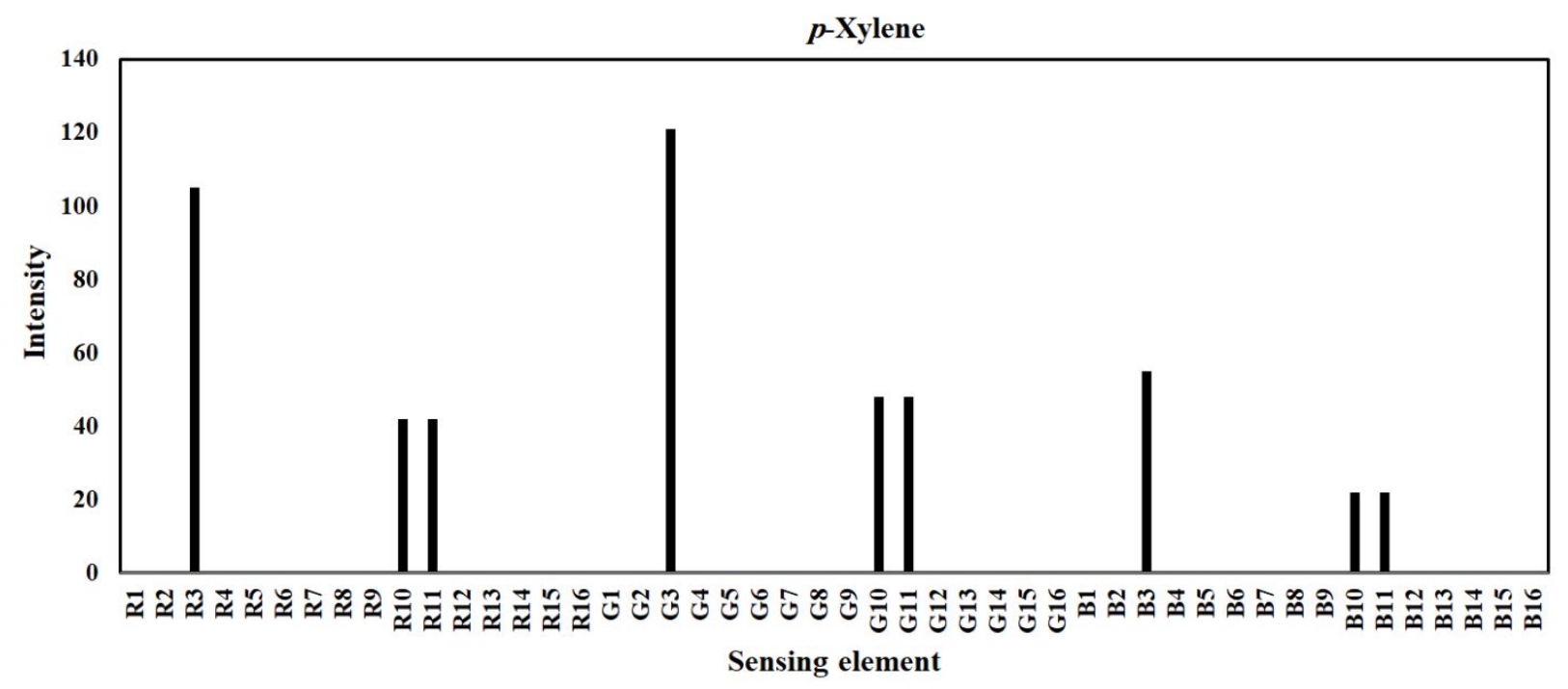



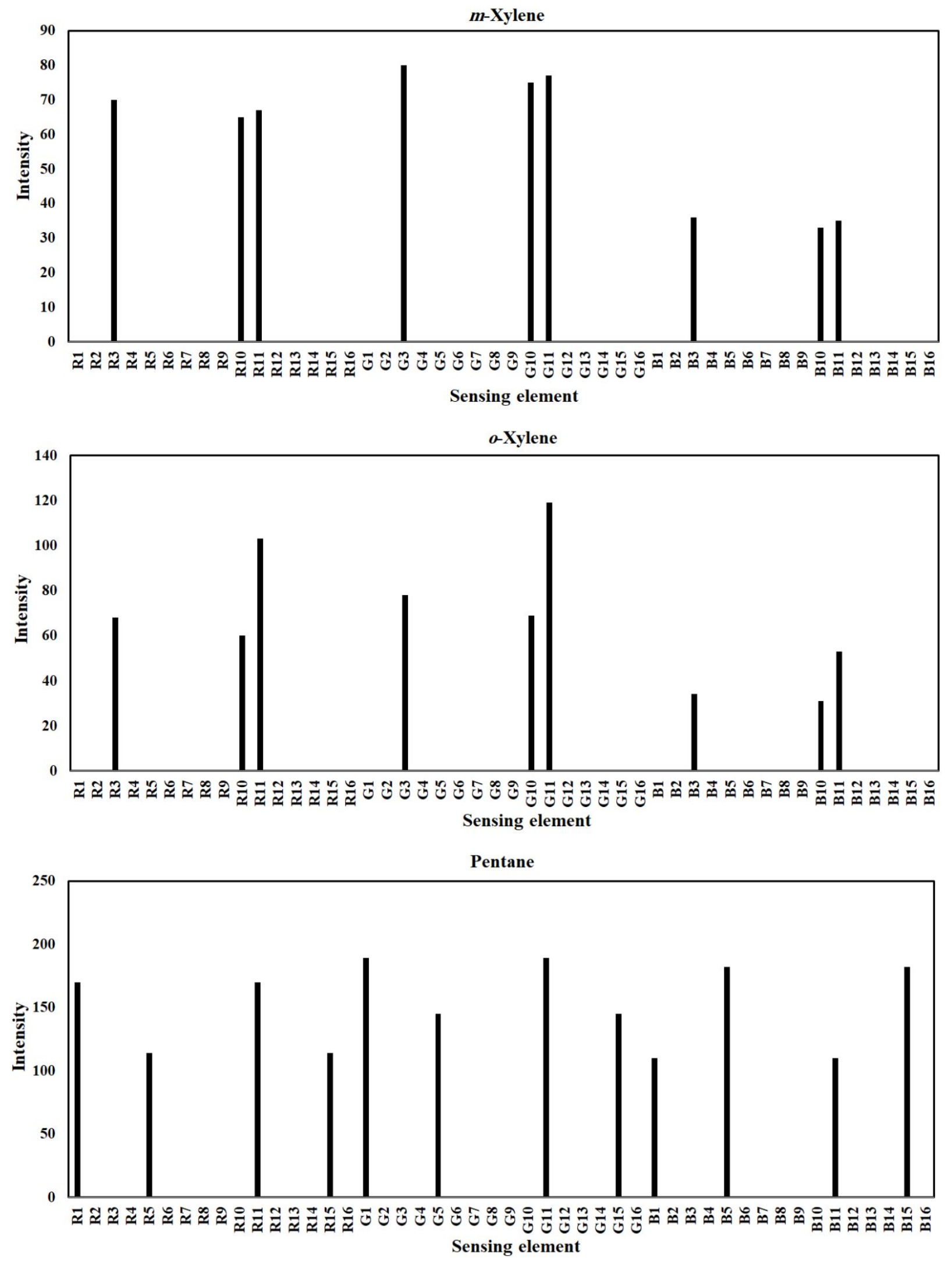


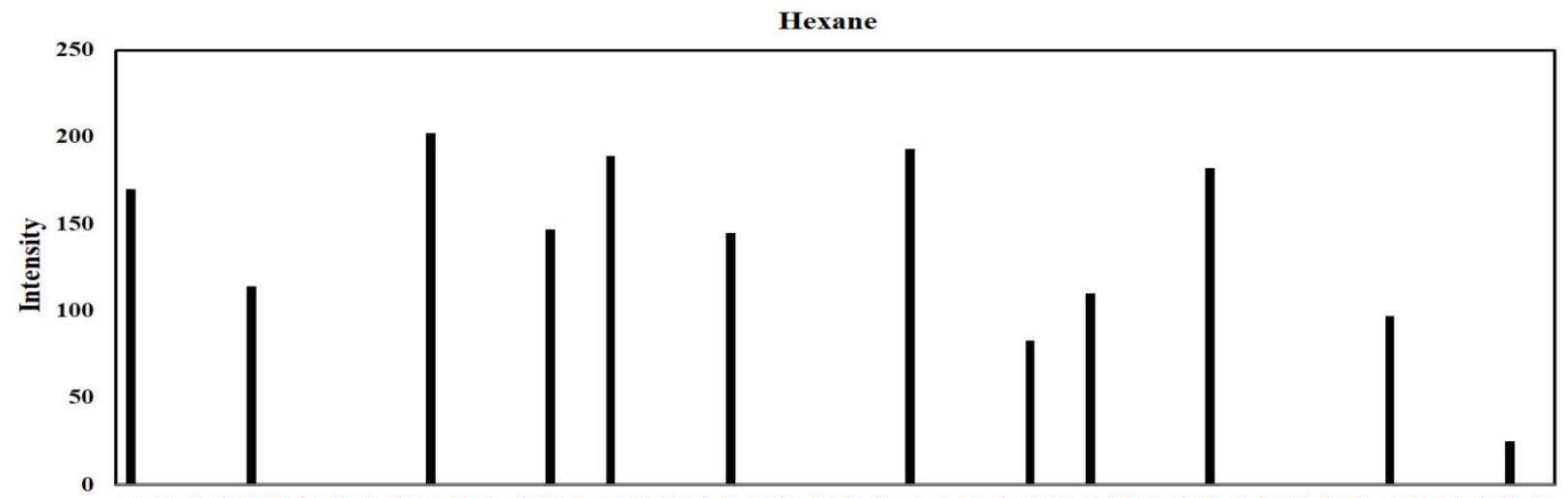

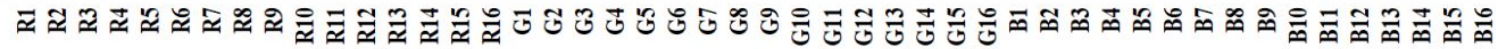
Sensing element

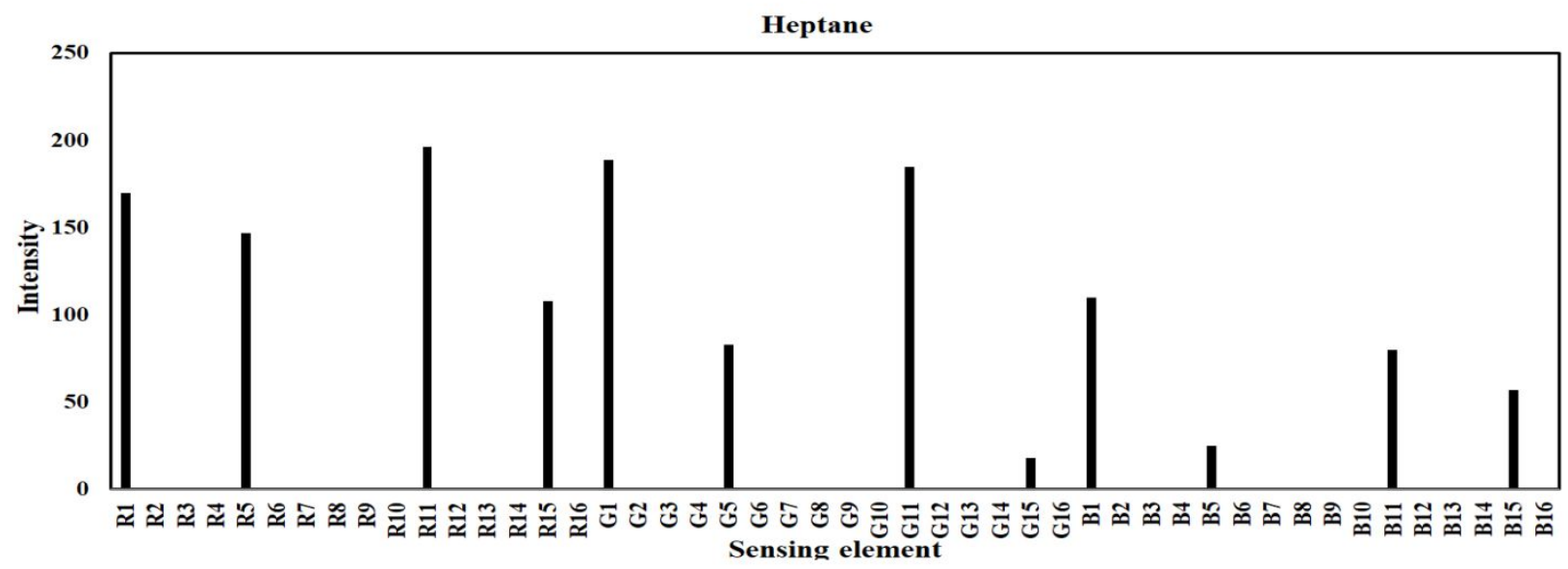

Cyclohexane

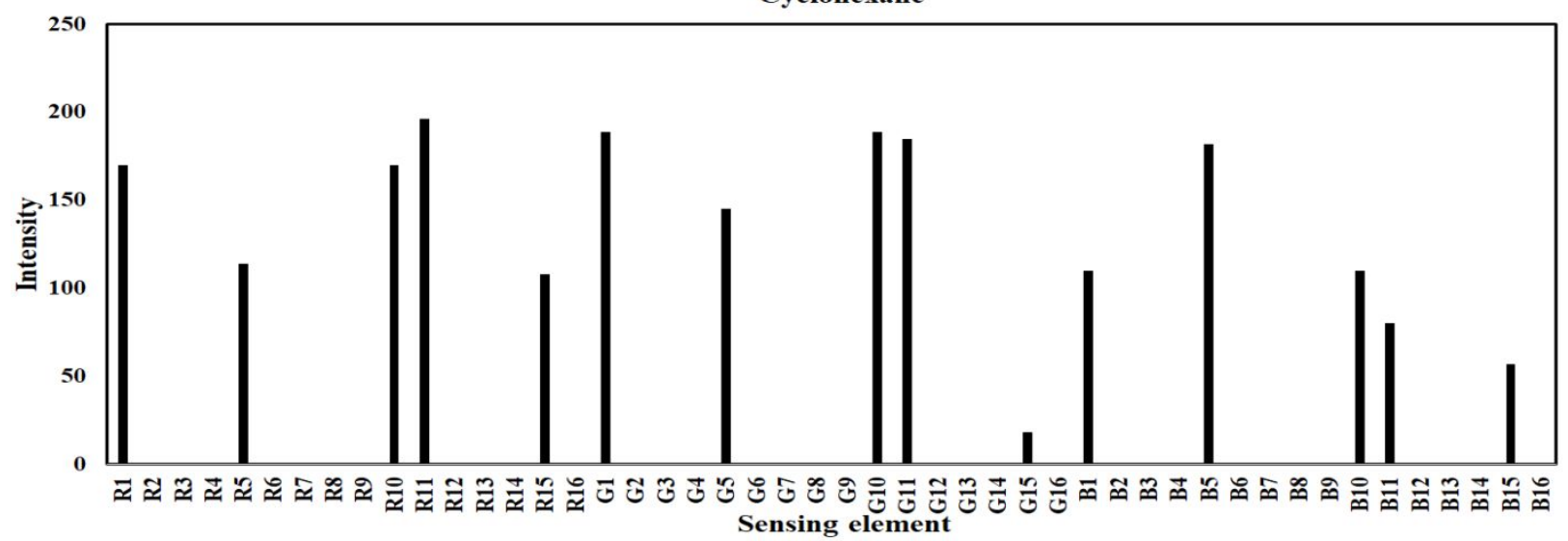

Figure S12. The response value of each sensing element (RGB values of the 16 NPs) corresponding to each analyte. In this figure, sensing elements were sorted from number 1 to number 16 which represent bare AgNPs, CTAB capped AgNPs, glucose capped AgNPs, Cys capped AgNPs, bare AuNPs, CTAB capped AuNPs, glucose capped AuNPs, Cys capped AuNPs, chitosan capped AgNPs, BSA capped AgNPs, PVP capped AgNPs, GSH capped AgNPs, chitosan capped AuNPs, BSA capped AuNPs, PVP capped AuNPs and GSH capped AuNPs, respectively. 
(a)

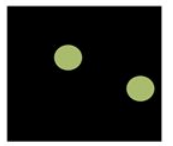

Benzene

(c)

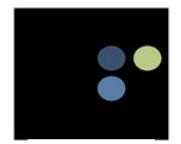

Methanol

(e)

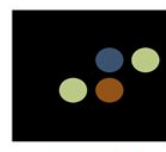

Ethanol

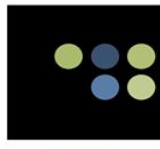

Phenol

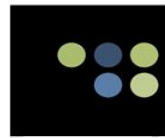

Phenol

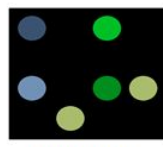

Acetic acid

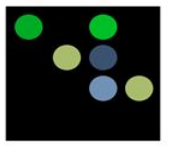

Acetophenone

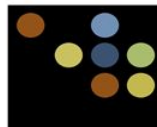

Salicylaldehyde 4-Hydroxybenzoic acid

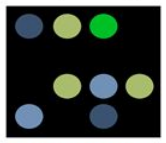

Ethylenediamine Acetaldehyde

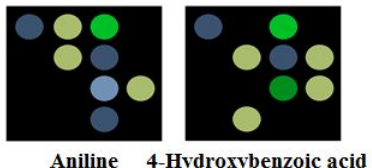

(b)

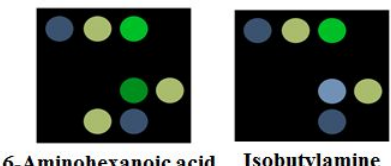

(d)
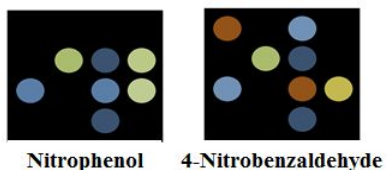

Figure S13. Color difference maps for different types of VOCs with the same functional groups consist of (a) aromatic ring, (b) amino substitute, (c) hydroxyl group, (d) nitro substitute and (e) compounds with 2 carbons in their structure. The aggregation of BSA capped AgNPs and glucose capped AgNPs were occurred when the NOEN exposed to all of aromatic compounds (a). The different compounds with amino substitute lead to change the color of NPs consist of bare AuNPs, AuNPs modified by chitosan, glucose and cysteine and AgNPs synthesized by glucose and chitosan (b). The presence of hydroxyl groups in the volatile compounds cause the aggregation of both AgNPs and AuNPs which are synthesized by CTAB (c). The simultaneous aggregation of AuNPs modified by PVP and cysteine can be a reason for presence of nitro substitute in the structure of volatile compounds (d). The volatile compounds with the same number of carbon but different functional groups indicate the different colorimetric patterns (e). 

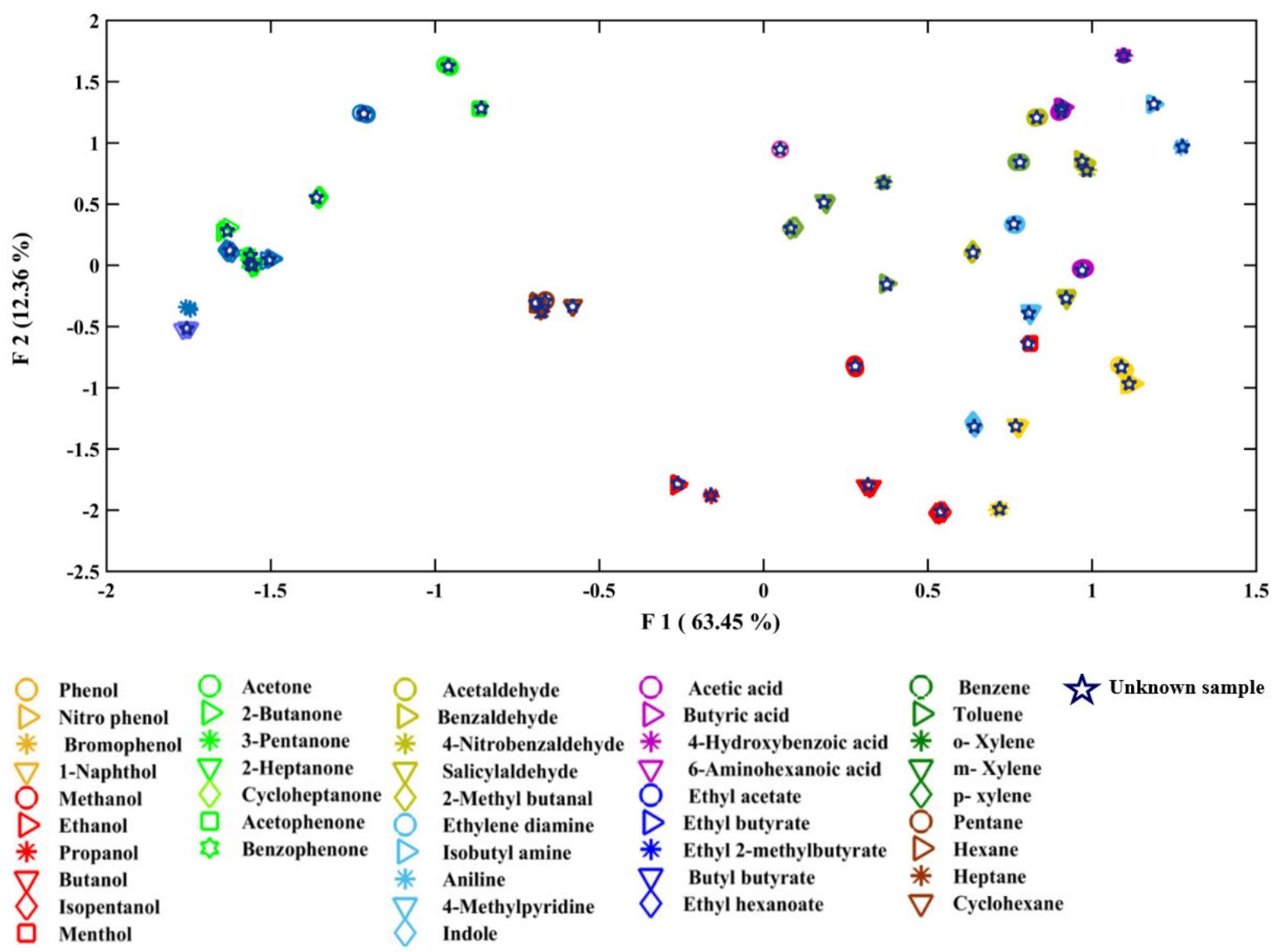

Figure S14. Classification results achieved by LDA score plot. The concentration of VOC in the vapor phase is $1000.0 \mathrm{ppm}$. Unknown sample for each VOC was shown with dark blue pentagram. 
Figure S15
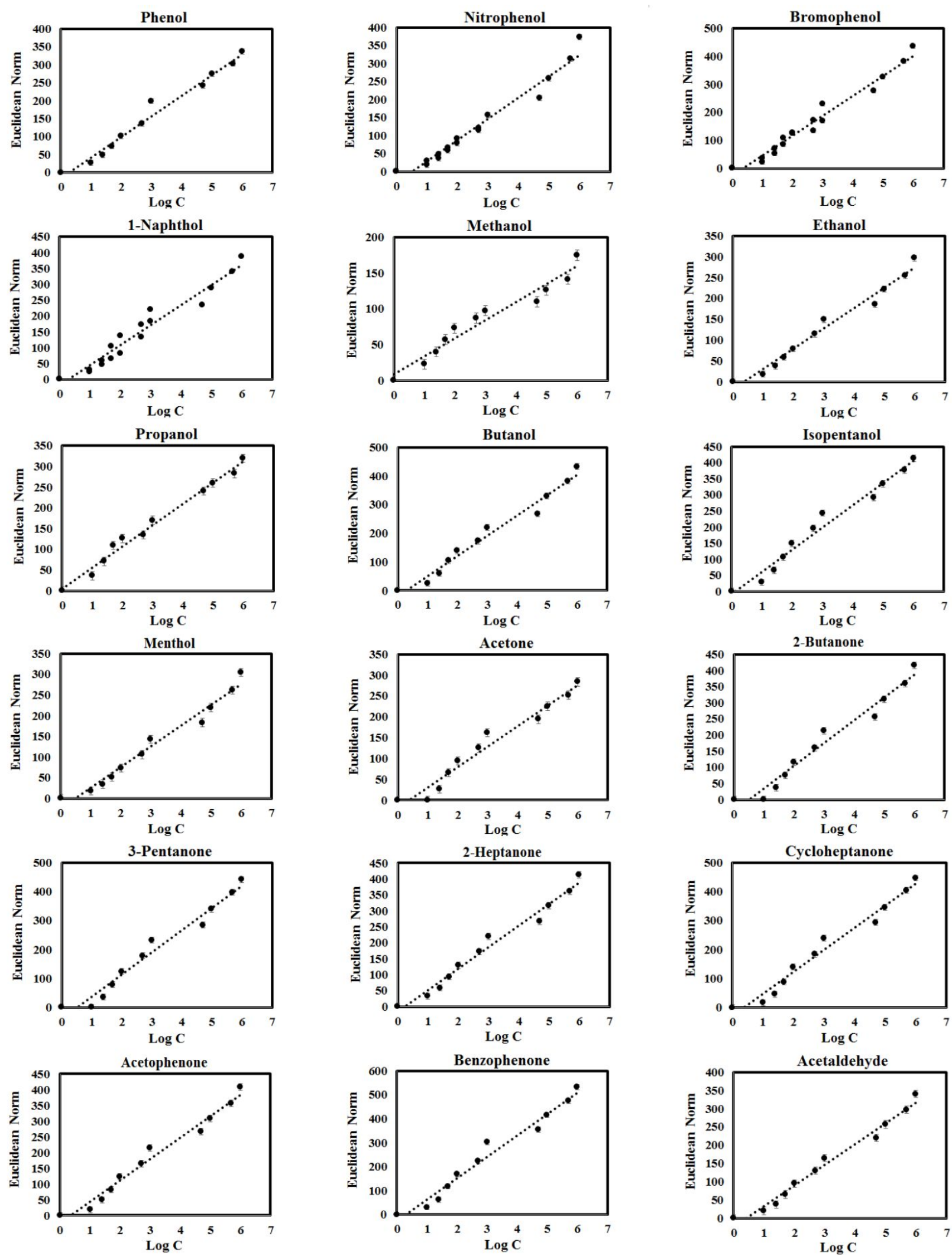

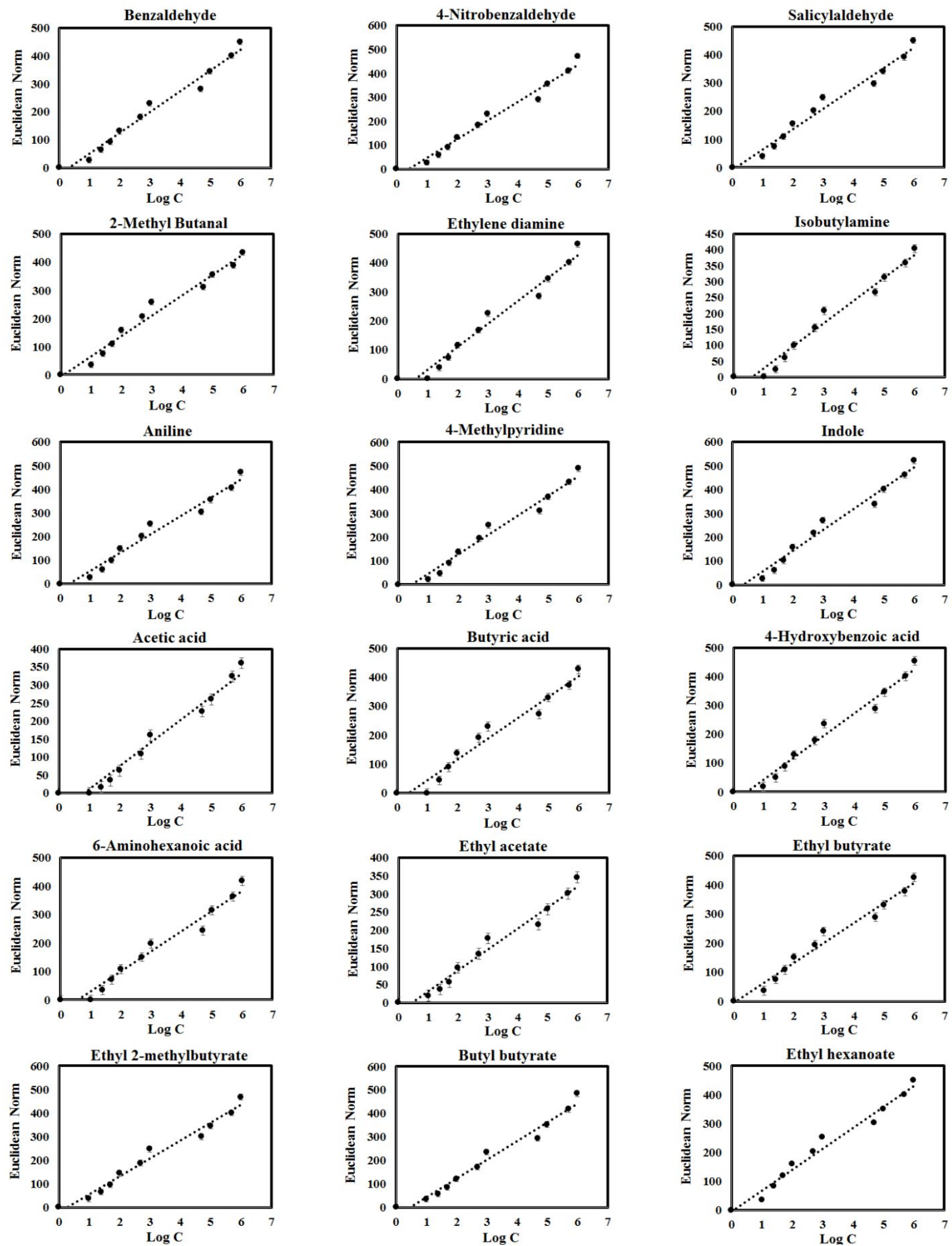

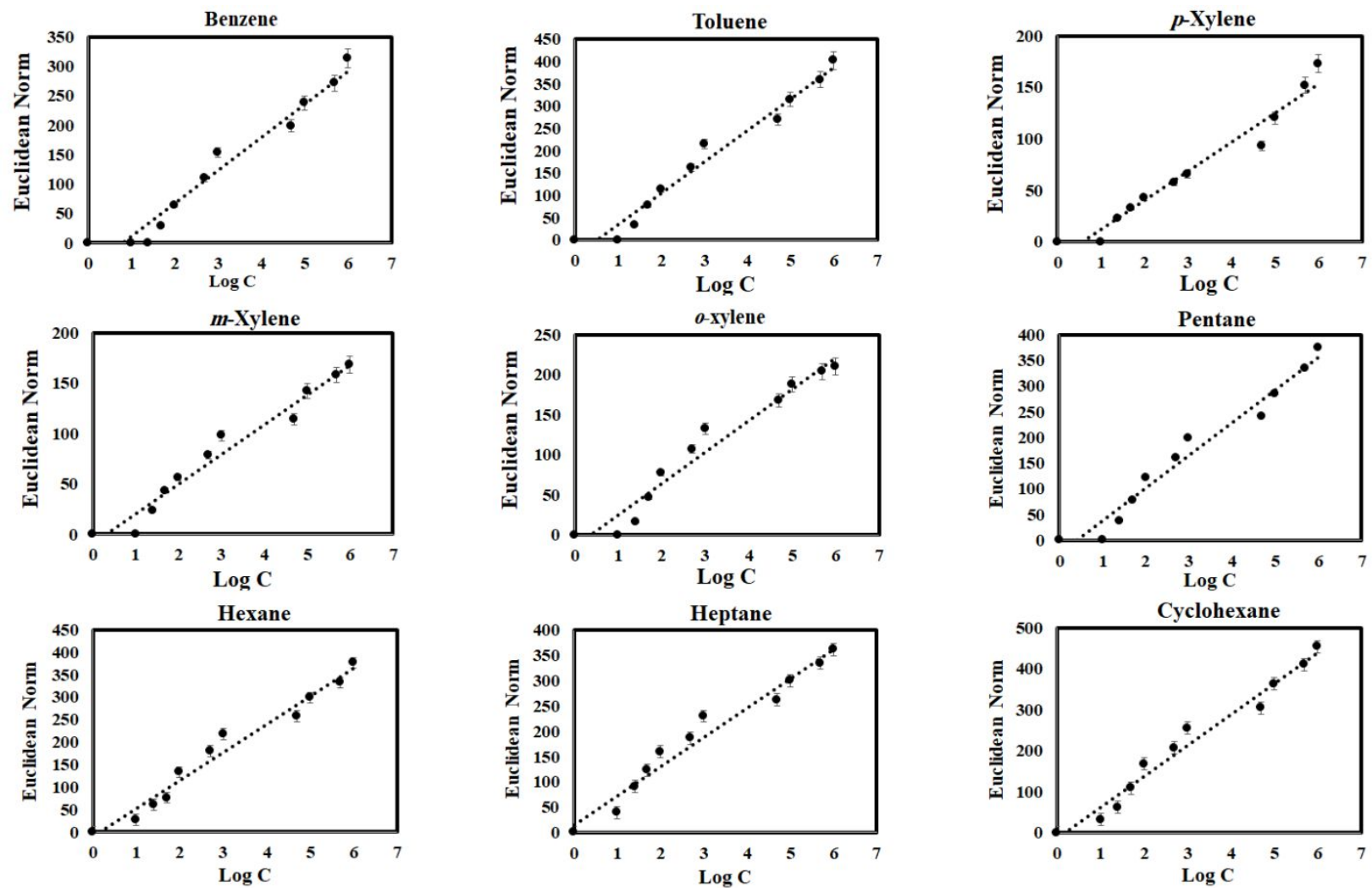

Figure S15. The calibration curve obtained by determining 45 VOC vapors. The Euclidean norm is the total length of the full dimensional color-difference vector, that is, the total array response. 
Figure S16

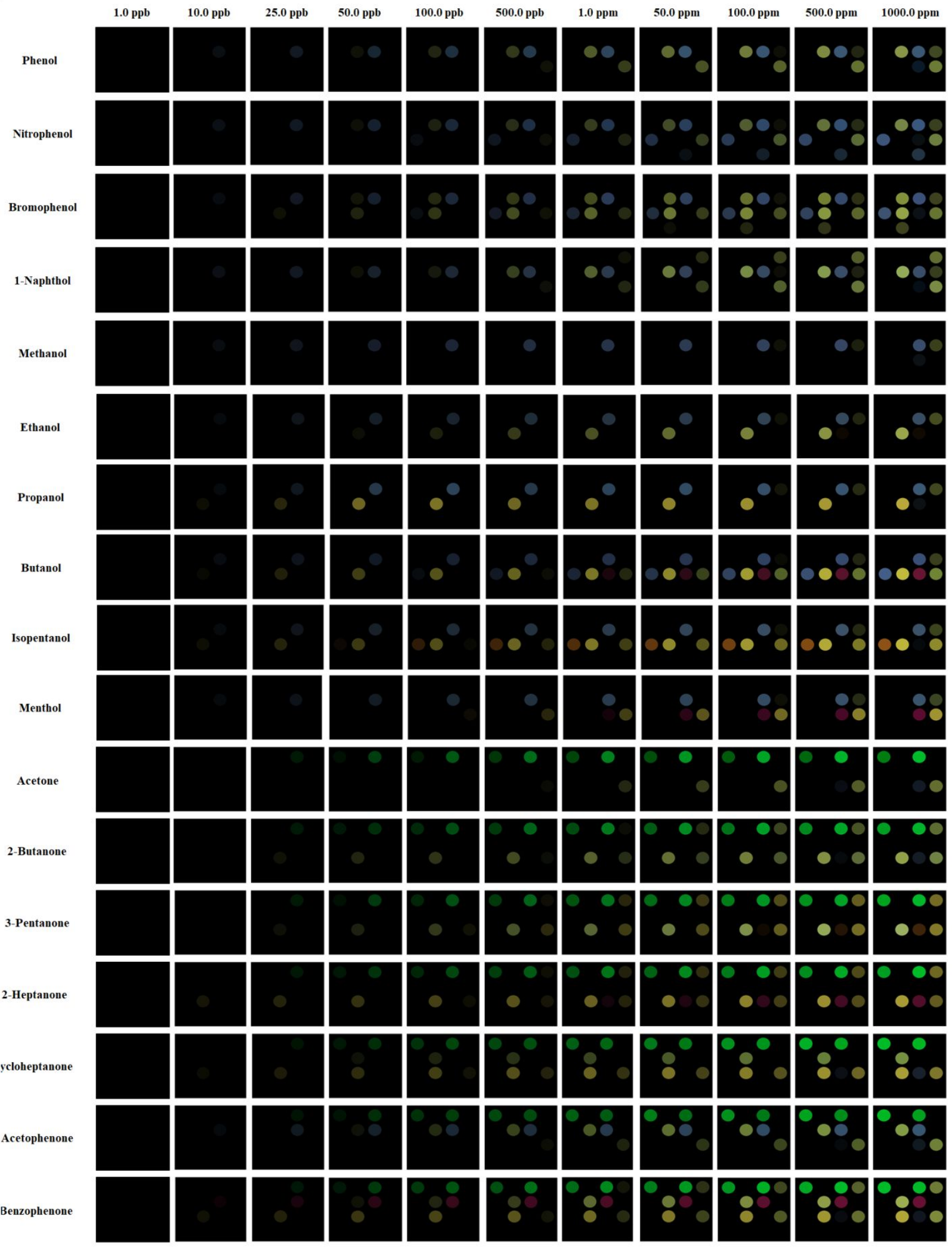




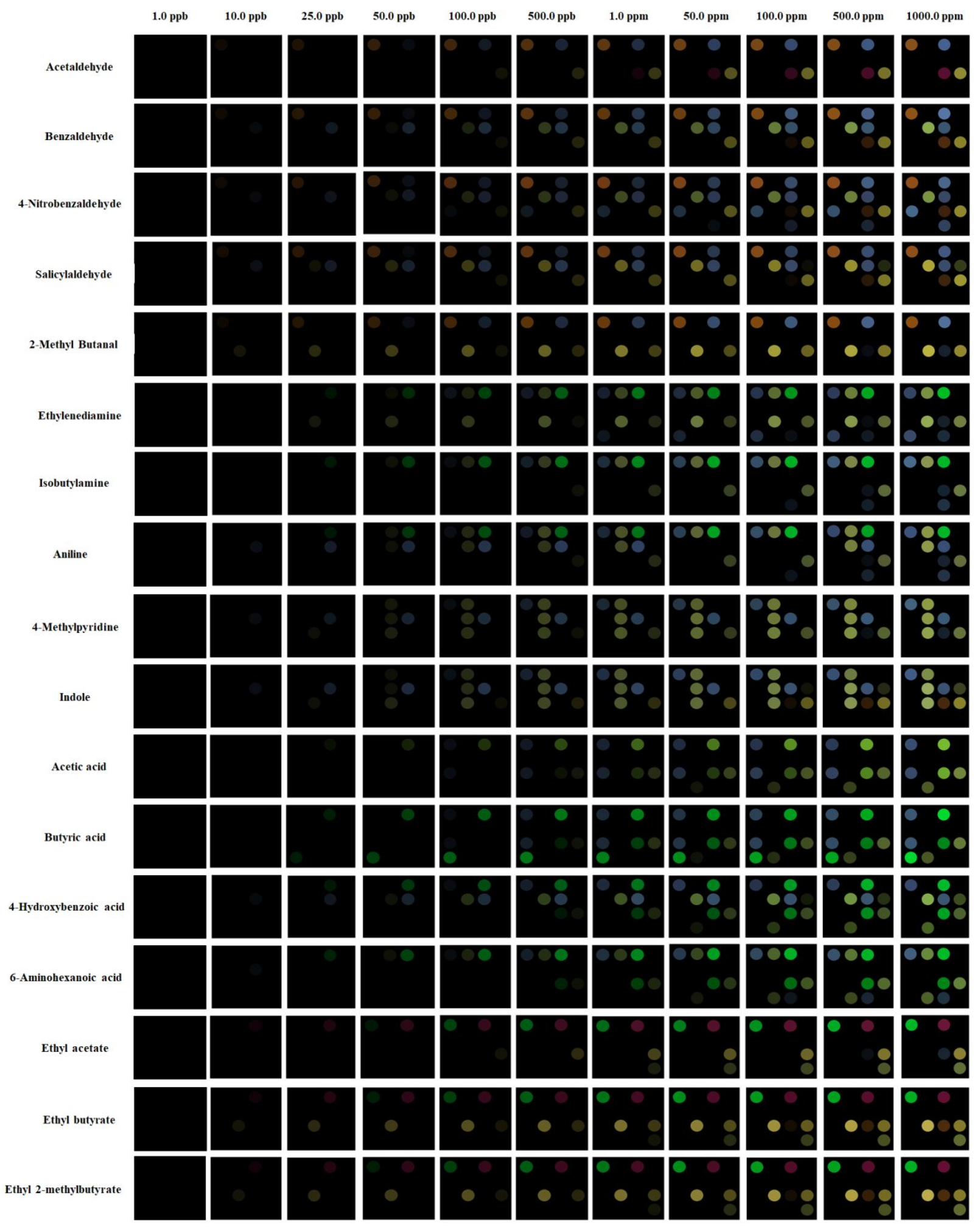




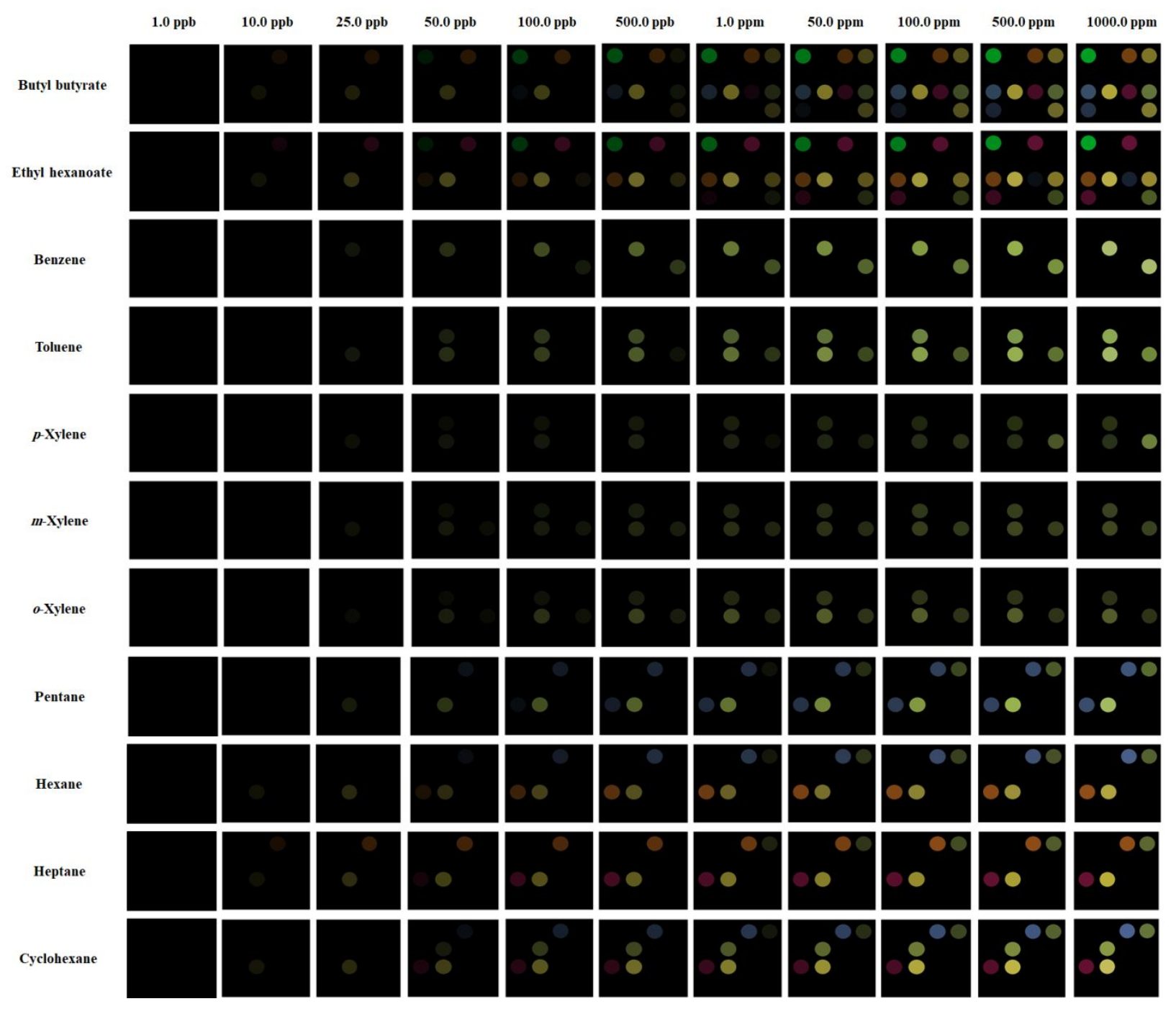

Figure S16. Color difference maps for the different concentrations of 45 VOC vapors. 
Figure S17.
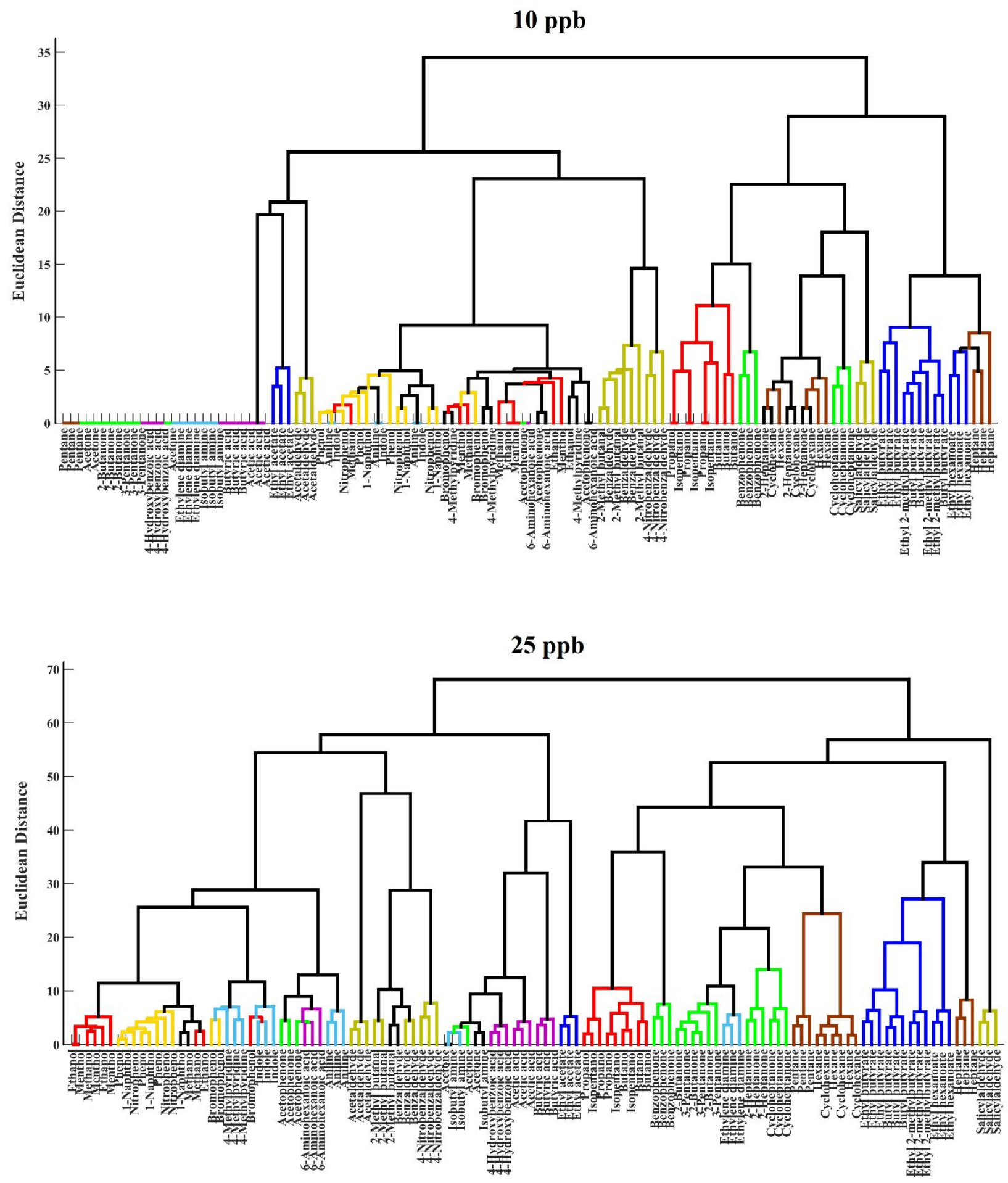

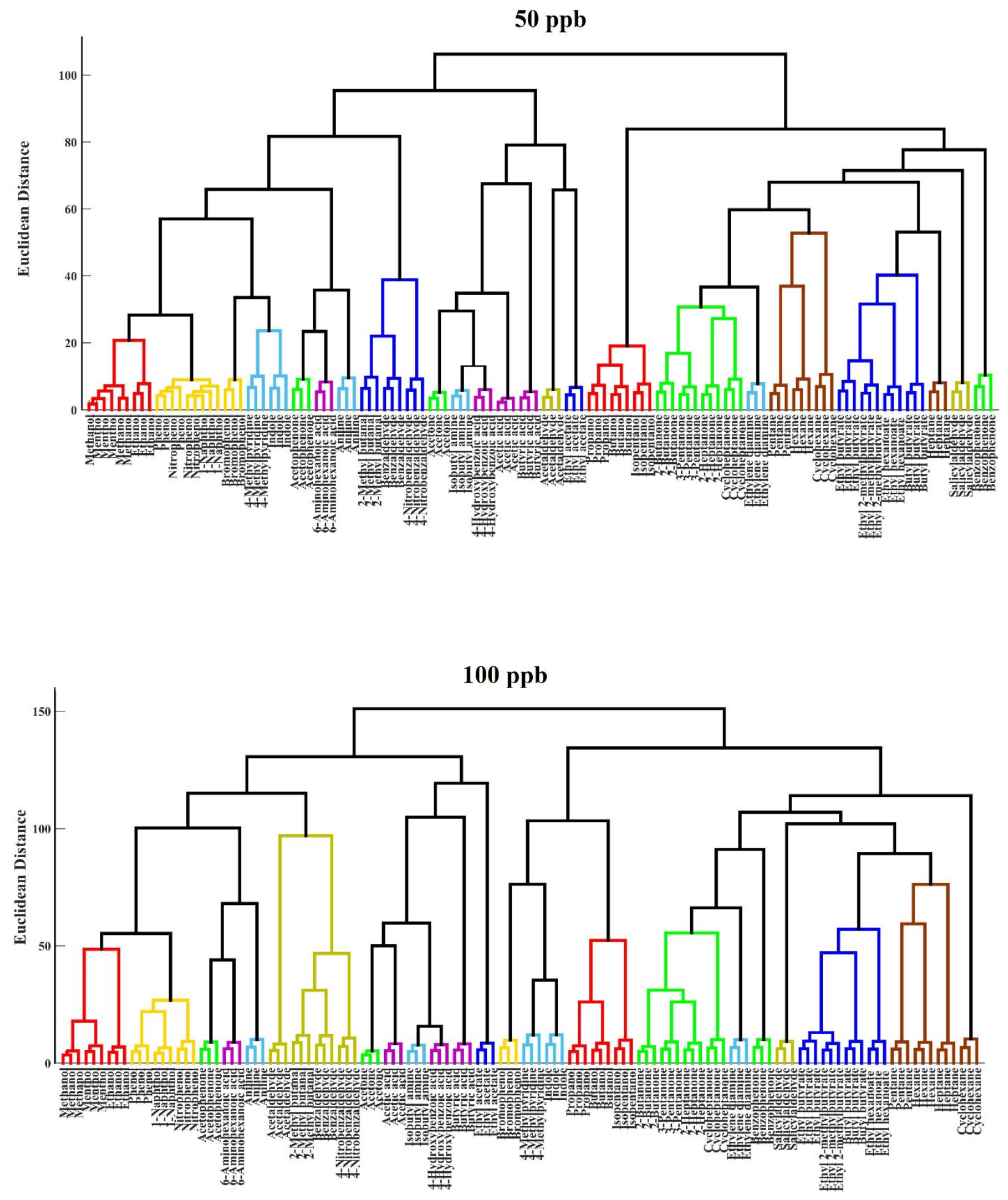

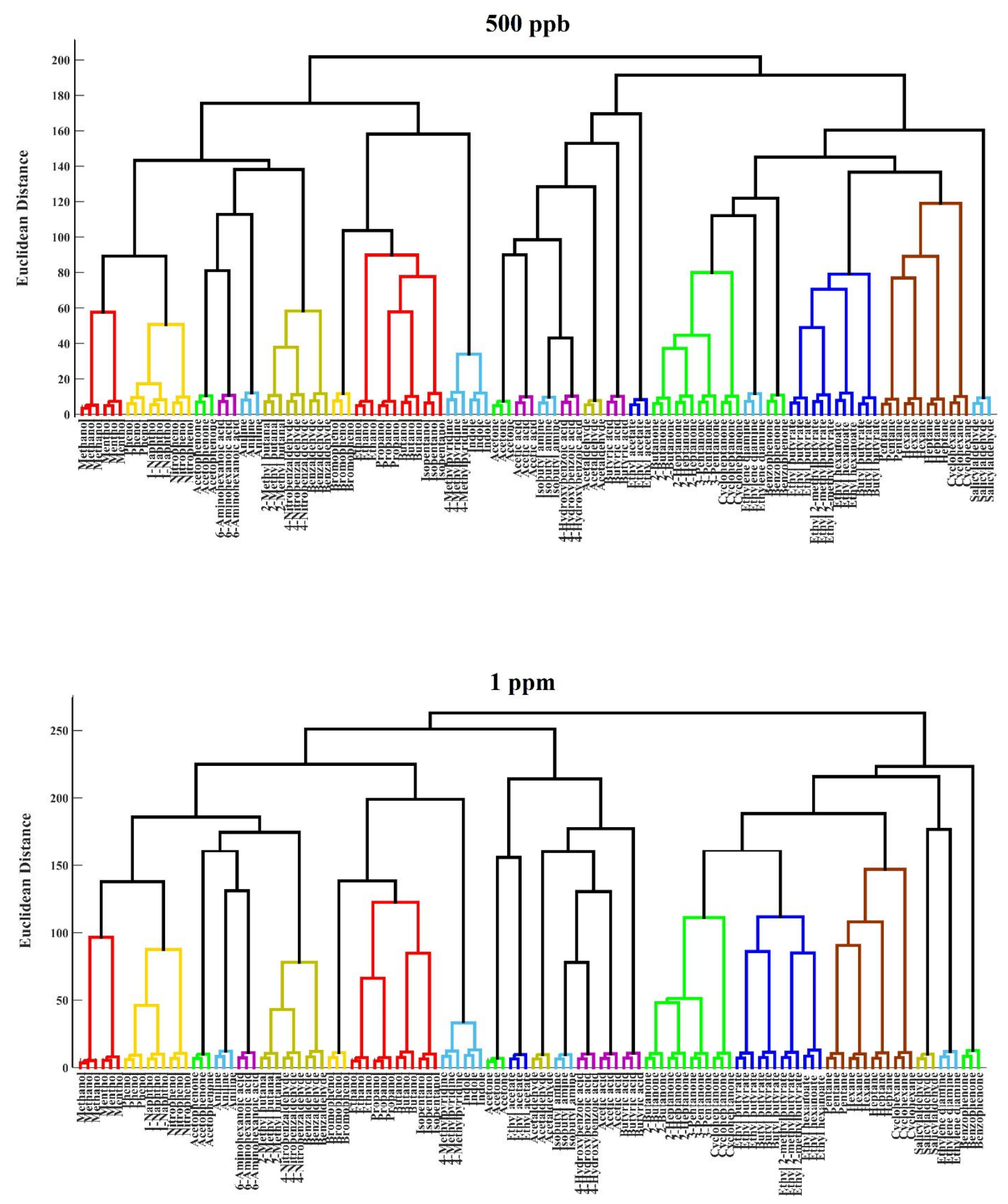

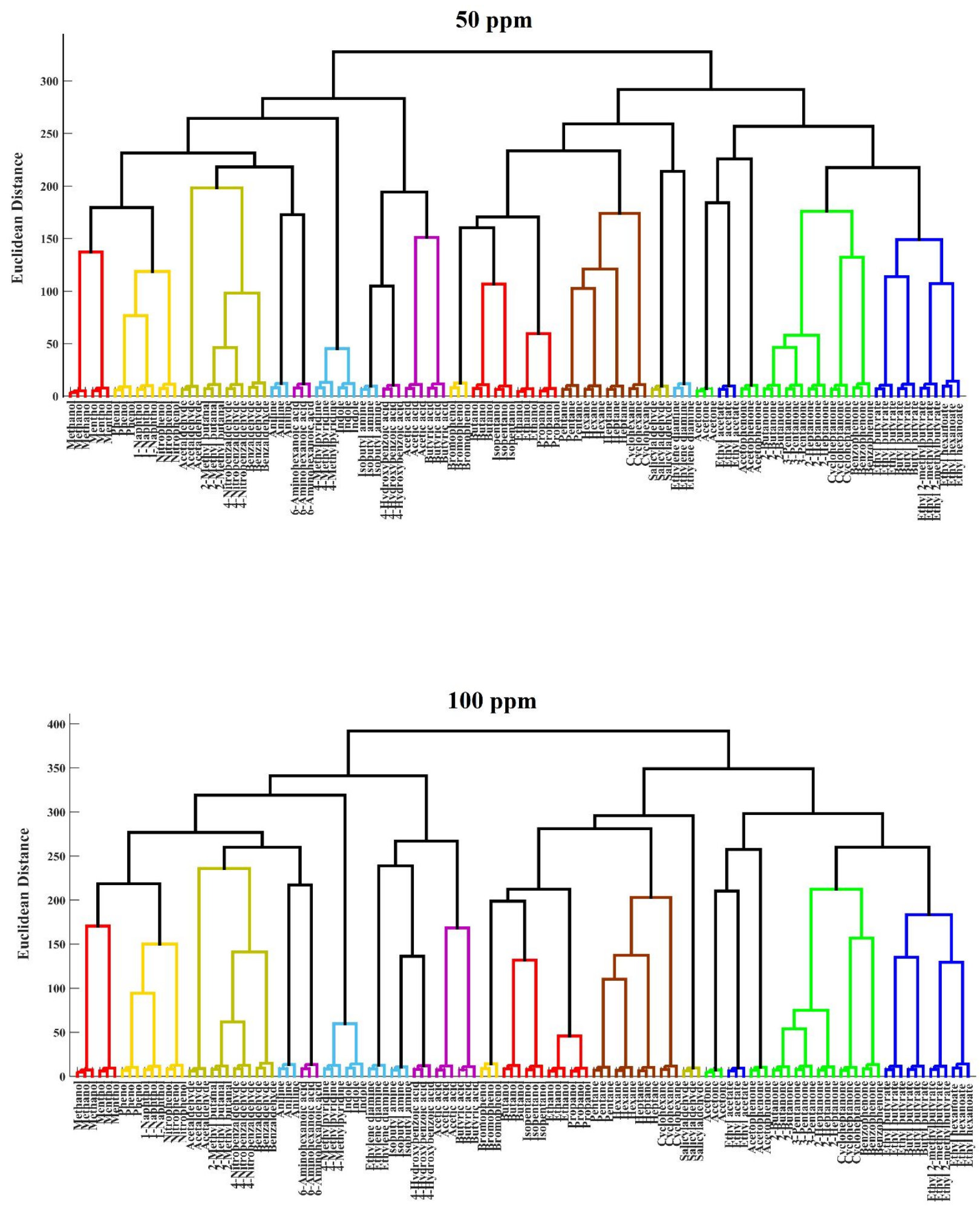

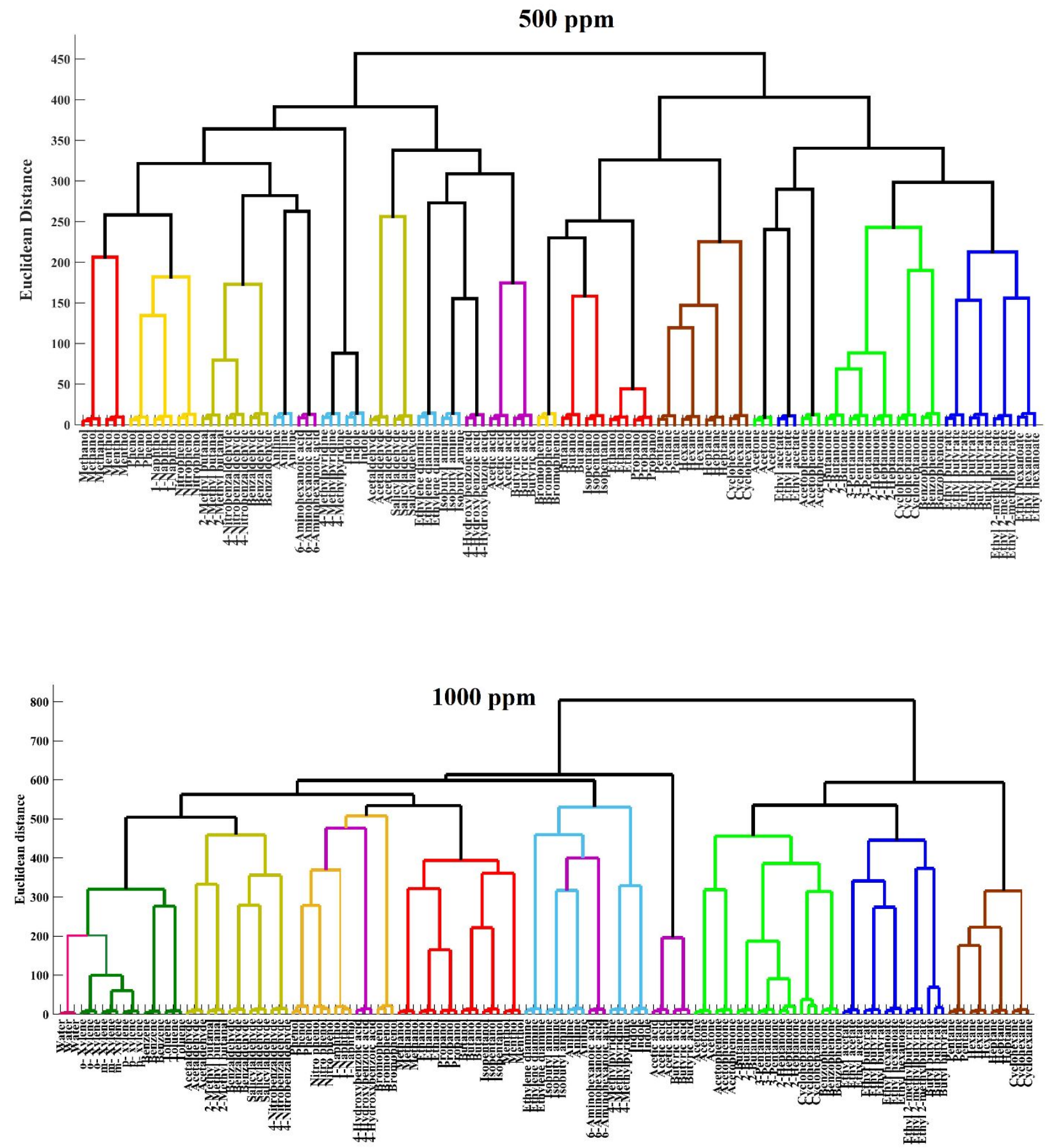

Figure S17. HCA dendrogram of the colorimetric array responses for 45 types of VOC vapors in different concentration. 
Table S1. The structure and classification of investigated volatile compounds.

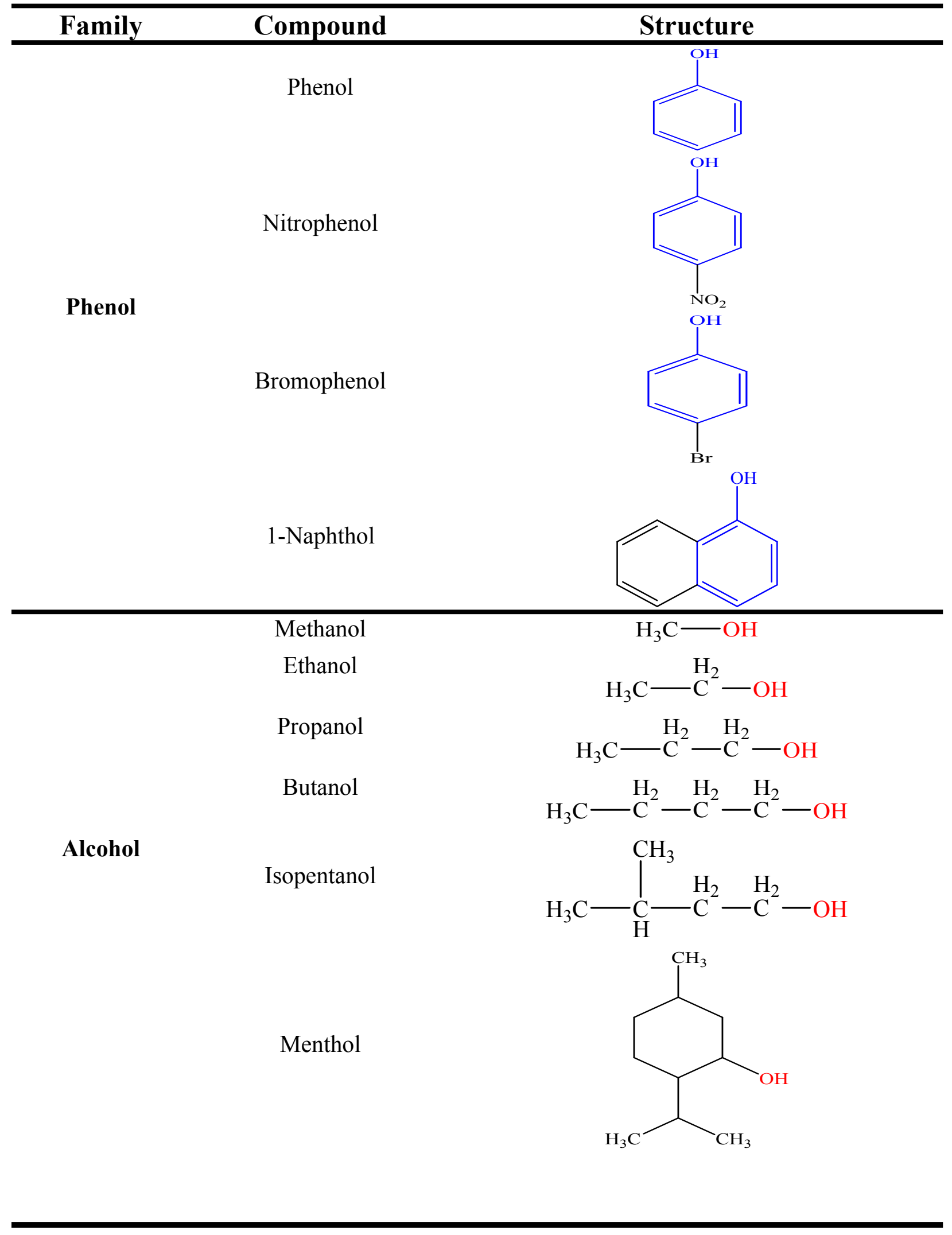




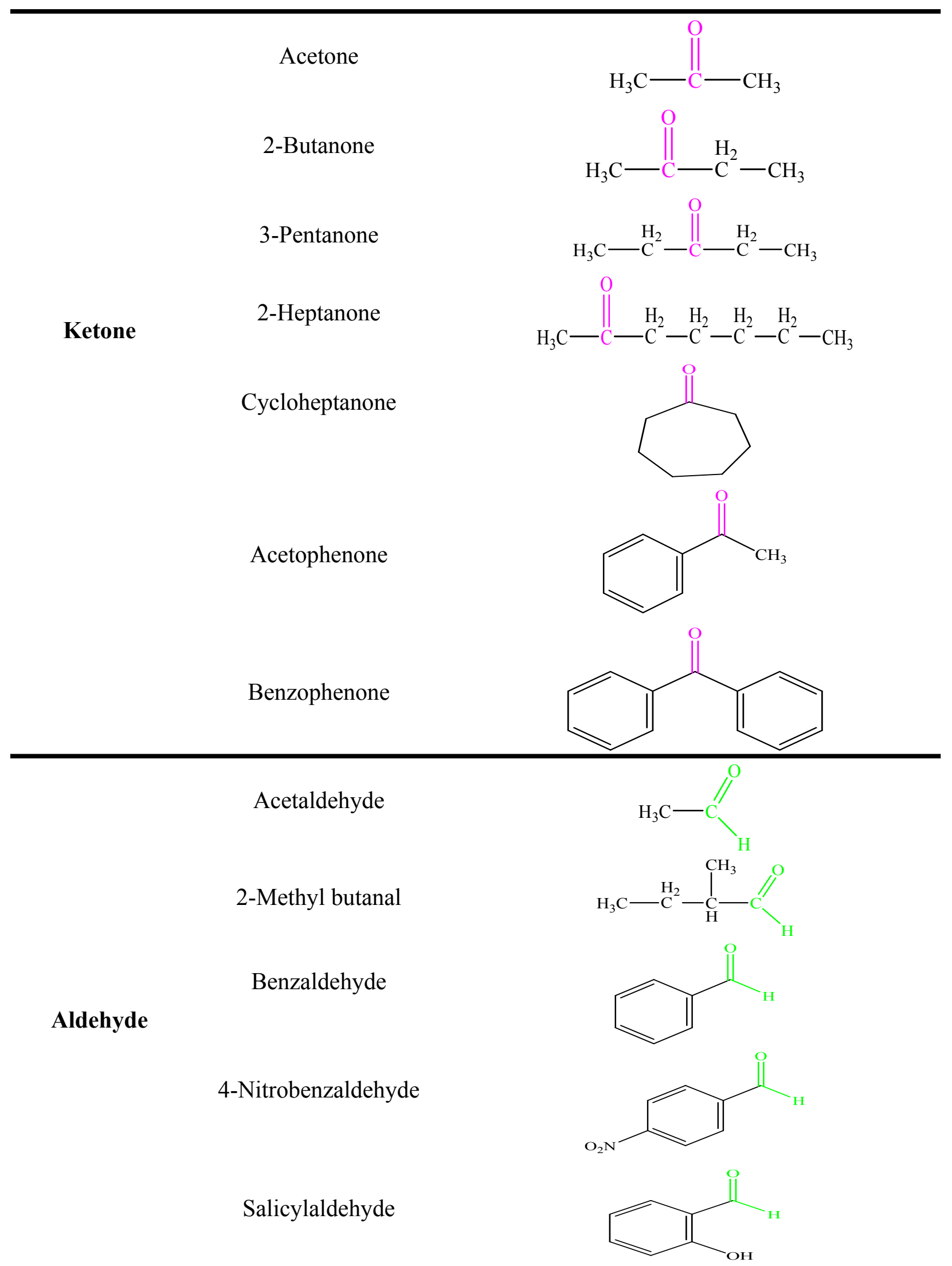




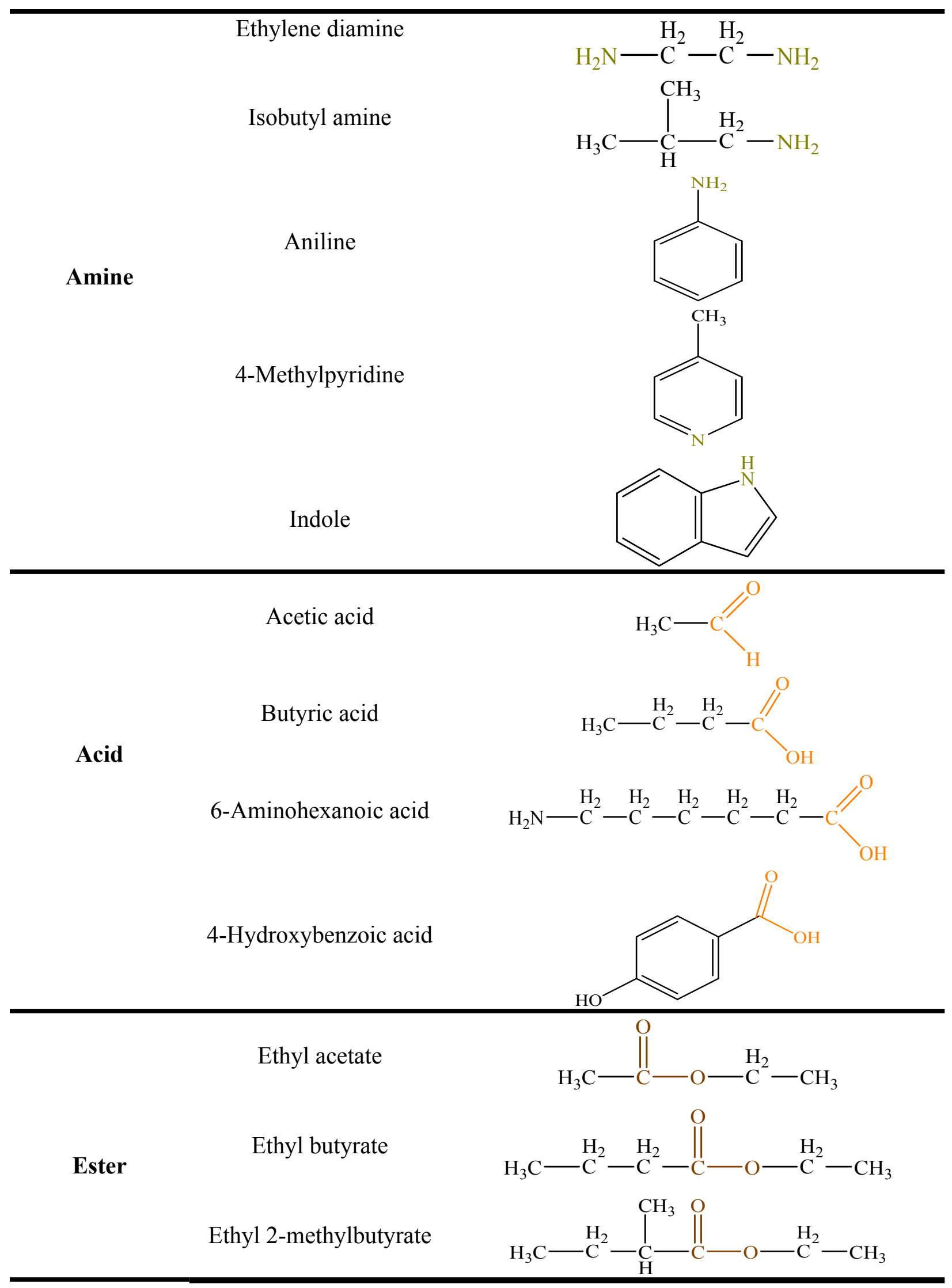




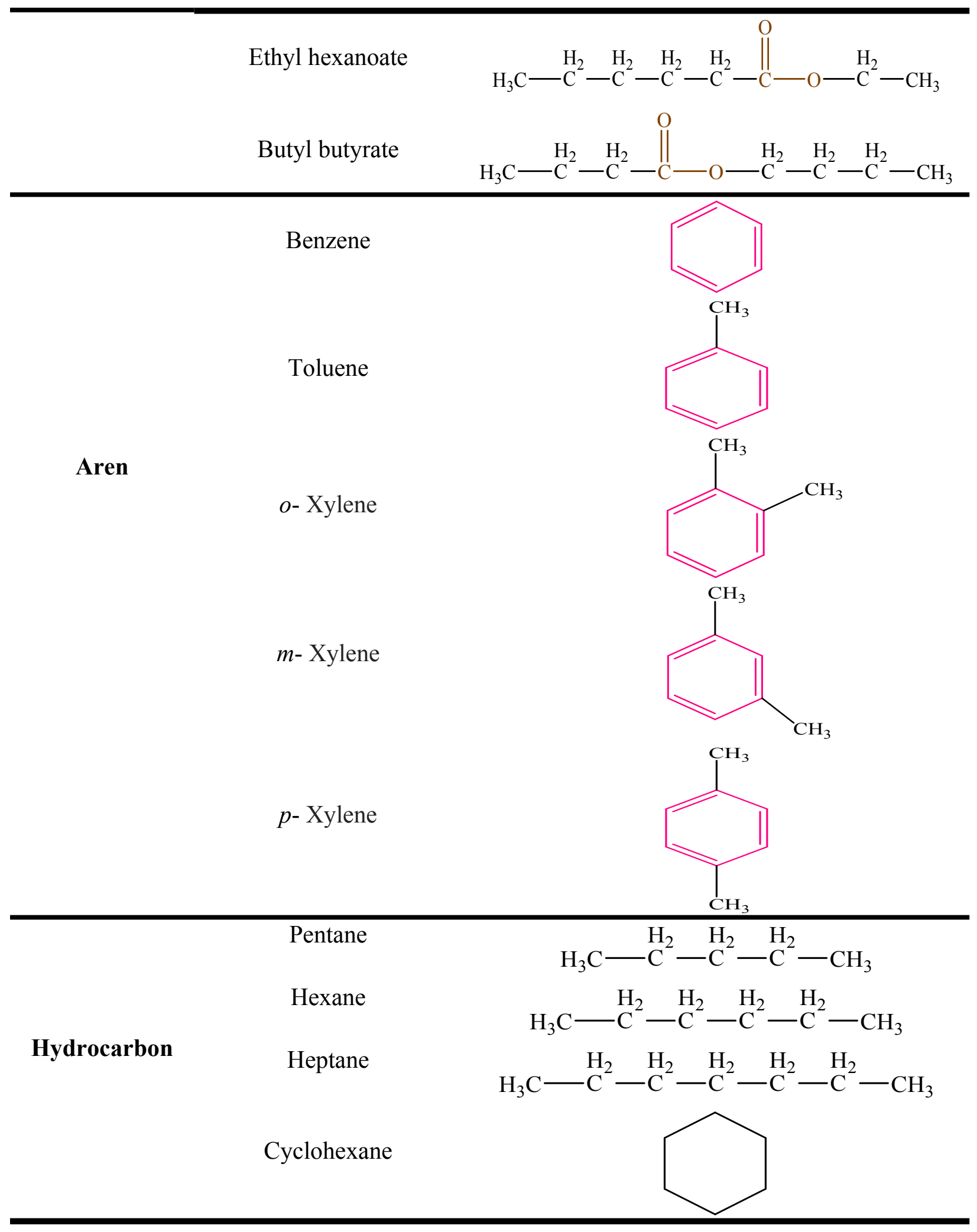


Table S2. EDS results for Quantitative analysis of silver and gold elements in 16 synthesized NPs.

\begin{tabular}{ccc}
\hline Type of Nanoparticles & \multicolumn{2}{c}{ Amount of element (\%) } \\
\cline { 2 - 3 } & $\mathbf{A g}$ & $\mathbf{A u}$ \\
\hline Bare AgNP & 40.36 & - \\
Bare AuNP & - & 43.15 \\
Chitosan capped AgNPs & 33.74 & - \\
Chitosan capped AuNPs & - & 31.52 \\
CTAB capped AgNPs & 35.49 & - \\
CTAB capped AuNPs & - & 31.08 \\
BSA capped AgNPs & 37.81 & - \\
BSA capped AuNPs & - & 44.32 \\
Glucose capped AgNPs & 36.33 & - \\
Glucose capped AuNPs & - & 38.51 \\
PVP capped AgNPs & 29.54 & - \\
PVP capped AuNPs & - & 30.29 \\
Cys capped AgNPs & 36.07 & - \\
Cys capped AuNPs & - & 32.13 \\
GSH capped AgNPs & 34.46 & - \\
GSH capped AuNPs & - & 38.19 \\
\hline
\end{tabular}


Table S3. Evaluation of repeatability of NOEN fabricating process.

\begin{tabular}{|c|c|c|c|c|c|c|c|}
\hline \multirow[t]{2}{*}{ Type of NPs } & \multirow[t]{2}{*}{ RGB values } & \multicolumn{5}{|c|}{ Number of sensor } & \multirow[t]{2}{*}{$\mathrm{RSD} \%$} \\
\hline & & $\mathrm{S} 1$ & $\mathrm{~S} 2$ & S3 & S4 & $\mathrm{S} 5$ & \\
\hline \multirow{3}{*}{ Bare AgNP } & $\mathrm{R}$ & 248 & 249 & 245 & 249 & 250 & 0.775 \\
\hline & G & 245 & 247 & 245 & 246 & 247 & 0.407 \\
\hline & $\mathrm{B}$ & 242 & 244 & 242 & 243 & 245 & 0.536 \\
\hline \multirow{3}{*}{ Bare AuNP } & $\mathrm{R}$ & 248 & 250 & 250 & 247 & 250 & 0.568 \\
\hline & G & 177 & 175 & 174 & 179 & 178 & 1.17 \\
\hline & B & 170 & 169 & 168 & 173 & 168 & 1.22 \\
\hline \multirow{3}{*}{ Chitosan capped AgNPs } & $\mathrm{R}$ & 251 & 251 & 247 & 251 & 248 & 0.781 \\
\hline & G & 248 & 247 & 248 & 249 & 245 & 0.613 \\
\hline & B & 245 & 244 & 240 & 246 & 241 & 1.06 \\
\hline \multirow{3}{*}{ Chitosan capped AuNPs } & $\mathrm{R}$ & 248 & 249 & 249 & 248 & 248 & 0.221 \\
\hline & $\mathrm{G}$ & 175 & 175 & 173 & 175 & 174 & 0.513 \\
\hline & B & 169 & 169 & 167 & 166 & 165 & 1.07 \\
\hline \multirow{3}{*}{ CTAB capped AgNPs } & $\mathrm{R}$ & 251 & 250 & 249 & 249 & 249 & 0.358 \\
\hline & G & 249 & 247 & 248 & 245 & 246 & 0.640 \\
\hline & $\mathrm{B}$ & 247 & 244 & 238 & 242 & 244 & 1.36 \\
\hline \multirow{3}{*}{ CTAB capped AuNPs } & $\mathrm{R}$ & 249 & 250 & 250 & 247 & 248 & 0.524 \\
\hline & $\mathrm{G}$ & 188 & 188 & 191 & 187 & 189 & 0.804 \\
\hline & B & 181 & 182 & 183 & 184 & 182 & 0.625 \\
\hline \multirow{3}{*}{ BSA capped AgNPs } & $\mathrm{R}$ & 250 & 250 & 252 & 251 & 248 & 0.593 \\
\hline & G & 247 & 247 & 246 & 249 & 244 & 0.737 \\
\hline & B & 245 & 245 & 243 & 246 & 242 & 0.673 \\
\hline \multirow{3}{*}{ BSA capped AuNPs } & $\mathrm{R}$ & 249 & 248 & 252 & 248 & 249 & 0.659 \\
\hline & $\mathrm{G}$ & 178 & 178 & 174 & 175 & 174 & 1.17 \\
\hline & B & 172 & 172 & 169 & 173 & 167 & 1.47 \\
\hline \multirow{3}{*}{ Glucose capped AgNPs } & $\mathrm{R}$ & 250 & 251 & 251 & 249 & 250 & 0.334 \\
\hline & $\mathrm{G}$ & 247 & 248 & 246 & 246 & 248 & 0.405 \\
\hline & B & 245 & 246 & 236 & 244 & 246 & 1.73 \\
\hline \multirow{3}{*}{ Glucose capped AuNPs } & $\mathrm{R}$ & 246 & 246 & 250 & 249 & 250 & 0.826 \\
\hline & G & 175 & 182 & 180 & 177 & 179 & 1.51 \\
\hline & B & 151 & 149 & 156 & 151 & 148 & 2.04 \\
\hline \multirow{3}{*}{ PVP capped AgNPs } & $\mathrm{R}$ & 250 & 251 & 248 & 251 & 251 & 0.521 \\
\hline & $\mathrm{G}$ & 247 & 248 & 241 & 249 & 248 & 1.30 \\
\hline & B & 244 & 246 & 239 & 247 & 245 & 1.27 \\
\hline \multirow{3}{*}{ PVP capped AuNPs } & $\mathrm{R}$ & 248 & 247 & 251 & 249 & 248 & 0.610 \\
\hline & G & 180 & 179 & 182 & 181 & 178 & 0.878 \\
\hline & $\mathrm{B}$ & 174 & 172 & 171 & 173 & 173 & 0.661 \\
\hline \multirow{3}{*}{ Cys capped AgNPs } & $\mathrm{R}$ & 249 & 250 & 245 & 250 & 248 & 0.835 \\
\hline & $\mathrm{G}$ & 247 & 248 & 241 & 248 & 245 & 1.20 \\
\hline & B & 245 & 247 & 238 & 246 & 242 & 1.49 \\
\hline \multirow{3}{*}{ Cys capped AuNPs } & $\mathrm{R}$ & 248 & 249 & 250 & 248 & 249 & 0.336 \\
\hline & G & 177 & 177 & 171 & 174 & 171 & 1.72 \\
\hline & B & 173 & 173 & 178 & 177 & 174 & 1.34 \\
\hline
\end{tabular}




\begin{tabular}{clllllll}
\hline \multirow{3}{*}{ GSH capped AgNPs } & R & 250 & 249 & 252 & 249 & 250 & 0.491 \\
& G & 247 & 246 & 243 & 247 & 247 & 0.704 \\
& B & 245 & 244 & 240 & 244 & 245 & 0.851 \\
& R & 249 & 249 & 251 & 247 & 245 & 0.919 \\
GSH capped AuNPs & G & 193 & 193 & 191 & 190 & 197 & 1.3 \\
& B & 189 & 188 & 185 & 184 & 190 & 1.38 \\
\hline
\end{tabular}


Table S4. The reproducibility of the response of developed NOEN for detection of 45 VOCs.

\begin{tabular}{|c|c|c|c|c|c|c|}
\hline \multirow[t]{2}{*}{ Analyte } & \multicolumn{5}{|c|}{ Euclidean Norm for } & \multirow[t]{2}{*}{ RSD \% } \\
\hline & S 1 & S 2 & S 3 & S 4 & S 5 & \\
\hline Phenol & 579 & 587 & 579 & 591 & 571 & 1.34 \\
\hline Nitrophenol & 651 & 632 & 658 & 674 & 647 & 2.36 \\
\hline Bromophenol & 798 & 768 & 746 & 770 & 734 & 3.23 \\
\hline 1-Naphthol & 669 & 675 & 669 & 674 & 689 & 1.21 \\
\hline Methanol & 413 & 419 & 411 & 415 & 425 & 1.33 \\
\hline Ethanol & 491 & 532 & 495 & 474 & 501 & 4.25 \\
\hline Propanol & 507 & 534 & 472 & 527 & 518 & 4.76 \\
\hline Butanol & 566 & 547 & 575 & 568 & 584 & 2.41 \\
\hline Isopentanol & 624 & 612 & 642 & 652 & 625 & 2.52 \\
\hline Menthol & 470 & 432 & 456 & 469 & 484 & 4.24 \\
\hline Acetone & 462 & 448 & 478 & 433 & 450 & 3.71 \\
\hline 2-Butanone & 606 & 619 & 598 & 626 & 584 & 2.75 \\
\hline 3-Pentanone & 592 & 578 & 614 & 583 & 604 & 2.5 \\
\hline 2-Heptanone & 589 & 574 & 556 & 598 & 615 & 3.85 \\
\hline Cycloheptanone & 648 & 654 & 637 & 668 & 627 & 2.43 \\
\hline Acetophenone & 560 & 552 & 572 & 586 & 524 & 4.17 \\
\hline Benzophenone & 679 & 659 & 691 & 647 & 702 & 3.34 \\
\hline Acetaldehyde & 436 & 472 & 419 & 453 & 490 & 6.20 \\
\hline Benzaldehyde & 552 & 536 & 580 & 525 & 556 & 3.82 \\
\hline 4-Nitrobenzaldehyde & 628 & 654 & 614 & 626 & 664 & 3.28 \\
\hline Salicylaldehyde & 626 & 603 & 644 & 684 & 695 & 5.96 \\
\hline 2-Methyl butanal & 561 & 565 & 580 & 541 & 556 & 2.52 \\
\hline Ethylene diamine & 670 & 685 & 648 & 622 & 697 & 4.51 \\
\hline Isobutylamine & 552 & 534 & 572 & 526 & 583 & 4.38 \\
\hline Aniline & 636 & 624 & 659 & 675 & 663 & 3.20 \\
\hline 4-Methylpyridine & 648 & 635 & 679 & 667 & 623 & 3.51 \\
\hline Indole & 680 & 703 & 656 & 678 & 641 & 3.55 \\
\hline Acetic acid & 550 & 566 & 536 & 603 & 521 & 5.67 \\
\hline Butyric acid & 584 & 562 & 608 & 546 & 581 & 4.08 \\
\hline 4-Hydroxybenzoic acid & 642 & 637 & 673 & 664 & 650 & 2.31 \\
\hline 6-Aminohexanoic acid & 580 & 562 & 595 & 582 & 557 & 2.70 \\
\hline Ethyl acetate & 533 & 489 & 558 & 562 & 482 & 7.17 \\
\hline Ethyl butyrate & 571 & 557 & 591 & 592 & 553 & 3.20 \\
\hline Ethyl 2-methylbutyrate & 641 & 624 & 661 & 680 & 620 & 3.92 \\
\hline Butyl butyrate & 735 & 761 & 755 & 717 & 702 & 3.40 \\
\hline Ethyl hexanoate & 632 & 606 & 652 & 614 & 678 & 4.59 \\
\hline Benzene & 392 & 355 & 401 & 381 & 364 & 5.04 \\
\hline Toluene & 480 & 502 & 480 & 468 & 463 & 3.15 \\
\hline$p$-Xylene & 194 & 186 & 175 & 183 & 188 & 3.77 \\
\hline$m$-Xylene & 188 & 172 & 183 & 195 & 176 & 5.03 \\
\hline o-Xylene & 221 & 214 & 231 & 226 & 217 & 3.08 \\
\hline Pentane & 536 & 524 & 557 & 515 & 563 & 3.84 \\
\hline
\end{tabular}




\begin{tabular}{ccccccc}
\hline Hexane & 510 & 498 & 518 & 526 & 524 & 2.22 \\
Heptane & 447 & 469 & 406 & 418 & 439 & 5.67 \\
Cyclohexane & 561 & 585 & 546 & 562 & 570 & 2.52 \\
\hline
\end{tabular}

Table S5. The reproducibility of the response of developed NOEN for determination of acetic acid in different concentrations.

\begin{tabular}{crrrrrrr}
\hline $\begin{array}{c}\text { Different concentration of } \\
\text { Acetic acid (ppb) }\end{array}$ & \multicolumn{9}{c}{ Euclidean Norm for } & \multirow{2}{*}{ RSD \% } \\
\cline { 2 - 6 } & S1 & \multicolumn{1}{c}{ S2 } & S3 & S4 & S5 & \\
\hline 10.0 & 16 & 15 & 15 & 14 & 17 & 7.40 \\
25.0 & 35 & 37 & 34 & 32 & 37 & 6.06 \\
50.0 & 62 & 66 & 61 & 57 & 65 & 5.73 \\
100.0 & 108 & 102 & 114 & 110 & 101 & 5.12 \\
500.0 & 160 & 176 & 155 & 163 & 172 & 5.23 \\
1000.0 & 207 & 218 & 222 & 201 & 210 & 3.99 \\
50000.0 & 260 & 252 & 278 & 264 & 277 & 4.20 \\
100000.0 & 324 & 311 & 339 & 330 & 320 & 3.24 \\
500000.0 & 420 & 425 & 418 & 407 & 448 & 3.57 \\
1000000.0 & 550 & 566 & 536 & 603 & 521 & 5.67 \\
\hline
\end{tabular}


Table S6. Multilevel partial factorial design for training and Test sets using in PLS algorithm

\begin{tabular}{cccccc}
\hline Set & Experiment & $\begin{array}{c}\text { Ethyl acetate } \\
(\mathbf{p p m})\end{array}$ & $\begin{array}{c}\text { Acetaldehyde } \\
(\mathbf{p p m})\end{array}$ & $\begin{array}{c}\text { Acetic acid } \\
(\mathbf{p p m})\end{array}$ & $\begin{array}{c}\text { Propanol } \\
\text { (ppm) }\end{array}$ \\
\hline \multirow{4}{*}{ Training set } & 1 & 50 & 50 & 50 & 50 \\
& 2 & 0.5 & 0.5 & 500 & 1 \\
& 3 & 0.5 & 500 & 1 & 500 \\
& 4 & 500 & 1 & 500 & 50 \\
& 5 & 500 & 50 & 1 & 1 \\
& 6 & 50 & 1 & 1 & 100 \\
& 8 & 1 & 1 & 100 & 500 \\
& 9 & 100 & 500 & 100 & 50 \\
& 10 & 500 & 100 & 50 & 500 \\
& 11 & 100 & 50 & 500 & 500 \\
& 12 & 500 & 500 & 0.5 & 100 \\
& 13 & 500 & 0.5 & 100 & 0.5 \\
& 14 & 50 & 0.5 & 500 & 50 \\
& 15 & 50 & 1 & 100 & 500 \\
& 16 & 1 & 1 & 0.5 & 100 \\
& 16 & 0.5 & 100 & 1 & 50 \\
\hline & 1 & 50 & 0.5 & 0.5 & 500 \\
& 2 & 1 & 500 & 50 & 1 \\
& 3 & 1 & 100 & 500 & 100 \\
& 4 & 50 & 500 & 500 & 0.5 \\
\hline
\end{tabular}


Table S7. Analytical information for determination of VOC vapors

\begin{tabular}{|c|c|c|c|c|c|}
\hline Analyte & $\begin{array}{l}\text { PEL* } \\
(p p b)\end{array}$ & $\begin{array}{c}\text { Linear } \\
\text { range }(p p b) \\
\end{array}$ & $\begin{array}{c}\text { Detection limit } \\
(\text { ppb) }\end{array}$ & $\%$ PEL & $\mathbf{R}^{2}$ \\
\hline Phenol & 5000 & $10-1000000$ & 8.72 & 0.174 & 0.979 \\
\hline Nitrophenol & 880 & $25-1000000$ & 17.30 & 1.96 & 0.964 \\
\hline Bromophenol & - & $10-1000000$ & 9.97 & - & 0.971 \\
\hline 1-Naphthol & - & $10-1000000$ & 9.31 & - & 0.955 \\
\hline Methanol & 200000 & $25-1000000$ & 22.25 & 0.011 & 0.948 \\
\hline Ethanol & 1000000 & $10-1000000$ & 9.66 & 0.001 & 0.977 \\
\hline Propanol & 200000 & $10-1000000$ & 6.03 & 0.003 & 0.985 \\
\hline Butanol & 100000 & $10-1000000$ & 9.89 & 0.0099 & 0.975 \\
\hline Isopentanol & 100000 & $10-1000000$ & 9.59 & 0.0096 & 0.975 \\
\hline Menthol & - & $10-1000000$ & 9.46 & - & 0.974 \\
\hline Acetone & 1000000 & $25-1000000$ & 17.61 & 0.0018 & 0.964 \\
\hline 2-Butanone & 200000 & $25-1000000$ & 14.20 & 0.0071 & 0.966 \\
\hline 3-Pentanone & - & $25-1000000$ & 14.46 & - & 0.969 \\
\hline 2-Heptanone & 100000 & $10-1000000$ & 8.94 & 0.0089 & 0.979 \\
\hline Cycloheptanone & - & $10-1000000$ & 9.32 & - & 0.974 \\
\hline Acetophenone & 10000 & $10-1000000$ & 9.22 & 0.0922 & 0.976 \\
\hline Benzophenone & - & $10-1000000$ & 9.70 & - & 0.973 \\
\hline Acetaldehyde & 200000 & $10-1000000$ & 7.78 & 0.0039 & 0.981 \\
\hline Benzaldehyde & - & $10-1000000$ & 9.43 & - & 0.978 \\
\hline 4-Nitrobenzaldehyde & - & $10-1000000$ & 9.93 & - & 0.977 \\
\hline Salicylaldehyde & - & $10-1000000$ & 9.36 & - & 0.976 \\
\hline 2-Methyl butanal & - & $10-1000000$ & 9.98 & - & 0.976 \\
\hline Ethylene diamine & 10000 & $25-1000000$ & 14.01 & 0.1401 & 0.969 \\
\hline Isobutylamine & - & $25-1000000$ & 13.34 & - & 0.970 \\
\hline Aniline & 5000 & $25-1000000$ & 12.11 & 0.2422 & 0.972 \\
\hline 4-Methylpyridine & - & $10-1000000$ & 9.03 & - & 0.974 \\
\hline Indole & - & $10-1000000$ & 9.89 & - & 0.977 \\
\hline Acetic acid & 10000 & $25-1000000$ & 16.03 & 0.1603 & 0.966 \\
\hline Butyric acid & - & $25-1000000$ & 18.7 & - & 0.962 \\
\hline 4-Hydroxybenzoic acid & - & $10-1000000$ & 9.02 & - & 0.974 \\
\hline 6-Aminohexanoic acid & - & $25-1000000$ & 16.23 & - & 0.966 \\
\hline Ethyl acetate & 400 & $25-1000000$ & 12.01 & 3.002 & 0.973 \\
\hline Ethyl butyrate & - & $10-1000000$ & 9.09 & - & 0.978 \\
\hline $\begin{array}{c}\text { Ethyl 2- } \\
\text { methylbutyrate }\end{array}$ & - & $10-1000000$ & 9.32 & - & 0.976 \\
\hline Butyl butyrate & - & $25-1000000$ & 12.57 & - & 0.974 \\
\hline Ethyl hexanoate & - & $10-1000000$ & 9.26 & - & 0.979 \\
\hline Benzene & 1000 & $50-1000000$ & 21.08 & 2.108 & 0.960 \\
\hline Toluene & 10000 & $25-1000000$ & 19.25 & 0.1925 & 0.971 \\
\hline$p$-Xylene & 100000 & $25-1000000$ & 22.08 & 0.02208 & 0.958 \\
\hline$m$-Xylene & 100000 & $25-1000000$ & 16.21 & 0.0162 & 0.966 \\
\hline$o$-Xylene & 100000 & $25-1000000$ & 23.83 & 0.0238 & 0.956 \\
\hline
\end{tabular}




\begin{tabular}{cccccc} 
Pentane & 1000000 & $25-1000000$ & 16.38 & 0.0016 & 0.966 \\
Hexane & 500000 & $25-1000000$ & 13.18 & 0.0026 & 0.971 \\
Heptane & 400000 & $25-1000000$ & 16.45 & 0.0041 & 0.966 \\
Cyclohexane & 300000 & $25-1000000$ & 11.8 & 0.0039 & 0.973 \\
\hline Prmissible exposure limit
\end{tabular}

